\title{
On social cognition : vulnerability and symptoms in psychosis
}

Citation for published version (APA):

Versmissen, D. (2009). On social cognition : vulnerability and symptoms in psychosis. [Doctoral Thesis, Maastricht University]. Wetenschapskring. https://doi.org/10.26481/dis.20090508dv

Document status and date:

Published: 01/01/2009

DOI:

$10.26481 /$ dis.20090508dv

Document Version:

Publisher's PDF, also known as Version of record

\section{Please check the document version of this publication:}

- A submitted manuscript is the version of the article upon submission and before peer-review. There can be important differences between the submitted version and the official published version of record.

People interested in the research are advised to contact the author for the final version of the publication, or visit the DOI to the publisher's website.

- The final author version and the galley proof are versions of the publication after peer review.

- The final published version features the final layout of the paper including the volume, issue and page numbers.

Link to publication

\footnotetext{
General rights rights.

- You may freely distribute the URL identifying the publication in the public portal. please follow below link for the End User Agreement:

www.umlib.nl/taverne-license

Take down policy

If you believe that this document breaches copyright please contact us at:

repository@maastrichtuniversity.nl

providing details and we will investigate your claim.
}

Copyright and moral rights for the publications made accessible in the public portal are retained by the authors and/or other copyright owners and it is a condition of accessing publications that users recognise and abide by the legal requirements associated with these

- Users may download and print one copy of any publication from the public portal for the purpose of private study or research.

- You may not further distribute the material or use it for any profit-making activity or commercial gain

If the publication is distributed under the terms of Article $25 \mathrm{fa}$ of the Dutch Copyright Act, indicated by the "Taverne" license above, 


\title{
On Social Cognition: \\ Vulnerability and Symptoms in Psychosis
}

\author{
PROEFSCHRIFT
}

Ter verkrijging van de graad van doctor aan de Universiteit Maastricht, op gezag van de Rector Magnificus, Prof. mr. G.P.M.F. Mols, volgens het besluit van het College van Decanen,

in het openbaar te verdedigen

op vrijdag 8 mei 2009

om 14.00 uur

door

\section{Dagmar Versmissen}

Geboren op 20 juli 1979 te Schoten 
Paranimfen

Mariëlle Lardinois

Debora op 't Eijnde 


\section{Promotor}

Prof. dr. J. van Os

\section{Copromotor}

Dr. L. Krabbendam

\section{Beoordelingscommissie}

Prof. dr. H. Merckelbach (voorzitter)

Prof. dr. A. Aleman, UMC Groningen

Prof. dr. M. de Vries

Dr. C. Henquet

Dr. F. Larøi, Université de Liège, België

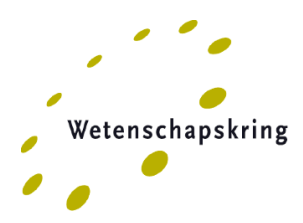

South Limburg Mental Health Research and Teaching Network PhD Series

The research presented in this thesis was conducted at the Maastricht Brain \& Behaviour Institute, the Department of Psychiatry and Neuropsychology of Maastricht University and Mondriaan Zorggroep

Publication of this thesis was financially supported by:

Stichting Jeugzorg Sint-Joseph 


\section{CONTENTS}

\section{CHAPTER I}

Psychosis: an introductory lecture

\section{CHAPTER II}

Social cognition and neurocognition as independent domains in psychosis

\section{CHAPTER III}

Verbal self monitoring in psychosis: a non-replication

\section{CHAPTER IV}

Impairment of self monitoring: part of the endophenotypic risk for psychosis

\section{CHAPTER V}

Source monitoring in psychosis: is the deficit specific for self-generated information?

\section{CHAPTER VI}

Evidence for a relationship between mentalising deficits and paranoia over the psychosis continuum

\section{CHAPTER VII}

Epilogue

Summary

Samenvatting

Dankwoord

Curriculum vitae

List of publications 


\section{PSYCHOSIS: AN INTRODUCTORY LECTURE}

\section{Phenomenology}

Psychotic disorders, of which DSM IV (APA, 1994) distinguishes schizophrenia, schizophreniform disorder, schizoaffective disorder, delusional disorder, shared psychotic disorder, psychotic disorder due to a general medical condition and psychotic disorder not otherwise specified, are characterised by a severe distortion in recognising and comprehending reality (Van Den Bosch, 1994). With a lifetime individual risk of approximately 0.5 to 1 percent, schizophrenia is the most prevalent psychotic disorder (APA, 1994). More specifically, 53,000 to 106,000 inhabitants of Belgium and 81,000 to 163,000 inhabitants of the Netherlands will be diagnosed with schizophrenia during the course of their life. The heterogeneous scale of phenomena, which features psychosis, can be subdivided into positive and negative symptomatology. Positive symptoms, e.g. auditory and visual hallucinations, persecutory delusions, delusions of influence, grandiose delusions or thought insertion, are experiences that are not present in healthy individuals, whereas negative symptoms, e.g. alogia, affective flattening or apathy, reflect an absence of certain abilities and impulses present in healthy individuals (Green, 2001). Delusions and hallucinations are the most typifying symptoms of the psychosis phenotype (Green, 2001). Delusions can be described as convictions that, despite facts and counter-arguments that normally would be satisfactory to refute the convictions, are still maintained. Hallucinations are perceptual experiences with all compelling subjective features of a real sensory impression, while the normal physical stimulus for this sensory modality is absent (Reber, 2001).

Rather than the syndrome-oriented, categorical approach that premises a dichotomous distribution of psychotic symptoms, the psychosis phenotype may better be represented by a continuum with healthy functioning at one extreme and florid psychosis with clinical need at the other (Hanssen et al., 2003, Johns and van Os, 2001). Growing evidence indicates that the disposition of psychosis corresponds with this continuity approach, since the prevalence of psychotic manifestations is not confined to clinical psychotic disorder (Hanssen et al., 2003, Peters et al., 1999). Alterations in psychological mechanisms which underlie psychotic symptoms may also operate at the lower levels of the continuum (Bentall, 1990, Hanssen et al., 2006, Janssen et al., 2003b), where they may contribute to the transition from harmless psychotic experiences to clinical psychotic symptoms in individuals at risk for developing psychosis. Examples of such high-risk groups are first-degree relatives of patients with a psychotic disorder, and individuals from the general population with subclinical psychotic experiences. The benefit of studying populations at risk is clear, as associations between an 
alteration in psychological mechanisms and psychosis in patients may be confounded by illness-related factors and do not necessarily reflect the vulnerability to develop psychotic symptoms.

\section{Aetiology}

The multiple factor vulnerability-stress model seems best suited to the aetiology of psychosis (Zubin and Spring, 1977). According to this model, the individual vulnerability for schizophrenia is determined both genetically and environmentally. The heritability for psychosis has been proven in various family studies. That is, the overall risk to develop psychosis in first-degree relatives of individuals with psychosis is ten times higher than the risk in the general population (Gottesman and Shields, 1982). Likewise, twin models, in which separately adopted twin pairs were studied, demonstrated a concordance of 10 to $15 \%$ in dizygotic twins, up to 45 to $50 \%$ in monozygotic twins (Neale et al., 1996). The latter results are proof of the genetic vulnerability for psychosis and, at the same time, for the influence of environmental factors on the development of psychosis. If the vulnerability were uniquely genetic, the concordance would be $100 \%$ in monozygotic twins that share all of their genes. Several environmental factors have been linked to an increase in psychosis risk: level of deprivation and social isolation (Driessen et al., 1998, van Os et al., 2000), cannabis use (Arseneault et al., 2004, Henquet et al., 2005), stress due to both life-events and small daily hassles (Bebbington et al., 1993, Lukoff et al., 1984, Myin-Germeys et al., 2001), living in an urban environment (Marcelis et al., 1999, Spauwen et al., 2004), bullying (Lataster et al., 2006) or other childhood trauma (Janssen et al., 2004) and discrimination (Janssen et al., 2003a).

\section{$V_{\text {ulnerability and }} \mathbf{E}_{\text {ndophenotypes }}$}

Each cell or organism has a large number of observable characteristics. The combination of all these observable features is called the phenotype and can be described as the expression of mainly genetic, yet also environmental factors. The genotype is solely the genetic information of an organism, thus is no more than a blueprint, with the potential of features and characteristics that can be displayed in the phenotype (Oxlade, 1999). The botanist Wilhelm Johanssen demonstrated that the phenotype is not always the perfect indicator for the genotype and, in addition, the genotype can be the origin for various phenotypes (Gottesman and Gould, 2003). These findings point to the necessity of a construct that represents the missing link between genotypes and phenotypes, thus between genes and behaviour, which is an endophenotype. Other names for endophenotypes are intermediate phenotypes or 
internal phenotypes, and they can be described as being measurable, but covert characteristics which are located between the genotype and the actual disorder (phenotype) and mark an underlying genetic vulnerability (Gottesman and Gould, 2003). Endophenotypes fulfil 5 criteria: association with the illness in the population; heritability; state independency; cosegregation with the illness within families and present in unaffected relatives, albeit to a lesser degree (Gottesman and Gould, 2003). Since genes predisposing to the clinical psychosis phenotype may be transmitted without the expression of the diagnostically determined phenotype, the study of endophenotypes can be an answer to the genetic vulnerability for psychosis. Endophenotypes can have their origin in neuroanatomy, neurophysiology, endocrinology, biochemistry and cognition. In explaining the aetiology of psychosis, candidate cognitive endophenotypes are working memory (Pflueger et al., 2007), sustained attention (Chen and Faraone, 2000) and social cognition (Keri and Janka, 2004). In comparison with neurocognition, fewer studies have been conducted in the area of social cognition. This thesis will investigate some of the criteria, i.e. association with the illness in the population, state independency and presence in unaffected relatives, albeit to a lesser degree.

\section{Social cognitive mechanisms and psychosis}

The term 'cognition' is used to describe mechanisms occurring in the brain in various domains, such as attention, executive functioning or memory. Cognitive processes related to interactions with another individual are clustered under the heading of social cognition. Social cognition encompasses the ability to observe emotions in others and to infer what other individuals think, together with the ability to comprehend the individual roles and rules that regulate social interactions (Penn et al., 1997). In this context, schizophrenia is described as an interpersonal disorder in which problems result from faulty constructions of the social environment and one's place in that environment (Penn et al., 1997).

Factor analyses have yielded four symptom dimensions with respect to the psychotic disorder: positive, negative, depressive and manic symptoms (McGorry et al., 1998, Van Os et al., 1999). This dimensional, symptom-oriented approach of the psychosis phenotype offers important clinical advantages in comparison with the traditional, categorical representation of psychopathology (Van Os et al., 1999). It is shown that neurocognitive dysfunctions are particularly associated with negative symptomatology, while social cognition is hypothesised to be associated with positive psychotic symptoms (Dominguez et al., in press). In line with this symptomatic approach of the psychosis phenotype, current cognitive models suggest that the genesis of psychotic symptoms is the result of deficiencies in psychological mechanisms, most frequent in the domain of social cognition (Bentall et al., 1991, Franck et al., 2001, Frith and Dolan, 1996, Frith, 1987, Hoffman, 1986, Johns et al., 2001). Examples of these social cognitive mechanisms are, amongst others, mentalisation, reasoning style, source-monitoring and attributional style. 


\section{Mentalisation}

Mentalisation, also referred to as theory of mind, is the ability to decouple an actual state from a mental representation. Premack and Woodruff (Premack and Woodruff, 1978), who introduced the term 'theory of mind', gave the following description: 'the ability to conceptualise other individuals' mental states and explain and predict much of their behaviour'. Previous research indicated that mentalisation is a capacity which distinguish humans from primates (Povinelli and Vonk, 2003, Premack and Woodruff, 1978). Deficits in mentalisation occur in individuals with an autism spectrum disorder (Baron-Cohen et al., 1985), as well as in individuals with a psychotic disorder (Blackwood et al., 2001, Corcoran et al., 1995, Frith, 2004, Frith and Corcoran, 1996, Hardy-Bayle et al., 1994, Pickup and Frith, 2001), with the difference that people with an autism spectrum disorder are characterised by a problematic development which hampers them ever acquiring normal mentalisation skills (Frith, 1992), whereas individuals with psychosis experience a fluctuation or decline in their mentalising abilities (Frith, 1992, Frith and Corcoran, 1996).

\section{Reasoning style}

'Jumping to conclusions' is a reasoning bias that can be observed in individuals with positive psychotic symptoms, in particular delusional ideation. Individuals with delusions may incline toward early acceptance and, to a lesser extent, early rejection of hypotheses. The 'jumping to conclusions' reasoning bias, also referred to as data gathering bias, is the tendency to seek less information in order to reach a decision (Garety and Freeman, 1999, Garety et al., 2001). Since a data gathering bias possibly results in erroneous inferences, it can explain the genesis and maintenance of delusional ideation. It has been postulated that a JTC reasoning bias with the quality of a state can be a mediating factor in the maintenance of delusional ideation, at the most, while it may contribute to the formation of delusions as a trait.

\section{Source monitoring}

Source monitoring encloses various processes involved in ascribing memories, knowledge and beliefs to a certain source of information (Hashtroudi et al., 1989, Johnson et al., 1993). Three different kinds of source monitoring are generally distinguished: internal source monitoring, i.e. correctly distinguishing between two internally generated items; external source monitoring, i.e. the ability to make a correct distinction between externally generated items; and, particularly interesting in the study of psychosis, self-monitoring or reality monitoring, i.e. the ability to correctly differentiate internally generated items from those that are externally generated (Johnson et al., 1993). It has been put forward by different authors that alterations in self-monitoring is not only a hallmark for psychosis, but underlie the genesis of certain positive psychotic symptoms (Bentall, 1990, Blakemore et al., 2003, Brebion et al., 2002, Johns et al., 2001, Keefe et al., 2002). 


\section{Attribution style}

To what would one ascribe the cause of an incident? Whether you think yourself, another person or circumstances are responsible for a situation, characterises your attributional style. Deviant attribution style can contribute to the development of mental health morbidity (Kinderman and Bentall, 2000). In depressive disorders, an internal attribution style for negative events is common (Alloy et al., 1988, Joiner et al., 2001, Peterson et al., 1983), contrary to the self-serving bias shown in healthy individuals, characterised by an avoidance of self-blame and an internal attribution style for positive events (Duval and Silvia, 2002, Kaney and Bentall, 1992). A deviant attribution style can also be observed in psychotic disorders (Bentall et al., 2001, Kinderman and Bentall, 2000). In patients with psychosis, in particular those with paranoia, an extreme form of the healthy self-serving bias, the externalising bias, is observed, in which negative events are externally attributed, whereas positive events are attributed to oneself (Kaney and Bentall, 1992). It has been hypothesised that the function of this defensive attribution style is to protect oneself against latent negative self beliefs.

\section{Outline and aims of the thesis}

The overall aim of this thesis was to investigate the contribution of several of these social cognitive mechanisms to the development and maintenance of psychosis and whether or not they are distinguishable from the neurocognitive vulnerability. The inclusion of research groups with a higher than average psychometric or familial risk to develop psychosis, in addition to patients with a lifetime history of non-affective psychosis, allows hypotheses to be investigated, not only with respect to associations between alterations in social cognitive mechanisms and clinical psychotic disorders, but also whether alterations in social cognitive mechanisms represent the vulnerability for psychosis. In addition, this thesis examined whether the studied mechanisms in the realm of social cognition represent one underlying construct or several subcomponents which have to be subdivided in order for the domain of social cognition to be correctly studied.

The study described in chapter 2 aims to investigate whether social cognition and neurocognition, which are two domains in which consistent proof of their association with psychosis is demonstrated, are the expression of a single underlying deficit or the representation of two separate areas of liability. An additional aim of the study is to investigate whether all mechanisms that are included under the term 'social cognition' reflect one underlying construct or need to be subdivided into several subcomponents. Besides patients with psychosis, high risk groups and controls are also included in the sample. 
In chapter 3, alterations in verbal, on-line self-monitoring will be investigated in four groups with a different vulnerability for psychosis. The inclusion of research groups comprising subjects who are at risk for psychosis without having current clinical needs, has not been a factor in previous studies using the same paradigm, and enables questions to be answered about the liability for developing psychosis. Thus, the role of a defective verbal self-monitoring in the expression of psychosis at clinical and subclinical level can be examined.

In chapter 4, the hypothesis concerning the association between self-monitoring and psychosis-vulnerability will be investigated further using a similar approach to the approach in the study described in chapter 3 , but now focusing on monitoring one's own actions, assessed using a motor, on-line self-monitoring task.

Cognitive models of psychosis suggest that not only are cognitive biases involved in the genesis of positive psychotic symptoms, but also the subsequent emotional appraisal of the anomalous experiences that occur due to these cognitive deficits (Garety et al., 2001). In chapter 5 , which is the last chapter focussing on source monitoring, we will elaborate on the role of emotion on the off-line source monitoring capacities in individuals who display the clinical psychosis phenotype and their first degree relatives.

Chapter 6 will centre on mentalisation skills, which is the ability to decouple an actual state from a mental representation. In line with the source monitoring studies, this study aims to investigate the unresolved issue on whether impairment in mentalisation is an expression of the vulnerability for psychosis. Again, four groups with various degrees of vulnerability for psychosis (patients, genetic risk group, psychometric risk group and controls) will be included. In addition, possible associations between mentalisation deficiencies and psychotic symptomatology will be investigated. Traditionally, false-belief tasks are used to investigate mentalising abilities. Nowadays, the interpretation of mentalising capacities is broader than that of the detection of false beliefs and new paradigms are being developed. Among other tasks, this resulted in the development of the 'Hinting Task' (Corcoran et al., 1995). This instrument enables the investigation of first-order mentalisation skills (Garety and Freeman, 1999), i.e. the interpretation about an individual's belief about another person's beliefs. Second-order mentalisation skills, i.e. the interpretation about an individual's belief about another person's beliefs about a third individual (Frith and Corcoran, 1996), cannot be investigated using the Hinting Task. The hinting task was administered to the sample described in chapters 2, 3 and 4 .

Finally, a concise resume of each study will be provided in chapter 7 , together with a discussion of the implications of the findings for clinical practice and future research. 


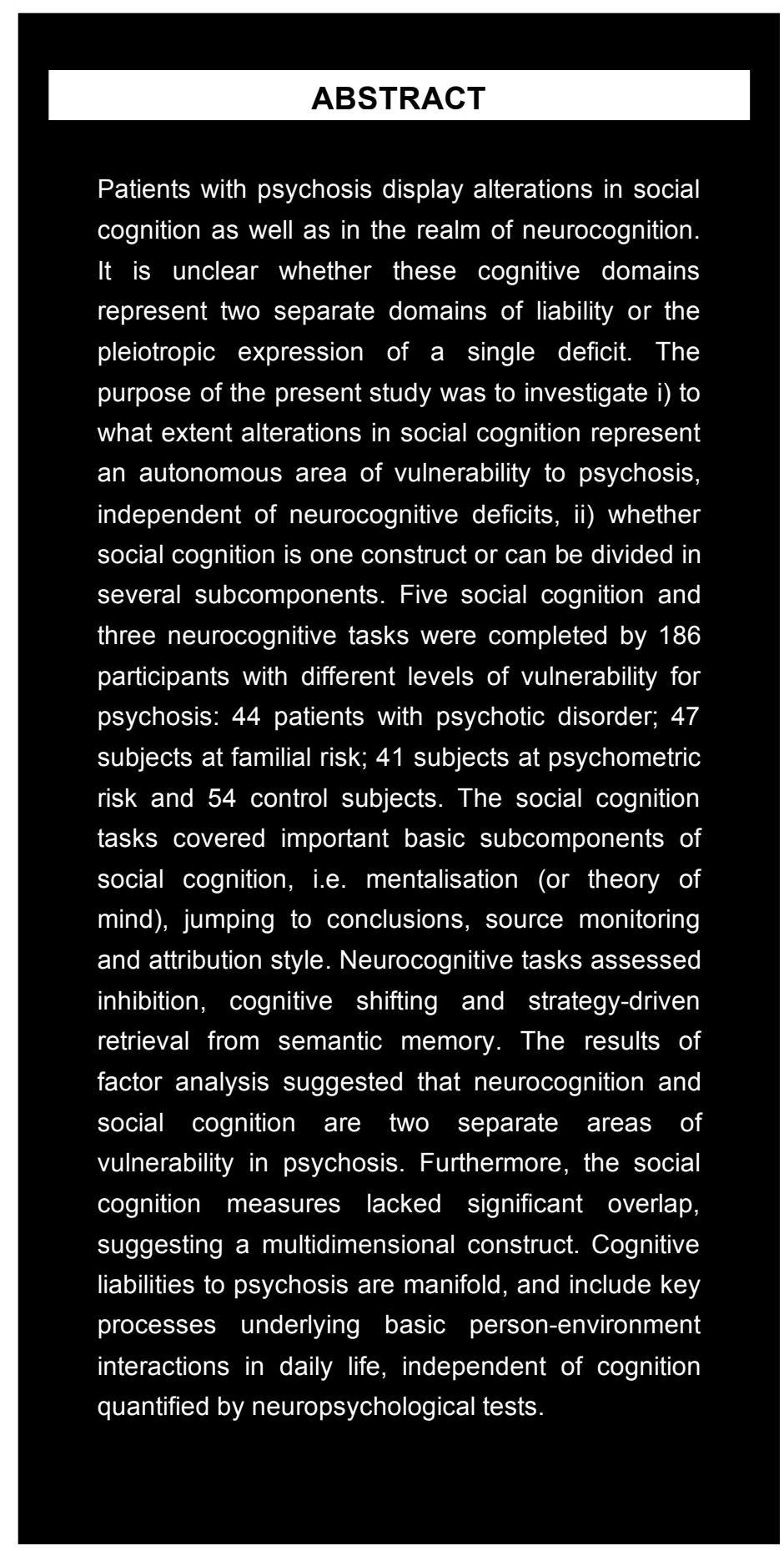

This paper was published as:

S. van Hooren*, D. Versmissen* (*Shared first author), I. Janssen, I. Myin-Germeys, J. a

Campo, R.Mengelers , J. van Os, L. Krabbendam. Social cognition and neurocognition as independent domains in psychosis, Schizophrenia Research, 103 (2008) 257-265. 


\section{INTRODUCTION}

Individuals with psychosis not only display neurocognitive deficits, but also experience alterations in processing social information. Alterations in areas of social cognition, including processing of emotions, social perception, mentalisation and social knowledge, may have important consequences for symptoms (Bentall et al., 1991, Frith et al., 1996, Garety et al., 2001) as well as for interpersonal relationships and community functioning (Vauth et al., 2004, Pinkham et al., 2006).

It has been hypothesised that social cognition may serve as a mediating link between neurocognition and community functioning (Vauth et al., 2004), suggesting that social cognition and neurocognition are related domains. Several studies have presented associations between social cognition and specific cognitive domains, such as attention (Addington et al., 1998), early visual processing (Sergi et al., 2006), executive functioning (Bryson et al., 1997) and verbal memory (Greig et al., 2004). Vauth (2004) analysed data from 133 inpatients with a diagnosis of schizophrenia showing that neurocognition accounted for $83 \%$ of the variance in social cognition. However, there is also evidence that the domains of social cognition and neurocognition are not overlapping because neural pathways for neurocognition and social cognition are separable (Adolphs, 2001, Pinkham et al., 2003). One study, analyzing data pertaining to 100 outpatients, showed that a two-factor model representing social cognition and neurocognition, fitted the data better than a one-factor model (Sergi et al., 2007). In conclusion, it is still unclear whether these cognitive domains represent two separate areas of liability or whether there is one overlapping factor underlying both deficiencies.

Part of the reason for the diversity of findings is likely related to the fact that studies generally treat social cognition as a unidimensional construct, represented by, for example, a single measure of emotion recognition. However, social cognition refers to the ability to construct representations about others, oneself, and relations between others and oneself (Adolphs, 2006). It includes an array of abilities, such as theory of mind, emotional processing, emotion perception, source monitoring, styles of attribution and data gathering. In the current study, therefore, not a single but five measures of social cognition, covering the areas of mentalisation, data gathering bias, source monitoring and attributional style, were examine to address two questions. The first question was to what degree the measures used to operationalise social cognition in psychosis represent a single construct or can be divided into several subcomponents. The second question was to what degree alterations in social cognition are associated with neurocognitive deficits, not only in patients with psychotic symptoms exposed to antipsychotic medication and other possible confounds, but also in individuals at risk. 


\section{Material and methods}

\section{Subjects}

The subjects were all participants of the 'Cognitive functioning in Psychosis' (CoP) study. This study consisted of four groups at variable risk for psychotic disorder: i) patients with a lifetime history of a period of non-affective psychosis in clear consciousness, ii) first degree relatives of patients with non-affective psychosis, iii) persons scoring high ( $>75^{\text {th }}$ pct.) on the positive dimension of psychosis-proneness measured by the Community Assessment of Psychic Experience (CAPE) (Stefanis et al., 2002) a self-report trait questionnaire to assess dimensions of the subclinical psychosis phenotype, validated in previous studies (Konings et al., 2006) and iv) 'healthy controls' i.e. participants scoring in the average range on the CAPE positive psychosis dimension (i.e. between $40^{\text {th }}$ and $60^{\text {th }}$ percentile). All participants were between the ages of 18 to 55 years, fluent in Dutch, and without a history of neurological disorders such as epilepsy and concussion with loss of consciousness. All participants signed an informed consent conforming to the local ethic's committee guidelines.

Patients were recruited from the catchment areas of the Community Mental Health Centre (source population: 350 000) and Psychiatric Hospital in the South of the Netherlands. Inclusion criteria for patients were the lifetime prevalence of a period of psychosis of at least two weeks in clear consciousness according to the RDC (Research Diagnosis Criteria: Spitzer, et al. 1978) and being sufficiently stable to allow psychological testing.

Relatives were all free from a lifetime history of psychosis. This group was sampled through participating patients or through associations for relatives of patients with psychotic symptoms. Subjects with average and high levels of psychotic experiences were recruited from an earlier longitudinal family study in the general population conducted in the city of Sittard [Continuum of Mental Disorders study, COMED; (Hanssen et al., 2003)]. All participants of the COMED study completed the CAPE. The subjects with mean and a high score on the CAPE positive psychosis dimensions were invited to participate in the CoP study.

The present study included 44 patients with psychosis, 47 non-psychotic first degree relatives, 41 subjects with a high level of psychotic experiences and 54 healthy controls with an average level of psychotic experiences. 
All patients were screened for symptoms listed in the operational Criteria Checklist for Psychotic Disorder [OCCPI; (McGuffin et al., 2001)]. Where necessary, additional information was derived from interviews with ward staff or personal casemanagers. Using the combined information in the OCCPI, the computer program OPCRIT yielded RDC diagnoses. Thirty-one patients had an OPCRIT-RDC diagnosis of schizophrenia, 3 patients an OPCRIT-RDC diagnosis of schizoaffective disorder (but diagnosed with schizophrenia by their psychiatrist and consequently included in the study) and 5 patients an OPCRIT-RDC diagnosis of unspecified functional psychosis.

\section{Neurocognitive tasks}

The neurocognitive task included the Stroop Colour Word Test, the Trail Making Task and semantic fluency.

\section{The Stroop Colour Word Test}

The shortened version of the Stroop Colour Word Test (SCWT) was used that involves three cards displaying forty stimuli each (Stroop, 1935, Houx et al., 1993). The first card contains colour words printed in black ink, which have to be read. The second card contains coloured patches, which have to be named. The third card displays colour names printed in incongruously coloured ink. Individuals are instructed to name the ink colour of the printed words. This interference task of the SCWT was used as an outcome measure and can be regarded as a measure of inhibition of a habitual response, which depends on adequate levels of executive functioning (Hanninen et al., 1997).

\section{Trail Making Test}

A modified version of the Trail Making Test (Vink et al., 1985) was used, consisting of three parts. On each test sheet, 16 small circles are grouped in a larger circle. The smaller circles contain numbers, letters or both, appearing in a fixed random order. Participants are requested to cross out the items in the right order. In the last part, participants have to alternate between numbers (1-8) and letters $(\mathrm{A}-\mathrm{H})$. The time needed to complete each trial is scored. The score on the last part was used as an outcome measure and reflects the time for cognitive shifting. Cognitive shifting or mental set shifting is considered a part of executive functioning (Miyake et al., 2000).

\section{Semantic Fluency}

Semantic Fluency was used to measure adequate, strategy-driven retrieval of information from semantic memory. Individuals were asked to name as many animals as possible in 1 minute.

\section{$\underline{\text { Social cognition tasks }}$}


In this study, five tasks were included to assess social cognition.

\section{Hinting task}

The Hinting task (Corcoran et al., 1995) measures the ability to infer real intentions behind indirect speech utterances. The original task consists of ten short passages presenting an interaction between two characters, four of which were used in the present study. At the end of each passage, one of the characters drops an obvious hint. Subjects were asked what the character really meant. An appropriate response was given the score of "2". If subjects failed to give an appropriate response, a more obvious hint was added to the short story. Subjects were asked what the character wants the other one to do. If an appropriate response was given, the subject received a score of " 1 " for that item. An inappropriate response after the second hint resulted in a score of "0". Thus, the total score ranged from zero to 20.

\section{Beads task}

The beads task measures the tendency to a data gathering bias known as the jumping to conclusion reasoning bias. In this study, a computerized version outlined by Phillips and Edwards (1966) was used as follows. A pair of jars was presented on the screen. One jar contains 85 green and 15 red beads, and the other jar contains the opposite ratio of green and red beads. Information about the proportion was told, and the two jars were withdrawn from sight. A bead drawn from one of the hidden jars is shown on the screen to the participant. Beads are sequentially being drawn and always replaced. Participants had to indicate whether the beads were drawn from the mainly green or mainly red jar. In this study, the condition was chosen in which participants were free to determine how many beads were drawn. The trial was only terminated once the participant affirmed that they were certain about their choice. A variable was constructed indicating whether a subject showed a jumping to conclusion reasoning bias (hereafter JTC). In line with previous work (Van Dael et al., 2006) this variable was dichotomous, defined as requesting only 1 bead before deciding or more beads. This cut off reflects the most definite expression of the reasoning bias and discriminates best between groups (Van Dael et al., 2006).

\section{Action recognition test (ART)}

The action recognition test (Franck et al., 2001) measures the degree to which participants attribute actions correctly. Images on a computer screen, placed faced down in a stillage, were reflected in a horizontal mirror. This mirror was placed 18 centimetres below the screen and 31 centimetres above a table at which the subject was seated. A joystick was placed on the table. The image of a virtual hand was presented in the mirror, superimposed on the subject's own hand. This setting allowed the participants to actually move the joystick, while being exclusively exposed to the image of the virtual hand, moving in an analogues manner to their own. Subjects sat in front of the setting with their forehead resting on a foam cushion 
which enveloped the metallic stillage. Subjects held the joystick with their preferred hand, while the elbow rested on the table.

During the task, a green spot was displayed for one second on the left, the right or the top of the screen. Then the virtual hand was presented for two seconds. At that moment, subjects had to move the joystick in the direction that was indicated by the green spot. Simultaneously, the virtual hand was moving. Subjects had to indicate verbally whether the movement of the virtual hand was an exact copy of the movement they had made.

The task consisted of 120 trials that were divided in three categories: 24 trials were neutral, in which the virtual hand made an exact copy of the movement made by the participant; 48 trials had a temporal bias, in which the virtual hand was delayed by a fixed time $(100,200,300$, $400 \mathrm{msec}$ ) compared to the movement of the participant; 48 had an angular bias, in which the movement of the virtual hand deviated by a specific angular value $\left(10^{\circ}, 20^{\circ}, 30^{\circ}, 40^{\circ}\right)$. The biases were randomly introduced. Before the task started, subjects were engaged in a training session in which the three categories were presented. The outcome variable was the total number of errors a participant made.

\section{Speech attribution task (SAT)}

A Shortened version of the speech attribution paradigm developed by Johns et al. (Johns et al., 2001) was used. This shortened version contained two thirds of the original 108 words. Single adjectives, half with a complimentary (for example 'cheerful') and half with a derogatory meaning (for example 'awful') were displayed to the participants on a computer screen. The adjectives were a subset of those used by Johns et al., translated into Dutch. During the task, participants wore a set of stereo headphones with a microphone attached. This microphone was connected to an acoustic effects unit and an amplifier. The presented adjectives were read aloud by the participant and the speech was fed back through the headphones in real time as they spoke. The pitch was either unchanged (no distortion), lowered by three semitones (moderate distortion), or 6 semitones (severe distortion). In another condition, participants heard someone else's voice (alien feedback condition) instead of their own as they spoke. The alien voice was also presented at three levels of distortion. Participants had to indicate the source of the speech by pressing a button that matched one of the three answers: 'self', 'someone else', or 'uncertain'. All this information was introduced by the interviewing psychologist in the introduction that preceded the test. The computer recorded the total errors in source monitoring.

\section{Internal, Personal, and Situational Attributions Questionnaire (IPSAQ)}

The IPSAQ (Kinderman et al., 1996) measures the degree to which individuals generate internal, personal or situational causal attributions for both positive and negative events. The questionnaire consists of 32 items that describe 16 positive and 16 negative social situations in the second person. For each item, the subject is asked to produce a single, most likely, causal explanation for the situation described. In the original version, participants have to 
categorize the cause as being internal (something to do with him or herself), personal (something to do with another person or persons) or situational (something to do with circumstances or chance). However, because of the difficulty of this categorization, the current study used independent ratings, as was done in a number of previous studies (Kinderman et al., 1992, Martin et al., 2002).

Two cognitive biases can be calculated: an externalising bias and a personalising bias. The present study focussed on the externalising bias, because only this bias showed significant differences between patients and high risk groups [i.e. relatives and individuals with subclinical psychotic experiences; (Janssen et al., 2006)]. The externalising bias is calculated by subtracting the number of internal attributions for negative events from the number of internal attributions for positive events relative to the number of valid answers for both positive and negative events. A positive score reflects self serving biases (i.e. blaming oneself less for negative events than for positive events).

\section{Statistical analysis}

The Hinting task and the fluency task were recoded so that higher scores indicated worse performance, similar to all other variables. First, correlation coefficients were computed between the tasks. This was done for the group as a whole and for each group separately. In order to examine clustering of neurocognitive and social cognition tasks, Principal Component Analysis (PCA) with oblique rotation was performed using STATA version 9.2. The clustering of tasks may differ between the groups. Therefore, additional PCA were repeated for each group separately. Nevertheless, since the results of the correlational analyses in the separate groups showed a similar pattern of results, our main focus was on the more powerful PCA performed in the total group (Tabbachnick and Fidell, 2004).

\section{Results}

\section{Correlation analyses}

The correlation coefficients between the tasks are presented in Table 1. As expected, all neurocognitive tests were significantly correlated with each other. The Hinting task was the only social cognition task that was correlated with all neurocognitive measures. The higher the score on the Hinting task, the better the performance on the neurocognitive measures. Several social cognition tasks were correlated with some neurocognitive tasks; the JTC bias on the Beads task was positively correlated with the Trail Making Test; the error score on the ART was positively correlated with the Fluency task; and errors on the SAT was positively correlated with the Stroop Colour word test. These correlations were all in the expected direction; the better the score on the social cognition task, the better the performance on the neurocognitive task. With respect to the social cognition tasks, only two tests were 
significantly correlated with each other; the SAT was associated with the ART; the more errors made on the SAT, the more errors on the ART. Performance on the IPSAQ was not associated with any of the other tasks. Results in the total group were largely similar to those in the separate groups. In all subgroups, the neurocognitive tasks were significantly correlated with each other (all $r$ between 0.33 and 0.69 , all $p<0.02$ ). Among the controls, the persons at risk and the patients, there was a correlation between the Hinting task and the neurocognitive tasks. In particular, the Hinting task correlated strongest with the Fluency task in the patient group $(r=0.55 ; p<0.01)$.

Table 1: Correlations between neurocognitive tasks and social cognition tasks for the total group $(n=149)$.

\begin{tabular}{|c|c|c|c|c|c|c|c|c|}
\hline & SCWT & TMT & Fluency & Hints & Beads & ART & SAT & IPSAQ \\
\hline SCWT & 1 & & & & & & & \\
\hline TMT & $0.46^{* *}$ & 1 & & & & & & \\
\hline Fluency & $0.46^{* *}$ & $0.54^{* *}$ & 1 & & & & & \\
\hline Hints & $0.31^{* *}$ & $0.30^{* *}$ & $0.44^{* *}$ & 1 & & & & \\
\hline Beads & 0.10 & $0.19^{*}$ & 0.11 & 0.08 & 1 & & & \\
\hline ART & 0.03 & 0.03 & $0.17^{*}$ & 0.11 & 0.06 & 1 & & \\
\hline SAT & $0.15^{*}$ & 0.09 & -0.04 & 0.01 & -0.02 & $0.20^{* *}$ & 1 & \\
\hline IPSAQ & -0.04 & -0.03 & -0.01 & 0.03 & 0.06 & 0.02 & 0.04 & 1 \\
\hline
\end{tabular}


${ }^{*} p>0.05 ;{ }^{* *} p>0.01$

Note: All tasks were coded as the higher the score, the worse the performance. SCWT=Stroop Colour Word Test; TMT=Trail Making Test; ART=Action Recognition Test; SAT=Speech Attribution Task; IPSAQ=Internal, Personal, and Situational Attributions Questionnaire.

\section{Factor analyses}

The PCA yielded 3 factors with an eigenvalue of $>1$ (see Table 2), explaining $58 \%$ of the variance. All neurocognitive tasks and the Hinting task loaded on the first factor, the error score on the ART loaded on the second factor, and the errors on the SAT and the score on the IPSAQ loaded on the third factor. The JTC bias on the Beads task did not show a high loading on any factor. The unique variance of the JTC bias on the Beads was 0.82, indicating that this task may not belong to any of the factor loadings.

Table 2: Summary of the Principal Component Analysis for the total group ( $n=149)$.

\begin{tabular}{|c|c|c|c|}
\hline & Factor 1 & Factor 2 & Factor 3 \\
\hline SCWT & & & \\
\hline TMT & & -0.14 & 0.10 \\
\hline Fluency & 0.83 & -0.11 & 0.12 \\
\hline Hints & 0.75 & 0.18 & -0.14 \\
\hline Beads & 0.61 & 0.24 & -0.21 \\
\hline
\end{tabular}




\begin{tabular}{|c|c|c|c|}
\hline ART & & & \\
& -0.01 & 0.95 & 0.06 \\
\hline SAT & & & \\
\hline IPSAQ & 0.03 & 0.09 & 0.82 \\
\hline
\end{tabular}

Note: All tasks were coded as the higher the score indicating the worse the performance. SCWT=Stroop Colour Word Test; TMT=Trail Making Test; ART=Action Recognition Test; $\mathrm{SAT}=$ Speech Attribution Task; IPSAQ=Internal, Personal, and Situational Attributions Questionnaire

A similar pattern of results was seen in the healthy control group $(R$-square $=0.64)$ and the individuals scoring high on the positive dimension of psychosis-proneness ( $R$-square $=0.68$ ). In the relatives $(R$-square $=0.73$ ) and the patient group $(R$-square $=0.83)$, a four factor solution was found. However, the PCA yielded a different clustering of the tasks in these two groups. In the relatives, the first factor was a neurocognitive factor (factor loadings $>0.72$ ) and the other three were social cognition factors. The score on the Hinting task, the JTC bias on the Beads and the IPSAQ loaded on the second factor (factor loadings > 0.55), the errors on the SAT loaded on the third factor (factor loading $=0.90$ ), and the error score on the ART loaded on the fourth factor (factor loading $=0.94$ ). In the patient group, the distinction between neurocognition and social cognition was not as evident as in the relatives. All the neurocognitive factors and the score on the Hinting task loaded on the first factor (factor loadings $>0.59$ ), the errors on the SAT loaded on the second factor (factor loading $=0.89$ ); the JTC bias on the Beads and the IPSAQ loaded on the third factor (factor loadings > 0.64), and the error score on the ART loaded on the fourth factor (factor loading $=0.89$ ).

\section{Discussion}

Summarizing the results of the current study, all neurocognitive assessments were mutually associated. Comparable results with respect to the relationship amongst the neurocognitive tasks were found when applying PCA. All neurocognitive assessments loaded on one factor, together with the Hinting task. With exception of this latter task, neurocognition and social cognition with the PCA loaded on different factors. In the domain of social cognition, the 
results from both the correlation analyses and the PCA indicate a lack of consistency between the different subcomponents which were included in the study.

Overall, the results of the current study show two major findings with respect to cognition in psychosis. First, the results suggest that neurocognition and social cognition likely represent two separate areas of vulnerability in psychosis. Second, the lack of significant overlap among the different social cognition measures suggests that the term 'social cognition' encompasses various cognitive mechanisms.

\section{Neurocognition and Social cognition, two separate domains}

Although deficits in neurocognition and social cognition can co-occur in patients with psychosis, the results of the current study suggest that neurocognition and social cognition can not be explained by a single underlying factor, but that there is a distinction between both. In agreement with these results, Sergi and colleagues (Sergi et al., 2007) found that a two-factor model representing neurocognition and social cognition as separate domains was a better fit than a one-factor model. Pinkham and co-workers (Pinkham et al., 2003) demonstrated that social cognition is an aspect of cognition independent from non-social cognition. The findings of the current study are in line with the theory that part of the heterogeneity in psychosis may be usefully reduced to the testable hypothesis of two separate pathways, characterised by relatively different mechanisms, in the development of psychosis (Myin-Germeys et al., 2002, Myin-Germeys et al., 2007). An earlier study (MyinGermeys et al, 2002) reported an inverse relationship between neurocognitive deficits and stress-sensitivity. Social cognition may be located on the affective pathway to psychosis, expressed as sensitivity to stress in combination with a predominance of positive symptoms and better outcome. The association between social cognition and the positive symptoms of psychosis has been demonstrated in a large number of studies (Heilbrun, 1980, Bentall et al., 1991, Frith et al., 1996, Johns et al., 2001, Janssen et al., 2006). The neurocognitive pathway to psychosis, on the other hand, may be characterised by brain structural deficits, negative symptomatology and a more chronic course (Murray et al., 1992). The two-pathway hypothesis is supported by the proposition of Frith (Frith, 1996) that the presence of severe delusions or hallucinations is not associated with neurocognitive impairment.

\section{Neurocognition}

The outcome of both the correlation analyses and the principal component analyses indicate the existence of a neurocognitive construct in which all components are highly correlated with each other. This finding applied to both the combined group and the subgroups separately (control group, psychometric risk group, familial risk group and patient group). This finding is 
consistent with a study among patients with schizophrenia that indicated a common factor underlying the cognitive deficits (Dickinson et al., 2004). Previous studies in healthy subjects that used factor analysis showed that two neurocognitive factors can be identified representing memory and speed/executive attention (McArdle, et al. 2007; Holtzer, et al. 2007). The neurocognitive tests used in the present study were all timed and assessed subcomponents that can be considered as part of executive functioning (i.e. inhibition, cognitive shifting and strategy driven retrieval). The focus on speeded executive functioning tasks in the present study may be another reason for the high correlations between the neurocognitive components.

\section{Social cognition}

Contrary to the findings relating to neurocognition, the social cognitive domain lacked overall consistency and therefore maybe construed as a multidimensional construct.

The correlation analyses demonstrated that the ART and SAT, both measuring sourcemonitoring, were the only two areas in social cognition that were associated with each other. Although this association reached significance, the effect size was very small which is in line with the findings of the PCA indicating loadings of these two assessments on different factors. These results suggest that there is only a minor association between ART and SAT.

Overall, results of the principal component analyses suggested that no single underlying factor can account for the different areas of social cognition in this study. Rather, the term 'social cognition' appears to encompasses various cognitive mechanisms, in accordance with other theoretical research (Adolphs, 2001).

In the last decade, a large amount of research in the domain of social cognition has been carried out. Many of these studies focused on the relationship between social cognitive alterations and psychotic symptomatology. Most results show a tendency towards an association between alterations in social cognition and positive psychotic symptoms (Frith, 1996, Bentall et al., 2001), for example the association between an impaired self monitoring and delusional ideations, in particular alien control (Stirling et al., 1998) or the association between an externalised attributional style and paranoia (Kinderman et al., 1992). Nevertheless, a substantial number of studies demonstrated associations between alterations in social cognition and other symptoms, such as the association between mentalising deficiencies and both negative symptoms (Corcoran et al., 1997) and disorganisation (HardyBayle et al., 1994). The lack of consistency may be caused by the fact that the mechanisms clustered together under the denominator 'social cognition' represent more than one vulnerability factor. Neurobiological evidence seems to support this notion, because specific brain regions are involved in independent subcomponents of social cognition (Adolphs, 2001, Satpute et al., 2006). For example, perception of social stimuli is linked to the superior temporal sulcus (Allison et al., 2000, Haxby et al., 2000), mentalising showed associations in 
functional imaging studies with medial prefrontal cortex (Gallagher et al., 2000), and recognition of basic emotions and social judgements may be mediated by the amygdala (LeDoux, 2003, Adolphs, 2006, 2007).

Theory of mind, or mentalisation, is often used to measure social cognition. Given the fact that the Hinting task is a commonly used tool to measure mentalising abilities, the findings of the current study with respect to the results derived from this instrument deserve attention. In particular in the patient group, the Hinting task, contrary to other measures of social cognition, was associated with neurocognitive tests. Previous research also reported an association between mentalising deficits, measured with the Hinting task and intelligence (Corcoran et al., 1995). The results from the factor analyses similarly indicate a strong relationship between the Hinting task and neurocognition. The reason why this shows more strongly in the patient group than it does in the other groups could be explained by the low sensitivity of the Hinting task, in particular in non-patient groups, as demonstrated before (Janssen et al., 2003).

\section{Conclusions}

Neurocognition and social cognition are two separate areas of vulnerability in psychosis. Besides this, the lack of significant overlap among the different social cognition measures suggests that social cognition is a multidimensional construct. Our findings support the tendency to include, next to neurocognitive tests, more social cognitive tasks to cover the various mechanisms that represent different domains in social cognitions, in general cognitive test batteries. 


\section{R EFERENCES}

Addington, J. Addington, D., 1998. Facial affect recognition and information processing in schizophrenia and bipolar disorder. Schizophr. Res. 32, 171-81.

Adolphs, R., 2001. The neurobiology of social cognition. Curr Opin Neurobiol 11, 231-9.

Adolphs, R., 2006. How do we know the minds of others? Domain-specificity, simulation, and enactive social cognition. Brain Res 1079, 25-35.

Adolphs, R., 2007. Looking at other people: mechanisms for social perception revealed in subjects with focal amygdala damage. Novartis Found Symp 278, 146-59; discussion 160-4, 216-21.

Allison, T., Puce, A. McCarthy, G., 2000. Social perception from visual cues: role of the STS region. Trends Cogn Sci 4, 267-278.

Bentall, R. P., Baker, G. A. Havers, S., 1991. Reality monitoring and psychotic hallucinations. Br. J. Clin. Psychol. 30 ( Pt 3), 213-22.

Bentall, R. P., Corcoran, R., Howard, R., Blackwood, N. Kinderman, P., 2001. Persecutory delusions: a review and theoretical integration. Clinical Psychology Review 21, 1143-92.

Bryson, G., Bell, M. Lysaker, P., 1997. Affect recognition in schizophrenia: a function of global impairment or a specific cognitive deficit. Psychiatry Res 71, 105-13.

Corcoran, R., Cahill, C. Frith, C. D., 1997. The appreciation of visual jokes in people with schizophrenia: a study of 'mentalizing' ability. Schizophr. Res. 24, 319-27.

Corcoran, R., Mercer, G. Frith, C. D., 1995. Schizophrenia, symptomatology and social inference: investigating "theory of mind" in people with schizophrenia. Schizophr. Res. 17, 5-13.

Dickinson, D., lannone, V. N., Wilk, C. M. Gold, J. M., 2004. General and specific cognitive deficits in schizophrenia. Biol Psychiatry 55, 826-33.

Franck, N., Farrer, C., Georgieff, N., Marie-Cardine, M., Dalery, J., d'Amato, T. Jeannerod, M., 2001. Defective recognition of one's own actions in patients with schizophrenia. Am. J. Psychiatry 158, 454-9. 
Frith, C., 1996. Neuropsychology of schizophrenia, what are the implications of intellectual and experiential abnormalities for the neurobiology of schizophrenia? $\mathrm{Br}$. Med. Bull. 52, 618-26.

Frith, C. D. Corcoran, R., 1996. Exploring 'theory of mind' in people with schizophrenia. Psychol. Med. 26, 521-30.

Gallagher, H. L., Happe, F., Brunswick, N., Fletcher, P. C., Frith, U. Frith, C. D., 2000. Reading the mind in cartoons and stories: an fMRI study of 'theory of mind' in verbal and nonverbal tasks. Neuropsychologia 38, 11-21.

Garety, P. A., Kuipers, E., Fowler, D., Freeman, D. Bebbington, P. E., 2001. A cognitive model of the positive symptoms of psychosis. Psychol. Med. 31, 189-95.

Greig, T. C., Bryson, G. J. Bell, M. D., 2004. Theory of mind performance in schizophrenia: diagnostic, symptom, and neuropsychological correlates. J. Nerv. Ment. Dis. 192, $12-8$.

Hanninen, T., Hallikainen, M., Koivisto, K., Partanen, K., Laakso, M. P., Riekkinen, P. J., Sr. Soininen, H., 1997. Decline of frontal lobe functions in subjects with ageassociated memory impairment. Neurology 48, 148-53.

Hanssen, M., Peeters, F., Krabbendam, L., Radstake, S., Verdoux, H. van Os, J., 2003. How psychotic are individuals with non-psychotic disorders? Soc. Psychiatry Psychiatr. Epidemiol. 38, 149-54.

Hardy-Bayle, M. C., Passerieux, C., Claudel, B., Olivier, V. Chevalier, J. F., 1994. Communication disorders in schizophrenic patients. Cognitive explanation and clinical reconsideration. Encephale 20, 393-400.

Haxby, J. V., Hoffman, E. A. Gobbini, M. I., 2000. The distributed human neural system for face perception. Trends Cogn Sci 4, 223-233.

Heilbrun, A. B., Jr., 1980. Impaired recognition of self-expressed thought in patients with auditory hallucinations. J. Abnorm. Psychology 89, 728-36.

Houx, P. J., Jolles, J. Vreeling, F. W., 1993. Stroop interference: aging effects assessed with the Stroop Color-Word Test. Exp Aging Res 19, 209-24.

Janssen, I., Krabbendam, L., Jolles, J. van Os, J., 2003. Alterations in theory of mind in patients with schizophrenia and non-psychotic relatives. Acta Psychiatr. Scand. 108, 110-7. 
Janssen, I., Versmissen, D., Campo, J. A., Myin-Germeys, I., Os, J. V. Krabbendam, L., 2006. Attribution style and psychosis: evidence for an externalizing bias in patients but not in individuals at high risk. Psychol. Med., 1-8.

Johns, L. C., Rossell, S., Frith, C., Ahmad, F., Hemsley, D., Kuipers, E. McGuire, P. K., 2001. Verbal self-monitoring and auditory verbal hallucinations in patients with schizophrenia. Psychol. Med. 31, 705-15.

Kinderman, P. Bentall, R., 1996. A new neasure of causal locus: the internal, personal and situational questionnaire. Personality and Individual differences 20, 261-264.

Kinderman, P., Kaney, S., Morley, S. Bentall, R. P., 1992. Paranoia and the defensive attributional style: deluded and depressed patients' attributions about their own attributions. Br J Med Psychol 65 ( Pt 4), 371-83.

Konings, M., Bak, M., Hanssen, M., van Os, J. Krabbendam, L., 2006. Validity and reliability of the CAPE: a self-report instrument for the measurement of psychotic experiences in the general population. Acta Psychiatr Scand 114, 55-61.

LeDoux, J., 2003. The emotional brain, fear, and the amygdala. Cell Mol Neurobiol 23, 72738.

Martin, J. A. Penn, D. L., 2002. Attributional style in schizophrenia: an investigation in outpatients with and without persecutory delusions. Schizophr Bull 28, 131-41.

McGuffin, P. Farmer, A., 2001. Polydiagnostic approaches to measuring and classifying psychopathology. Am. J. Med. Genet. 105, 39-41.

Miyake, A., Friedman, N. P., Emerson, M. J., Witzki, A. H., Howerter, A. Wager, T. D., 2000. The unity and diversity of executive functions and their contributions to complex "Frontal Lobe" tasks: a latent variable analysis. Cognit Psychol 41, 49-100.

Murray, R. M., O'Callaghan, E., Castle, D. J. Lewis, S. W., 1992. A neurodevelopmental approach to the classification of schizophrenia. Schizophr Bull 18, 319-32.

Myin-Germeys, I., Krabbendam, L., Jolles, J., Delespaul, P. A. van Os, J., 2002. Are cognitive impairments associated with sensitivity to stress in schizophrenia? An experience sampling study. Am. J. Psychiatry 159, 443-9.

Myin-Germeys, I. van Os, J., 2007. Stress-reactivity in psychosis: evidence for an affective pathway to psychosis. Clin Psychol Rev 27, 409-24.

Pinkham, A. E. Penn, D. L., 2006. Neurocognitive and social cognitive predictors of interpersonal skill in schizophrenia. Psychiatry Res 143, 167-78. 
Pinkham, A. E., Penn, D. L., Perkins, D. O. Lieberman, J., 2003. Implications for the neural basis of social cognition for the study of schizophrenia. Am. J. Psychiatry 160, 815-24.

Satpute, A. B. Lieberman, M. D., 2006. Integrating automatic and controlled processes into neurocognitive models of social cognition. Brain Res 1079, 86-97.

Sergi, M. J., Rassovsky, Y., Nuechterlein, K. H. Green, M. F., 2006. Social perception as a mediator of the influence of early visual processing on functional status in schizophrenia. Am. J. Psychiatry 163, 448-54.

Sergi, M. J., Rassovsky, Y., Widmark, C., Reist, C., Erhart, S., Braff, D. L., Marder, S. R. Green, M. F., 2007. Social cognition in schizophrenia: relationships with neurocognition and negative symptoms. Schizophr Res 90, 316-24.

Stefanis, N. C., Hanssen, M., Smirnis, N. K., Avramopoulos, D. A., Evdokimidis, I. K., Stefanis, C. N., Verdoux, H. Van Os, J., 2002. Evidence that three dimensions of psychosis have a distribution in the general population. Psychol. Med. 32, 34758.

Stirling, J. D., Hellewell, J. S. Quraishi, N., 1998. Self-monitoring dysfunction and the schizophrenic symptoms of alien control. Psychol. Med. 28, 675-83.

Stroop, J. R., 1935. Studies of interference in serial varbal reactions. Journal of Experimental Psychology 18, 643-662.

Van Dael, F., Versmissen, D., Janssen, I., Myin-Germeys, I., van Os, J. Krabbendam, L., 2006. Data gathering: biased in psychosis? Schizophr Bull 32, 341-51.

Vauth, R., Rusch, N., Wirtz, M. Corrigan, P. W., 2004. Does social cognition influence the relation between neurocognitive deficits and vocational functioning in schizophrenia? Psychiatry Res 128, 155-65.

Versmissen, D., Myin-Germeys, I., Janssen, I., Franck, N., Georgieff, N., a Campo, J., Mengelers, R., van Os, J. Krabbendam, L., submitted. Impairment of selfmonitoring: part of the endophenotypic risk for psychosis.

Vink, M. Jolles, J., 1985. A new version of the Trail-Making Test as an information processing task. Journal of Clinical Neuropsychology 7, 162. 


\section{Verbal self-monitoring in psychosis: a non-replication}

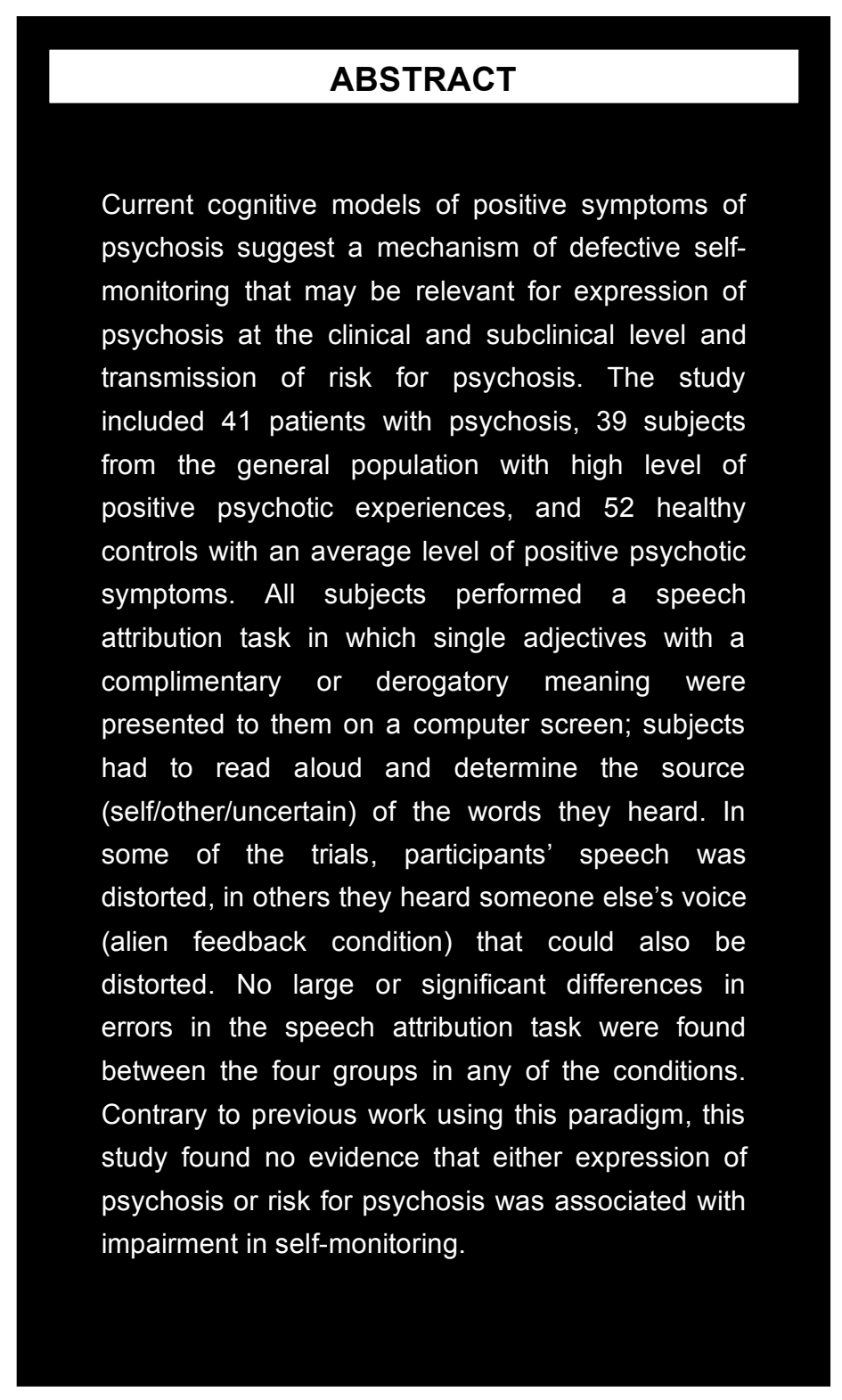

This paper was published as:

D. Versmissen, I. Janssen, L. Johns, P. McGuire, M. Drukker, J. a Campo, I. Myin-Germeys, J. van Os, L. Krabbendam. Verbal self-monitoring in psychosis: a non-replication,

Psychological Medicine, (2007). 1-8 


\section{INTRODUCTION}

Current cognitive models of positive symptoms of psychosis suggest that auditory hallucinations are the result of defective self-monitoring (Hoffman, 1986, Frith, 1987, Bentall et al., 1991b, Frith et al., 1996). Defective monitoring of verbal thoughts may lead to a failure in the recognition of one's own thoughts as self-generated and, as a consequence, these thoughts are misidentified as externally generated voices (Frith, 1987, Frith et al., 1989, Bentall et al., 1991b, Frith et al., 1996). Empirical work has shown that patients with acute psychotic symptoms have difficulties discriminating between self-generated items and external-generated items (Bentall, 1990, Keefe et al., 1999, Brebion et al., 2002). To further examine this hypothesis, Johns et al. (2001) developed a paradigm in which immediate auditory verbal feedback was manipulated, leading to discrepancies in what subjects heard and what they expected to hear. Overall, patients with schizophrenia, in particular those with auditory hallucinations, made more errors than controls, with a bias towards misattributing their own distorted voice to another person (Johns et al., 2001a, Johns et al., 2006).

Rates of psychotic symptoms approaching $5-15 \%$ in the general population (van Os et al., 2000, van Os et al., 2001, Hanssen et al., 2003, Johns, 2005) suggest that rather than a discrete entity, the psychosis phenotype may be better represented by a continuum with healthy functioning at one extreme and florid psychosis with clinical need at the other (Johns et al., 2001b, Hanssen et al., 2003). There is evidence that psychological mechanisms also operate at lower levels of the continuum in individuals who have no current clinical needs but nevertheless are at risk of developing them (Bentall, 1990, Janssen et al., 2003, Hanssen et al., 2006). First-degree relatives of patients with psychosis, and individuals with subclinical psychotic experiences in the general population, are examples of such risk groups (Claridge, 1994, Cunningham Owens et al., 2006). Evidence for a deficit in self-monitoring in individuals at risk would imply that such a deficit is associated not only with phenotypic expression of psychosis but also with endophenotypic risk for psychosis. Indeed, one initial study showed partial misattribution in individuals with attenuated positive psychotic symptoms (Johns et al., 2005).

The current study set out to extend these findings by including four groups with different levels of vulnerability to psychosis: patients with a lifetime history of non-affective psychosis, non-psychotic first-degree relatives, subjects from the general population with a high level of positive psychotic experiences, and healthy controls from the general population with an average level of positive psychotic experiences. The following hypotheses were investigated: (i) patients with non-affective psychosis are more likely than healthy volunteers to misidentify their own voice as someone else's when its acoustic characteristics are altered; (ii) this bias is also present in individuals at risk of developing psychosis, albeit to a lesser degree; (iii) relatives of patients will show less impairment compared to their psychotic relatives, but more 
than unrelated individuals with subclinical psychotic experiences, and (iv) the presence of positive psychotic experiences will be associated with misidentifications in both patients and high-risk groups.

\section{Method}

\section{Subjects}

The Cognitive functioning in Psychosis (CoP) study included (i) patients with a lifetime history of a period of non-affective psychosis in clear consciousness; (ii) first-degree relatives of patients with non-affective psychosis; (iii) subjects scoring high (>75th percentile) on the positive dimension of psychosis-proneness measured by the Community Assessment of Psychic Experiences [CAPE; (Stefanis et al., 2002)], and (iv) subjects scoring in the average range on the CAPE. All participants were between the ages of 18 and 55 years, fluent in Dutch and without a history of central neurological disorders. Written informed consent was obtained from all participants conforming to the local ethical committee guidelines.

Patients were recruited from the catchment area Community Mental Health Centre (source population: 350 000) and the catchment area Psychiatric Hospital. Initial inclusion criteria for patients were the lifetime prevalence of a period of psychosis in clear consciousness (i.e. being aware of themselves and their environment, in order to exclude psychosis in delirium), according to the Research Diagnosis Criteria [RDC; (Spitzer et al., 1978)]. Relatives were sampled through participating patients or through associations for relatives of patients with psychotic symptoms. Subjects with average and high levels of psychotic experiences were recruited from an earlier longitudinal family study (Continuum of Mental Disorders Study, COMED) in the general population conducted in the city of Sittard (Hanssen et al., 2005). All participants filled in the CAPE (Stefanis et al., 2002), a self-report trait questionnaire to assess dimensions of the subclinical psychosis phenotype. The CAPE includes dimensions of positive (20) and negative (14) psychotic experiences as well as depressive experiences (8). Subjects with a mean (i.e. between the 40th and 60th percentile) and a high (i.e. above the 75th percentile) score on the CAPE positive psychosis dimension were invited to participate in the CoP study.

The study included 45 patients with psychosis (44\% in-patients), 47 non-psychotic firstdegree relatives, 41 subjects from the general population with a high level of positive psychotic experiences, and 54 healthy controls from the general population with an average level of positive psychotic experiences.

For all participating patients, the Operational Criteria Checklist for Psychotic Disorder (OCCPI) was completed based on case-note material and the Positive and Negative Syndrome Scale [PANSS; (Kay et al., 1987)] interview. Where necessary, additional 
information was derived from ward staff or case managers. Using the information in the OCCPI, the computerized program OPCRIT yielded RDC diagnoses. There were 31 patients $(69 \%)$ with an OPCRIT diagnosis of schizophrenia, three patients $(7 \%)$ with an OPCRIT diagnosis of schizo-affective disorder, who were diagnosed with schizophrenia by their psychiatrist and consequently included in the study, and five patients (11\%) with an OPCRIT diagnosis of unspecified functional psychosis.

\section{Instruments}

\section{Speech attribution task}

A shortened version, compiled of two-thirds of the original 108 words in the study by Johns et al. (2001), of the speech attribution paradigm developed by Johns and colleagues was used (Johns et al., 1999, Johns et al., 2001a). Single adjectives, half with a complimentary (e.g. 'cheerful') and half with a derogatory meaning (e.g. 'awful') were displayed to the participants on a computer screen. The adjectives were a subset of those used by Johns et al. (2001), translated into Dutch.

\section{Procedure}

Participants wore a set of stereo headphones with a microphone attached. This microphone was connected to an acoustic effects unit and an amplifier. The presented adjectives were read aloud by the participant and the speech was fed back through the headphones in real time as they spoke. In some of the trials, participants' speech was distorted. The pitch was either unchanged (no distortion), lowered by three semitones (moderate distortion), or six semitones (severe distortion). In another condition participants heard someone else's voice (alien feedback condition) instead of their own as they spoke. Similar to the person's own voice, the alien voice was presented at three levels of distortion. Summarizing, there were three self-conditions, one with distortion and one without distortion, and two alien-conditions, again with and without distortion. All this information was presented by the interviewing psychologist in the introduction that preceded the test. In each condition, four complimentary and four derogatory adjectives were presented. Participants had to indicate their opinion about the source of the speech by pressing the button that matched one of the three possible answers: 'self', 'someone else' or 'uncertain'.

\section{The Present State Examination (PSE)}

The purpose of the PSE (Wing, 1974) is to assess the presence and severity of symptoms associated with a broad range of major psychiatric disorders over a designated period (i.e. the last week), by means of a structured clinical cross-examination of the patient. In this study, only the sections that cover signs and symptoms of psychotic disorders were used (43 items: PSE 55-92, plus their subscale scores). 


\section{General intelligence}

General intelligence was measured by a combined score on one performance subtest and one verbal subtest from the Groninger Intelligence Test (GIT), a widely used Dutch intelligence test (Luteijn, 1983). This test yields results that are comparable to those of the Wechsler Adult Intelligence Scale-Revised (Wechsler, 1981).

\section{Statistical analyses}

Statistical analyses were carried out using STATA version 8.0 (StataCorporation, 2005). A four-level ordinal group variable was constructed reflecting the risk for psychosis, with value 3 for patients, 2 for relatives, 1 for subclinical psychotic experiences, and 0 for controls. This creates the possibility to examine whether the four subject groups differ in a linear fashion.

Four words of the Speech Attribution Task were excluded from the analyses because their length caused difficulties in reading those specific words properly in the time span provided.

An error on the speech attribution task was defined as either an 'uncertain' response or a response that misidentified the source of the feedback given through the headphones. Analyses were repeated after exclusion of the 'unsure' answers. Errors were subdivided into two categories: (i) subjects misidentifying their own voice as someone else's, and (ii) subjects misidentifying an alien voice as their own. To examine whether the groups differed in the type of errors they produced, a variable was constructed that reflected the proportion of errors in which subjects did not recognize their own voice (self errors), relative to the total number of errors. The association between errors and symptomatology was assessed using continuous outcome variables for the PSE total score, as well as for the delusions and hallucinations subscales separately.

A multi-level approach to logistic regression, using the XTGEE module in STATA, was applied to assess the association between making an error on the speech attribution task and (i) the four-level group variable for psychosis risk and (ii) symptomatology as assessed with the PSE. Effect sizes were expressed as odds ratios (ORs) with their $95 \%$ confidence intervals (Cls), with the control group as the reference category. Multi-level random effects modelling techniques are a variant of the more often used uni-level regression analyses (Golstein, 1987) and are ideally suited for the analysis of data in which repeated observations (eight adjectives per level of distortion) are nested within subjects (Golstein, 1987). The main analysis was also performed in the subsets of subjects with current auditory hallucinations and Schneiderian symptoms respectively. 
All analyses were a priori adjusted for age, general intelligence and sex because these are possible confounders of the association between psychosis risk and cognition.

\section{Power analysis}

Power of the analyses was calculated by simulation adapted from an example on the Stata website (www.stata.com/support/faqs/stat/power.html). The linear function of the In(odds) was used to randomly generate a dichotomous variable, using the genbinomial procedure (STATA). This dependent variable was analysed 1000 times using logistic regression analyses. The power is the percentage in which the OR was statistically significant. Because the data had a multi-level structure, the multi-level $n$ (7903) was first translated into the unilevel equivalent, using a multiplication factor (Snijders et al., 1999). The uni-level equivalent of the $n$ in the present analyses was 2023. These power simulations showed that the study has a power of approximately $80 \%$ to show an OR of $1 \cdot 6$.

\section{$\mathbf{R}_{\text {ESULTS }}$}

\section{Sample characteristics}

The speech attribution task was carried out by 41 patients with psychosis, 39 non-psychotic first-degree relatives, 39 subjects from the general population with a high level of positive psychotic experiences and 52 healthy controls with an average level of positive psychotic experiences. Missing data were due to technical $(n=10)$ or hearing problems $(n=4)$. Two subjects from the patient group could not finish the task because of concurrent auditory hallucinations.

Demographic details are listed in Table 1. The mean total PSE score in the patient group was 16.2 (S.D. = 15.4) (see Table 1). Of the patient group, $15.2 \%$ had current auditory hallucinations, while $56 \cdot 1 \%$ had current Schneiderian symptoms. We found that $19 \cdot 5 \%$ of the subject group from the general population with a high level of positive psychotic experiences had had experiences of hearing voices during their lives. This is concordant with studies that suggest that psychotic experiences occur outside the realm of clinical disorder (Johns et al., 2001b, Hanssen et al., 2003). In addition, $78 \%$ of the latter group had experienced at least one of the Schneiderian-like symptoms.

Table 1: Summary statistics and symptom scores PSE of sample

\begin{tabular}{|c|c|c|c|c|c|}
\hline $\begin{array}{c}\text { Controls } \\
(\mathrm{n}=52)\end{array}$ & $\begin{array}{c}\text { Subclinical psychosis } \\
(\mathrm{n}=39)\end{array}$ & $\begin{array}{c}\text { Relatives } \\
(\mathrm{n}=39)\end{array}$ & $\begin{array}{c}\text { Patients } \\
(\mathrm{n}=41)\end{array}$ \\
\hline Mean & SD & Mean & SD & Mean & SD \\
\hline
\end{tabular}




\begin{tabular}{|c|c|c|c|c|c|c|c|c|}
\hline Age & 47.0 & 7.6 & 44.0 & 9.8 & 40.4 & 11.1 & 32.3 & 10.4 \\
\hline Education $^{a}$ & 5.6 & 0.8 & 4.9 & 1.4 & 5.5 & 1.2 & 4.6 & 1.2 \\
\hline $\begin{array}{c}\text { General } \\
\text { Intelligence }\end{array}$ & 124.5 & 17.0 & 119.0 & 14.8 & 124.8 & 15.8 & 111.3 & 20.6 \\
\hline Gender ( $\%$ male) & \multicolumn{2}{|c|}{36.5} & \multicolumn{2}{|c|}{46.2} & \multicolumn{2}{|c|}{36.5} & \multicolumn{2}{|c|}{75.9} \\
\hline Error (\%) ${ }^{b}$ & 18.7 & & 29.1 & & 27.5 & & 27.7 & \\
\hline Delusions $^{c}$ & 0.0 & 0.0 & 0.4 & 1.4 & 0.1 & 0.9 & 8.0 & 8.8 \\
\hline Hallucinations $^{c}$ & 0.0 & 0.0 & 0.4 & 1.7 & 0.3 & 1.0 & 3.3 & 4.7 \\
\hline Total $^{c}$ & 0.02 & 0.1 & 1.6 & 4.3 & 0.8 & 2.8 & 16.2 & 15.4 \\
\hline
\end{tabular}

${ }^{\mathrm{a}}$ Education was measured on an eight-point scale from primary school to university degree (De Bie, 1987).

b Errors are defined as either an 'uncertain' response or a response that misidentified the source of the feedback.

c Present State Examination-scores.

\section{Verbal self-monitoring and psychosis}

All four groups made errors. As no large or significant differences in error rates were found between the complimentary adjectives condition (OR 0.97, 95\% $\mathrm{Cl} 0.89-1.06, p=0.53$ ) and the derogatory adjectives condition (OR 0.98, 95\% Cl 0.89-1.08, $p=0.74$ ), these conditions were combined into a single variable in the analysis.

There were no large or significant differences in the error rates between the four groups in any of the conditions (see Table 2). In the self-condition with distortion, which was the condition of interest for the present study, the ORs, relative to the controls, for the association between making an error and the psychosis-liability group variable were 0.94 (95\% Cl 0.60$1.47)$ in the group with a high level of psychotic experiences, 0.87 (95\% Cl 0.56-1.35) in the relatives group and $1.04(95 \% \mathrm{Cl} 0.61-1.48)$ in the patient group.

Table 2: Means and OR for the percentage of errors made in each condition

\begin{tabular}{|c|c|c|c|c|c|c|c|}
\hline & Controls & \multicolumn{2}{|c|}{ Subclinical psychosis } & \multicolumn{2}{|c|}{ Relatives } & \multicolumn{2}{|c|}{ Patients } \\
\hline & $\begin{array}{l}\text { Mean } \\
\text { (SE) }\end{array}$ & $\begin{array}{l}\text { Mean } \\
\text { (SE) }\end{array}$ & $\begin{array}{l}\text { OR } \\
(95 \% \mathrm{Cl})\end{array}$ & $\begin{array}{l}\text { Mean } \\
\text { (SE) }\end{array}$ & $\begin{array}{l}\text { OR } \\
(95 \% \mathrm{Cl})\end{array}$ & $\begin{array}{l}\text { Mean } \\
\text { (SE) }\end{array}$ & $\begin{array}{l}\text { OR } \\
(95 \% \mathrm{Cl})\end{array}$ \\
\hline \multicolumn{8}{|l|}{ With 'unsure' } \\
\hline $\begin{array}{l}\text { Self } \\
\text { No distortion }\end{array}$ & $8.3(1.1)$ & $\begin{array}{l}16.7 \\
(2.1)\end{array}$ & $\begin{array}{c}2.06 \\
(0.83- \\
5.13)\end{array}$ & $\begin{array}{l}12.8 \\
(1.9)\end{array}$ & $\begin{array}{c}2.01 \\
(0.78- \\
5.20)\end{array}$ & $\begin{array}{l}12.5 \\
(1.8)\end{array}$ & $\begin{array}{c}2.30 \\
(0.74- \\
7.20)\end{array}$ \\
\hline
\end{tabular}




\begin{tabular}{|c|c|c|c|c|c|c|c|}
\hline $\begin{array}{l}\text { Self } \\
\text { Distortion }\end{array}$ & $35.8(1.7)$ & $\begin{array}{l}34.5 \\
(2.0)\end{array}$ & $\begin{array}{c}0.88 \\
(0.56- \\
1.39)\end{array}$ & $\begin{array}{l}32.8 \\
(1.9)\end{array}$ & $\begin{array}{c}0.84 \\
(0.53- \\
1.31)\end{array}$ & $\begin{array}{l}33.6 \\
(1.9)\end{array}$ & $\begin{array}{c}0.74 \\
(0.42- \\
1.30)\end{array}$ \\
\hline $\begin{array}{l}\text { Alien } \\
\text { No distortion }\end{array}$ & $34.5(2.4)$ & $\begin{array}{l}37.9 \\
(2.9)\end{array}$ & $\begin{array}{c}1.11 \\
(0.65- \\
1.92)\end{array}$ & $\begin{array}{l}32.0 \\
(2.7)\end{array}$ & $\begin{array}{c}0.89 \\
(0.51- \\
1.56)\end{array}$ & $\begin{array}{l}35.8 \\
(2.8)\end{array}$ & $\begin{array}{r}1.03 \\
(0.53- \\
2.02)\end{array}$ \\
\hline $\begin{array}{l}\text { Alien } \\
\text { Distortion }\end{array}$ & $29.6(1.6)$ & $\begin{array}{l}26.1 \\
(1.8)\end{array}$ & $\begin{array}{c}0.86 \\
(0.57- \\
1.30)\end{array}$ & $\begin{array}{l}27.9 \\
(1.8)\end{array}$ & $\begin{array}{c}1.03 \\
(0.68- \\
1.55)\end{array}$ & $\begin{array}{l}26.1 \\
(1.7)\end{array}$ & $\begin{array}{c}0.91 \\
(0.55- \\
1.52)\end{array}$ \\
\hline \multicolumn{8}{|c|}{ Without 'unsure' } \\
\hline $\begin{array}{l}\text { Self } \\
\text { No distortion }\end{array}$ & $2.3(0.7)$ & $4.4(1.2)$ & $\begin{array}{r}2.20 \\
(0.54- \\
8.99)\end{array}$ & $\begin{array}{c}4.9 \\
(1.3)\end{array}$ & $\begin{array}{c}2.06 \\
(0.49- \\
8.64)\end{array}$ & $4.7(1.2)$ & $\begin{array}{r}2.08 \\
(0.36- \\
11.8)\end{array}$ \\
\hline $\begin{array}{l}\text { Self } \\
\text { Distortion }\end{array}$ & $34.2(1.7)$ & $\begin{array}{l}31.9 \\
(2.0)\end{array}$ & $\begin{array}{c}0.84 \\
(0.52- \\
1.34)\end{array}$ & $\begin{array}{l}29.9 \\
(1.9)\end{array}$ & $\begin{array}{c}0.78 \\
(0.48- \\
1.25)\end{array}$ & $\begin{array}{l}30.1 \\
(1.9)\end{array}$ & $\begin{array}{r}0.63 \\
(0.35- \\
1.13)\end{array}$ \\
\hline $\begin{array}{l}\text { Alien } \\
\text { No distortion }\end{array}$ & $31.6(2.4)$ & $\begin{array}{l}35.2 \\
(2.9)\end{array}$ & $\begin{array}{c}1.10 \\
(0.61- \\
1.96)\end{array}$ & $\begin{array}{l}28.8 \\
(2.7)\end{array}$ & $\begin{array}{c}0.86 \\
(0.47- \\
1.57)\end{array}$ & $\begin{array}{l}31.7 \\
(2.8)\end{array}$ & $\begin{array}{r}0.95 \\
(0.46- \\
1.97)\end{array}$ \\
\hline $\begin{array}{l}\text { Alien } \\
\text { Distortion }\end{array}$ & $23.8(1.5)$ & $\begin{array}{l}22.7 \\
(1.7)\end{array}$ & $\begin{array}{r}1.00 \\
(0.63- \\
1.58)\end{array}$ & $\begin{array}{l}21.5 \\
(1.7)\end{array}$ & $\begin{array}{r}0.99 \\
(0.63- \\
1.58)\end{array}$ & $\begin{array}{l}20.8 \\
(1.7)\end{array}$ & $\begin{array}{r}0.93 \\
(0.52- \\
1.64)\end{array}$ \\
\hline
\end{tabular}

All analyses adjusted for age, general intelligence and sex.

Control group used as the reference category.

The proportions of self-errors relative to the total number of errors were comparable across groups. Of all errors made by the patient group, $47.9 \%$ were misidentifications of their own voice (self-error). Proportions of self-errors were $45.7 \%$ in the group of first-degree relatives, $48.0 \%$ in the subclinical psychosis group and $45.3 \%$ in the control group.

There was no association between error rates and positive psychotic symptoms (PSE total) for the total subject group in the self-condition without distortion (OR 0.98, 95\% CI 0.95-1.02), nor in the self-condition with distortion (OR $1.00,95 \% \mathrm{Cl} 0.98-1.02)$, the other-condition without distortion (OR 0.99, 95\% Cl 0.97-1.01), and the other-condition with distortion (OR $0.99,95 \% \mathrm{Cl} 0.97-1 \cdot 01)$. Similarly, there were no significant group differences in error rates on the speech attribution task in subsets of patients with current Schneiderian symptoms (OR $1 \cdot 18,95 \% \mathrm{Cl} 0 \cdot 82-1 \cdot 72$ ) or current auditory hallucinations (OR $0.95,95 \% \mathrm{Cl} 0 \cdot 54-1 \cdot 69$ ).

The same analyses using only true source misidentifications (errors), rather than source misidentifications and 'uncertain' responses, similarly did not yield any large or significant effect sizes.

\section{Discussion}

No evidence was found for abnormalities in task performance in patients with psychosis or in individuals at risk of developing psychosis. These results deviate from previous findings with a similar paradigm (Johns et al., 2001a, Johns et al., 2003, Johns et al., 2005, Johns et al., 2006) and with a different source-monitoring paradigm (Bentall et al., 1991a, Morrison et al., 1997), but agree with other recent studies failing to detect differences with regard to the 
response bias in the detection of auditory signals in patients with psychotic disorder compared to controls ( $\mathrm{Li}$ et al., 2002) and likewise in groups with varying levels of schizotypy (Li et al., 2003). On the basis of absence of abnormalities in response bias in the studies by Li et al. (2002, 2003), it could be speculated that impaired self-monitoring and the associated positive symptoms in psychosis are related to a top-down processing bias (e.g. expectations about sensorial information) rather than a bottom-up deficit (e.g. sensorial information to which one is exposed) (Aleman et al., 2003). This hypothesis is compatible with a study (Allen et al., 2004) by the same group that developed the current speech attribution paradigm (Johns et al., 2001a). A crucial element of the original speech attribution paradigm was the on-line monitoring of one's own speech, in line with the concept that a difficulty in the monitoring of intended speech increases the risk for positive psychotic symptoms. However, in a modified version of the task, Allen et al. (2004) had subjects listen passively to their own recorded voice or to the voice of someone else, rather than speaking at the same time they received the feedback. Ascribing internally generated items to an external source occurred in patients in both experimental conditions. These findings cast some doubt on the original hypothesis that defective performance on the task reflects a deficit of self-monitoring. However, a top-down deficit would also have shown on the modified version of the task in the current study.

It is not likely that the lack of replication can be ascribed to a low level of symptoms. Although only a few of the patients had florid psychosis at the time of the assessment, the scores on the PSE show that, to a degree, persistent positive symptoms were present in the sample. In addition, a previous study demonstrated abnormal performance in people without frank psychotic symptoms but who were at risk of developing psychotic symptoms in the future (Johns, 2005). However, more recent findings of the same group (Johns et al., 2006) demonstrate that difficulty with source monitoring is associated more strongly with acute verbal auditory hallucinations than with a history of this symptom. When the current analysis was restricted to subjects with current hallucinations, however, again no significant associations with error rate on the speech attribution task were found.

The original version of the speech attribution paradigm developed by Johns and colleagues (Johns et al., 1999, Johns et al., 2001a) was shortened by two-thirds. This abbreviated version was used to avoid a drop in performance due to sustained attention dysfunction in patients with psychosis (Orzack et al., 1966, Wohlberg et al., 1973) and in at-risk groups (Mirsky et al., 1995, Chen et al., 1998). Additionally, four more words were excluded from the analyses because their length caused difficulties in reading those specific words properly in the time span provided. The possibility that the inconclusive findings were caused by a lack of power, considering the reduced number of stimuli in comparison with the original paradigm, is not likely given the size of the study groups, which is much larger than in previous sourcemonitoring studies (Cahill, 1996, Morrison et al., 1997, Johns et al., 2001a). Power simulations showed that the study has a power of approximately $80 \%$ to show an OR of 1.6 . 
Furthermore, the fact that not even a trend towards more errors in the patient group was found renders the explanation that the negative finding was due to the reduced number of stimuli unlikely. Inspection of the performance of the control groups in this study and the study by Johns et al. (2001) shows comparable error rates. This suggests that both tests had the same level of difficulty and makes it unlikely that technical issues, for example timing of the feedback, influenced performance on our version of the task.

The choice to subdivide the 32 items into two categories (positive words/negative words), in contrast to the three categories (positive/negative/neutral) used by Johns et al. (2001), was made to allow for a sufficient number of items in each condition in the abbreviated test, with the strongest contrast expected between these two categories.

Contrary to previous source-monitoring research, the patient group in this study was not subdivided into patients with and without auditory hallucinations. Studies that did subdivide the patients into these two categories showed that patients with auditory hallucinations are impaired compared to controls whereas the deficit in patients without auditory hallucinations is much smaller (Bentall et al., 1991a, Morrison et al., 1997). However, as noted above, in the current data, the association between current auditory hallucinations and self-monitoring performance was neither large nor significant.

\section{Conclusions}

In summary, the study investigated whether defective self-monitoring occurs in patients with a psychotic disorder as well as in individuals at risk without current clinical needs. No evidence for abnormalities in self-monitoring was found in either group. These results deviate from previous findings using this paradigm. 


\section{References}

Aleman, A., Bocker, K. B., Hijman, R., de Haan, E. H. Kahn, R. S., 2003. Cognitive basis of hallucinations in schizophrenia: role of top-down information processing. Schizophr. Res. 64, 175-85.

Allen, P. P., Johns, L. C., Fu, C. H., Broome, M. R., Vythelingum, G. N. McGuire, P. K., 2004. Misattribution of external speech in patients with hallucinations and delusions. Schizophr. Res. 69, 277-87.

Bentall, R. P., 1990. The illusion of reality: a review and integration of psychological research on hallucinations. Psychological Bull. 107, 82-95.

Bentall, R. P., Baker, G. A. Havers, S., 1991a. Reality monitoring and psychotic hallucinations. Br. J. Clin. Psychol. 30 ( Pt 3), 213-22.

Bentall, R. P., Kaney, S. Dewey, M. E., 1991b. Paranoia and social reasoning: an attribution theory analysis. Br. J. Clin. Psychol. 30 ( Pt 1), 13-23.

Brebion, G., Gorman, J. M., Amador, X., Malaspina, D. Sharif, Z., 2002. Source monitoring impairments in schizophrenia: characterisation and associations with positive and negative symptomatology. Psychiatry Res. 112, 27-39.

Cahill, C., 1996. Psychotic experiences induced in deluded patients using distorted auditory feedback. Cognit. Neuropsychiatry 1, 201-11.

Chen, W. J., Hsiao, C. K., Hsiao, L. L. Hwu, H. G., 1998. Performance of the Continuous Performance Test among community samples. Schizophr. Bull. 24, 163-74.

Claridge, G., 1994. Single indicator of risk for schizophrenia: probable fact or likely myth? Schizophr. Bull. 20, 151-68.

Cunningham Owens, D. G. Johnstone, E. C., 2006. Precursors and prodromata of schizophrenia: findings from the Edinburgh High Risk Study and their literature context. Psychol. Med. 36, 1501-14.

Frith, C. Dolan, R., 1996. The role of the prefrontal cortex in higher cognitive functions. Brain Res. Cogn. Brain Res. 5, 175-81.

Frith, C. D., 1987. The positive and negative symptoms of schizophrenia reflect impairments in the perception and initiation of action. Psychol. Med. 17, 631-48. 
Frith, C. D. Done, D. J., 1989. Experiences of alien control in schizophrenia reflect a disorder in the central monitoring of action. Psychol. Med. 19, 359-63.

Golstein, H., 1987. Multilevel models in educational and social research. Charles Griffin \& Co, London.

Hanssen, M., Krabbendam, L., de Graaf, R., Vollebergh, W. van Os, J., 2005. Role of distress in delusion formation. Br. J.Psychiatry Suppl. 48, s55-8.

Hanssen, M., Krabbendam, L., Vollema, M., Delespaul, P. Van Os, J., 2006. Evidence for instrument and family-specific variation of subclinical psychosis dimensions in the general population. J. Abnorm. Psychology 115, 5-14.

Hanssen, M., Peeters, F., Krabbendam, L., Radstake, S., Verdoux, H. van Os, J., 2003. How psychotic are individuals with non-psychotic disorders? Soc. Psychiatry Psychiatr. Epidemiol. 38, 149-54.

Hoffman, R. C., 1986. Verbal hallucinations and language production processes in schizophrenia. Behav. Brain Sci. 9, 503-548.

Janssen, I., Krabbendam, L., Jolles, J. van Os, J., 2003. Alterations in theory of mind in patients with schizophrenia and non-psychotic relatives. Acta Psychiatr. Scand. 108, 110-7.

Johns, L. C., 2005. Hallucinations in the general population. Current Psychiatry Report 7 , 162-7.

Johns, L. C., Allen, P., Broome, M., Woolley, J., Wykes, T. McGuire, P. K., 2005. Verbal selfmonitoring in people at high risk of psychosis. Schizophr. Bull.: Abstr. XX congress schizophr. res. april 2005, 183-605.

Johns, L. C., Gregg, L., Allen, P. McGuire, P. K., 2006. Impaired verbal self-monitoring in psychosis: effects of state, trait and diagnosis. Psychol. Med. 36, 465-74.

Johns, L. C., Gregg, L., Vythelingum, N. McGuire, P. K., 2003. Establishing the reliability of a verbal self-monitoring paradigm. Psychopathology 36, 299-303.

Johns, L. C. McGuire, P. K., 1999. Verbal self-monitoring and auditory hallucinations in schizophrenia. The Lancet 353, 469-70.

Johns, L. C., Rossell, S., Frith, C., Ahmad, F., Hemsley, D., Kuipers, E. McGuire, P. K., 2001a. Verbal self-monitoring and auditory verbal hallucinations in patients with schizophrenia. Psychol. Med. 31, 705-15. 
Johns, L. C. van Os, J., 2001b. The continuity of psychotic experiences in the general population. Clinical Psychology Review 21, 1125-41.

Kay, S. R., Fiszbein, A. Opler, L. A., 1987. The positive and negative syndrome scale (PANSS) for schizophrenia. Schizophr. Bull. 13, 261-76.

Keefe, R. S., Arnold, M. C., Bayen, U. J. Harvey, P. D., 1999. Source monitoring deficits in patients with schizophrenia; a multinomial modelling analysis. Psychol. Med. 29, 903-14.

Li, C. S., Chen, M. C., Yang, Y. Y. Tsay, P. K., 2002. Altered performance of schizophrenia patients in an auditory detection and discrimination task: exploring the 'selfmonitoring' model of hallucination. Schizophr. Res. 55, 115-28.

Li, C. S., Yang, Y. Y., Chen, M. C., Chen, W. J. Liu, J. L., 2003. Auditory discrimination in female adolescents varying in schizotypal features: preliminary findings. Psychiatry and Clinical Neurosciences 57, 391-7.

Luteijn, F., Van der Ploeg, F.A.E. (1983). Handleiding Groninger Intelligentietest (GIT) (Manual Groningen Intelligence Test). Swets \& Zeitlinger: Lisse, The Netherlands.

Mirsky, A. F., Yardley, S. L., Jones, B. P., Walsh, D. Kendler, K. S., 1995. Analysis of the attention deficit in schizophrenia: a study of patients and their relatives in Ireland. Journal of Psychiatric Research 29, 23-42.

Morrison, A. P. Haddock, G., 1997. Cognitive factors in source monitoring and auditory hallucinations. Psychol. Med. 27, 669-79.

Orzack, M. H. Kornetsky, C., 1966. Attention dysfunction in chronic schizophrenia. Arch. gen. Psychiatry 14, 323-6.

Snijders, T. Bosker, R., 1999. Multilevel analysis, an introduction to basic and advanced modeling. SAGE Publications, London.

Spitzer, R. L., Endicott, J. Robins, E., 1978. Research diagnostic criteria: rationale and reliability. Arch. gen. Psychiatry 35, 773-82.

StataCorporation (2005). STATA Statistical Software. Stata Corporation College Station: Texas.

Stefanis, N. C., Hanssen, M., Smirnis, N. K., Avramopoulos, D. A., Evdokimidis, I. K., Stefanis, C. N., Verdoux, H. Van Os, J., 2002. Evidence that three dimensions of 
psychosis have a distribution in the general population. Psychol. Med. 32, 34758.

van Os, J., Hanssen, M., Bijl, R. V. Ravelli, A., 2000. Strauss (1969) revisited: a psychosis continuum in the general population? Schizophr. Res. 45, 11-20.

van Os, J., Hanssen, M., Bijl, R. V. Vollebergh, W., 2001. Prevalence of psychotic disorder and community level of psychotic symptoms: an urban-rural comparison. Arch. gen. Psychiatry 58, 663-8.

Wechsler, D. (1981). Wechsler Adult Intelligence Scale-Revised. Psychological Corporation: New York.

Wohlberg, G. W. Kornetsky, C., 1973. Sustained attention in remitted schizophrenics. Arch. gen. Psychiatry 28, 533-7.

\section{Impairment of self monitoring:} part of the endophenotypic risk for psychosis

\section{ABSTRACT}

Background: A disorder of self-monitoring may underlie the positive symptoms of psychosis. The cognitive mechanisms associated with these symptoms may be detectable in individuals at risk of psychosis. Aims: To investigate (a) whether patients with psychosis show impaired self-monitoring, (b) to what degree this is associated with positive symptoms, and (c) whether this is associated with liability to psychotic symptoms.

Method: The sample included: individuals with a lifetime history of non-affective psychosis $(n=37)$, a genetically defined risk group $(n=41)$, a psychometrically defined risk group $(n=40)$, and a control group $(n=49)$. All participants carried out an action-recognition task.

Results: Number of action-recognition errors was associated with psychosis risk (OR linear trend over 3 levels: $1.12,95 \% \mathrm{Cl} 1.04-1.20)$ and differential error rate was associated with the degree of delusional ideation in a dose-response fashion (OR linear trend over 3 levels: $1.13,95 \% \mathrm{Cl} 1.00-1.26)$. 
This paper was published as: Impairment of self-monitoring: part of the endophenotypic risk for psychosis. D. Versmissen, I. Myin-Germeys, I. Janssen, N. Franck, N. Georgieff, J. a Campo, R. Mengelers, J. Van Os and L. Krabbendam. British Journal of psychiatry (2007) 191 (suppl. 51), s58-s62

\section{INTRODUCTION}

Source-monitoring refers to different processes involved in ascribing memories, knowledge and beliefs to a certain source of information (Johnson, Hashtroudi et al. 1993; Henquet, Krabbendam et al. 2005). Self-monitoring is a specific type of source-monitoring, namely the capacity to distinguish the consequences of self-generated items from those that are externally generated. The hypothesis that alterations in self-monitoring underlie the positive symptoms of psychosis has been put forward by different authors (Bentall 1990; Johns, Rossell et al. 2001). For example, the phenomenon that people attribute self-generated actions to an external cause, one of the first-rank symptoms of psychosis according to Schneider (Schneider 1959), is possibly due to impaired self-monitoring. Defective monitoring may be the outcome of a bottom-up deficit, specifically, a lack of awareness of the predicted consequences of self-generated actions (Frith, Blakemore et al. 2000), in combination with a top-down externalising bias, which makes someone prone to ascribing erroneously actions to an external agent (Allen, Johns et al. 2004). The current study aimed to examine potential deficits in the bottom-up process. When monitoring a self-generated action, the individual has to match the consequences of the executed movement to the internal representation. In order

to test the hypothesis that this process is flawed in psychosis, Franck and colleagues developed a procedure allowing the experimenter to distort performed actions with respect to the participant's own movement (Franck, Farrer et al. 2001).

An essential issue is whether the psychological mechanisms of psychosis can also be shown to operate in individuals at risk but without current clinical need (Bentall 1990; Janssen, Krabbendam et al. 2003). First-degree relatives of individuals with psychosis (higher than average genetic risk) and individuals with subclinical psychotic experiences in the general 
population (higher than average psychometric risk) are examples of such risk groups (Claridge 1994). Evidence for a deficit in self-monitoring in individuals at risk would imply that such a deficit is associated not only with the expression of the phenotype, but also with transmission of risk. The current study, therefore, included four groups with different levels of vulnerability to psychosis: (a) a patients with a lifetime history of non-affective psychosis, (b) a genetic risk group of non-psychotic first-degree relatives of individuals with a lifetime history of non-affective psychosis, (c) a psychometric risk group of healthy subjects from the general population with a higher than average level of positive psychotic experiences and (d) well controls from the genera population, with the aim of extending the findings by Franck and colleagues (2001). The hypothesis was tested that (a) patients with non-affective psychosis show impaired monitoring of their actions, (b) this alteration is also present in individuals at risk, albeit in a lesser degree, and (c) this alteration is conditional on the presence of positive psychotic symptoms or experiences.

\section{Method}

\section{Participants}

Four groups differing in the degree of vulnerability to psychosis were sampled in the Cognitive functioning in Psychosis (CoP) study: (a) individuals with lifetime history of non-affective psychosis, (b) first-degree relatives of individuals with non-affective psychosis, (c) healthy subjects scoring high ( $>75^{\text {th }}$ percentile) on the positive dimension of psychosis-proneness measured by the Community Assessment of Psychic Experiences [CAPE, (Hanssen, Peeters et al. 2003)] and (d) healthy controls, i.e. participants scoring in the average range $\left(40-60^{\text {th }}\right.$ percentile) in the CAPE. All participants were between the ages of 18 and 55 years, sufficiently fluent in Dutch and without a history of central neurological disorders. Written informed consent was obtained from all participants.

Participants were recruited from the catchment area community mental health centre (source population of 350000 ) and the catchment area psychiatric hospital. Initial inclusion criteria for participants with psychosis were lifetime prevalence of a period of psychosis in clear consciousness, according to the Research Diagnosis Criteria. Relatives were sampled through participants with psychosis or through associations for relatives of individuals with psychotic symptoms. Participants with average and high levels of psychotic experiences were recruited from a general population sampling frame in the city of Sittard (Hanssen, Peeters et al. 2003). Participants, 2287 females and 2302 males, had been randomly selected and sent a letter in which they were asked to participate. In addition to the 
participants themselves, family members were also invited to participate using a snowballsampling procedure. A total of 765 subjects aged 17-77 years, pertaining to 374 families filled in the CAPE. The subjects with a mean (i.e. between $40^{\text {th }}$ and $60^{\text {th }}$ percentile) and a high (i.e. above $75^{\text {th }}$ percentile) score on the CAPE positive psychosis dimension were invited to participate in the CoP study. The CAPE (http://www.cape42.homestead.com) is a self-report questionnaire designed to assess dimensions of the subclinical psychosis phenotype. It includes dimensions of positive $(n=20)$ and negative $(n=14)$ psychotic experiences as well as depressive experiences $(n=8)$.

The study sample included 45 individuals with psychosis (44\% in-patients), 47 first-degree relatives with no psychosis, 41 healthy participants with a high level of psychotic experiences and 54 healthy controls with an average level of psychotic experiences. Of the 47 healthy relatives there were 13 mothers, 8 fathers, 15 sisters, 8 brothers, 2 daughters and 1 son. Twenty-seven families contributed at least 1 patient and 1 relative. Four relatives participated without their family member with psychosis.

For all participating patients, the 'operational Criteria Checklist for Psychotic Disorders (OCCPI) was completed based on case note material and Positive and Negative Syndrome Scale (PANSS) interview. Where necessary, additional information was derived from ward staff or case-managers. Using the information in the OCCPI, the computerized program OPCRIT yielded Research Diagnosis Criteria diagnoses.

\section{Instruments}

\section{Action-Recognition Task}

An action-recognition task designed by Franck et al (2001) was carried out by all subjects. A stillage held a computer screen that was placed face down. Images on this computer screen were reflected in a horizontal mirror, placed $18 \mathrm{~cm}$ below the screen and $31 \mathrm{~cm}$ above a table at which the participant was seated. A joystick was placed on the table. The image of a virtual hand was presented in the mirror, superimposed on the participant's own hand. This setting enables participants to actually move the joystick, while being exclusively exposed to the image of the virtual hand, moving analogously to their own. Participants sat on a chair in front of the setting, their forehead resting on a foam cushion which enveloped the metallic stillage. The joystick had to be held with the hand of preference, which was in all cases the right hand., while the elbow rested on the table. Participants executed a series of discrete movements with the joystick. A green spot was displayed for a brief moment (1s) on the left, the right or the top of the screen. In the following $2 \mathrm{~s}$ the virtual hand was brought to vision. During these $2 \mathrm{~s}$ participants had to move the joystick in the direction indicated before by the green spot. Simultaneously, a movement of the virtual hand was shown. Participants had to decide whether the movement they saw on the screen was an exact copy of the movement they had made. This decision had to be made immediately after each trail and could be 
revealed by a simple 'yes' or 'no'.

The task consisted of 120 trials that were divided into three categories: (a) 24 neutral trials in which the virtual hand made an exact copy of the actual movement made by the participant, (b) 48 trials with temporal biases, and (c) 48 trials with angular biases. The temporal biases, in which the movement of the virtual hand was delayed by a fixed time $(100,200,300$ or $400 \mathrm{~ms}$ ) compared to the actual movement, and angular biases, in which the movements of the virtual hand deviated by a specific angular value $\left(10^{\circ}, 20^{\circ}, 30^{\circ}, 40^{\circ}\right)$ with regard to the point of comparison, were randomly introduced.

Before the actual task started, participants had the opportunity to familiarize themselves with the techniques to handle a joystick. During this training session an angular bias, temporal bias and neutral trial were presented.

\section{Present state examination}

The purpose of the Present State Examination [PSE; (Wing, Cooper et al. 1974)] is to assess the presence and severity of symptoms associated with the broad range of major psychiatric disorders over a designated period, i.e. the past week, by means of a structured clinical cross-examination of the individual. In this study, only the sections that cover signs and symptoms of psychotic disorders were used (43 items: PSE 55-92, plus their sub-scale scores).

\section{General intelligence}

General intelligence was measured by a combined score on one performance subtest and one verbal subtest from the Groninger Intelligence Test [GIT; (Luteijn 1983)], a widely used Dutch intelligence test. This test yields results that are comparable to those of the Wechsler Adult Intelligence Scale-Revised.

\section{Analyses}

Statistical analyses were carried out using STATA version 9.1. A four-level group variable was constructed reflecting the risk for psychosis in order of a priori hypothesised strength with value 3 for participants with psychosis, 2 for genetic risk, 1 for psychometric risk and 0 for controls. Two types of errors could potentially be made (a) participants misidentifying a neutral trials as different from their own action and (b) participants misidentifying trials with temporal or angular biases as similar to their own movement. Errors of this latter type could be subdivided into angular biases and temporal biases. Results of subjects who gave the same answer in $90 \%$ or more of the total number of trials were excluded from the analyses. Utilizing the XTGEE module in STATA, a multilevel approach to logistic regression was used to assess the association between making an error on the action-monitoring task and the four-level group variable for psychosis risk. The association between committing an error on the action-monitoring task and symptomatology was similarly established with additional 
adjustment for group. Multilevel random effects modeling techniques are a variant of the more often used unilevel regression analyses and are ideally suited for the analysis of data in which repeated observations (120 action monitoring trials) are nested within participants. All analyses were a priori adjusted for age and gender. In order to examine dose-response relationships between symptomatology and errors on the action-monitoring task, the group was derived into three groups according to their tertile level of symptom score. Odds ratios $(\mathrm{OR})$ with their $95 \%$ confidence intervals $(95 \% \mathrm{Cl})$ were used to express effect sizes, with the control group as the reference category.

\section{RESULTS}

\section{Sample characteristics}

The action-recognition task was carried out by 36 participants with non-affective psychosis, 40 non-psychotic first degree relatives of participants with non-affective psychosis, 39 healthy participants from the general population scoring high $\left(>75^{\text {th }}\right.$ percentile) on the positive dimension of psychosis-proneness measured by the CAPE and 49 healthy control participants with an average score on the positive dimension of the CAPE. Missing data were due to technical problems $(n=23)$. Two participants, 1 participant with psychosis and 1 participant with subclinical psychotic experiences, were excluded from the analyses since they gave directionally persistently similar answers in at least $90 \%$ of all trials. The participants with psychosis group, in which men were overrepresented (78\%), was younger than the other groups (Table 1). According to the OPCRIT, there were 27 participants with psychosis $(75 \%)$ with a Research Diagnostic Criteria diagnosis of schizophrenia, 3 patients $(8 \%)$ with a diagnosis of schizoaffective disorder, 5 patients (14\%) with a diagnosis of unspecified functional psychosis and $1(3 \%)$ for whom the OPCRIT data were missing but who had a clinical diagnosis of non-affective psychotic disorder.

\section{Table 1: Sample summary statistics}

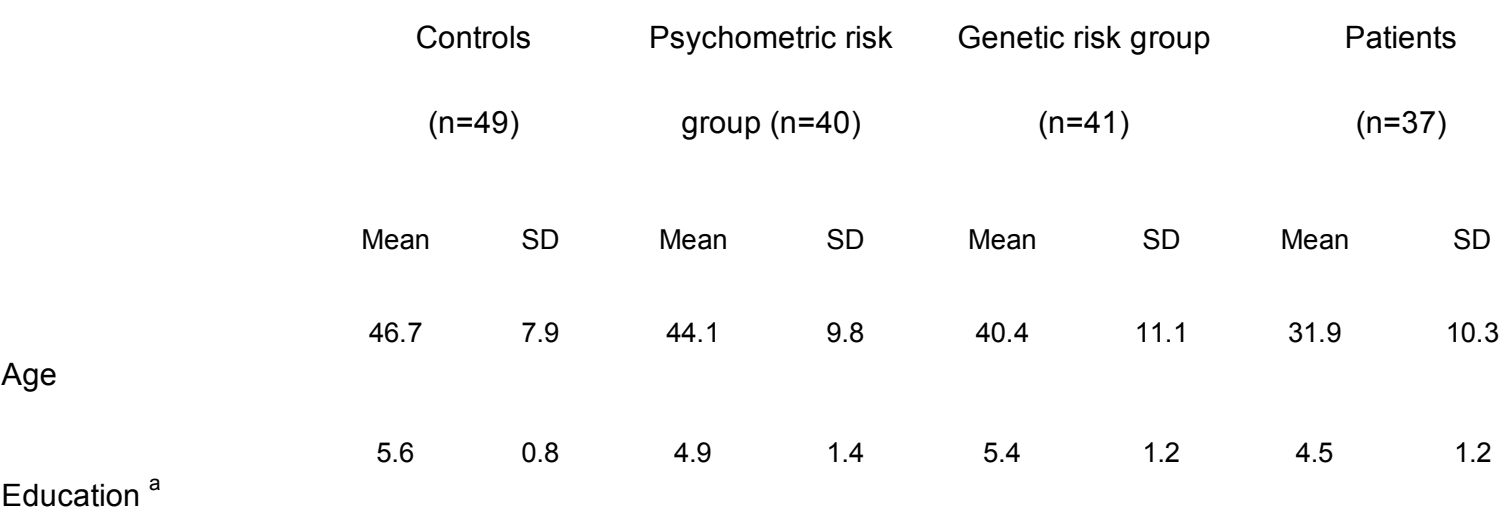




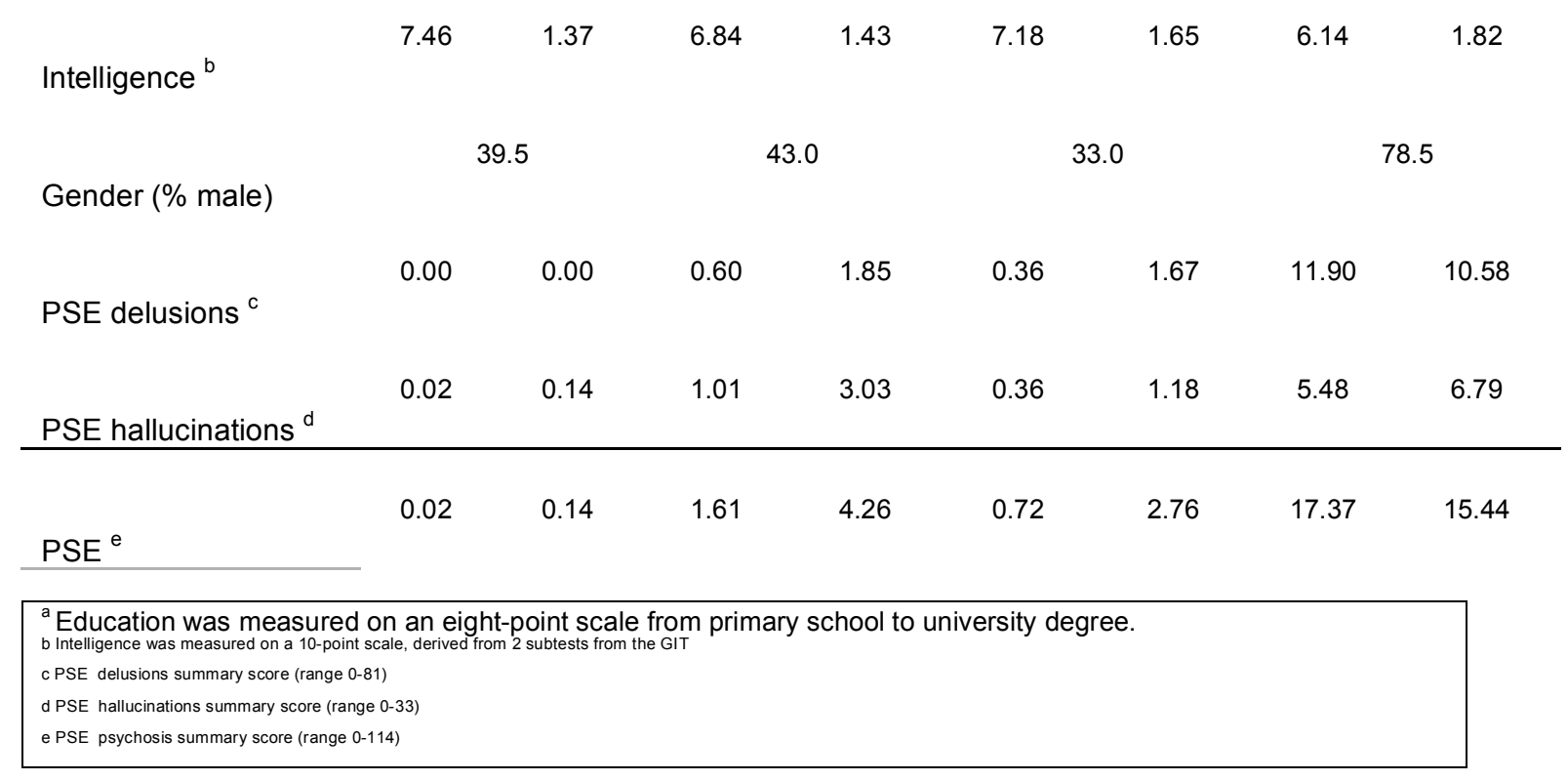

\section{Action-monitoring and psychosis risk}

The number of errors in all trials combined increased progressively with risk group, although differences between the risk groups and controls were small (controls: 29.7\%; psychometricrisk group: $31.1 \%$; genetic-risk group: $31.8 \%$; participants with psychosis: $37.4 \%$; OR linear trend $=1.12,95 \% \mathrm{Cl} 1.04-1.20)$. The separate Ors relative to the controls were: $1.06(95 \% \mathrm{Cl}$ $0.85-1.32)$ for the psychometric-risk group, 1.17 (95\% $\mathrm{Cl} 0.94-1.45)$ for the genetic-risk group and $1.41(95 \% \mathrm{Cl} 1.14-1.76)$ for the patient group.

The proportion of errors made, for each group, in the different bias-conditions are shown in Fig.1. In trials with a temporal bias, the error rate of the participants with psychosis group was on average $15.4 \%$ higher than the error rate of the control group.

FIGURE 1: Proportion of errors in the action monitoring task in matching the movement on the computer screen to the own movement with conditions of i) temporal and ii) angular bias 

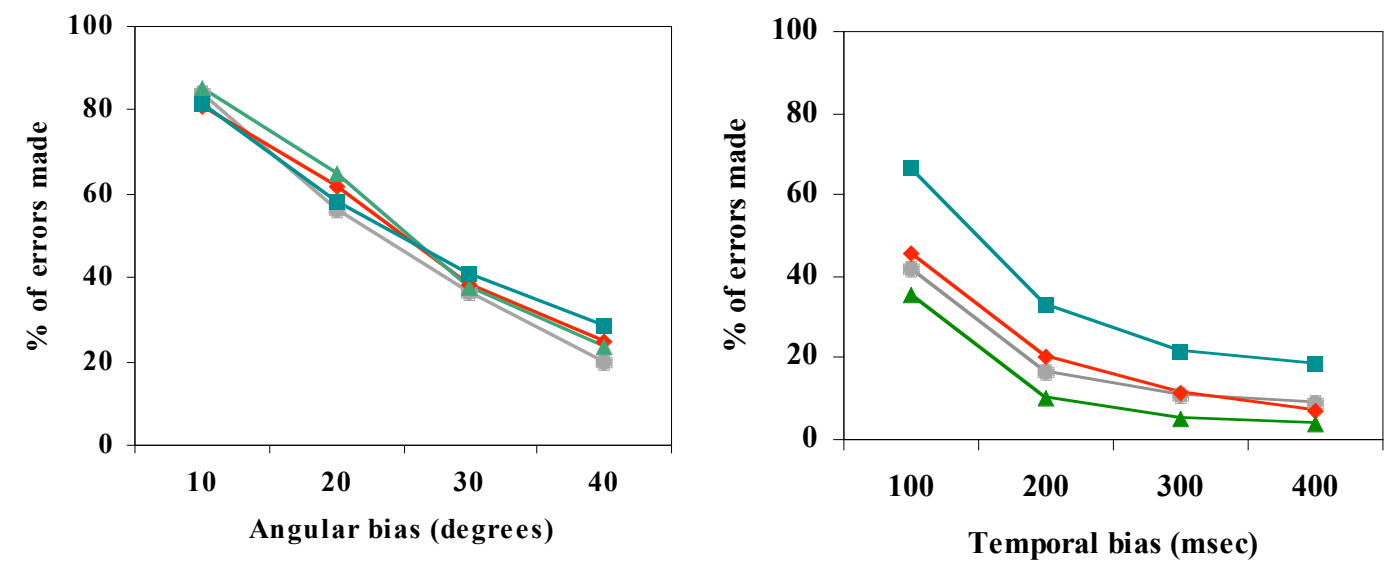

Controls $\longrightarrow$ Psychometric risk group $\longrightarrow$ Genetic risk group $\longrightarrow-$ Patients

The proportion of errors made for each of the four groups in the neutral condition in shown in figure 2.

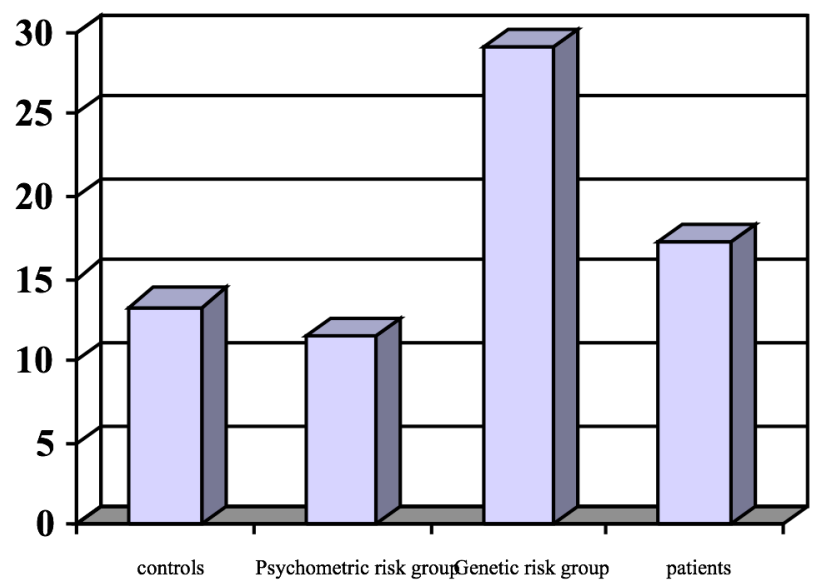

FIGURE 2: Proportion of errors in action monitoring task with neutral condition

After subdividing errors in trials with temporal delay, trial with an angular bias and neutral trials respectively, a significant difference between the participants with psychosis and the control group was seen in the trials with temporal delay ( $\mathrm{OR}=2.40,95 \% \mathrm{Cl} 1.44-3.97$ ), but not in neutral trials, nor in trials with angular biases (see Table 2). Differences between the genetic-risk group and controls were highest for errors in the neutral condition ( $O R=2.09,95 \%$ $\mathrm{Cl}$ 1.02-4.27). In the participants with psychosis group, the number of errors in the neutral condition was also higher than in controls, but the difference failed to reach statistical 
significance (Table 2).

Table 2: OR and $95 \% \mathrm{Cl}$, relative to well controls, for each action monitoring condition in three groups with different risk for psychosis

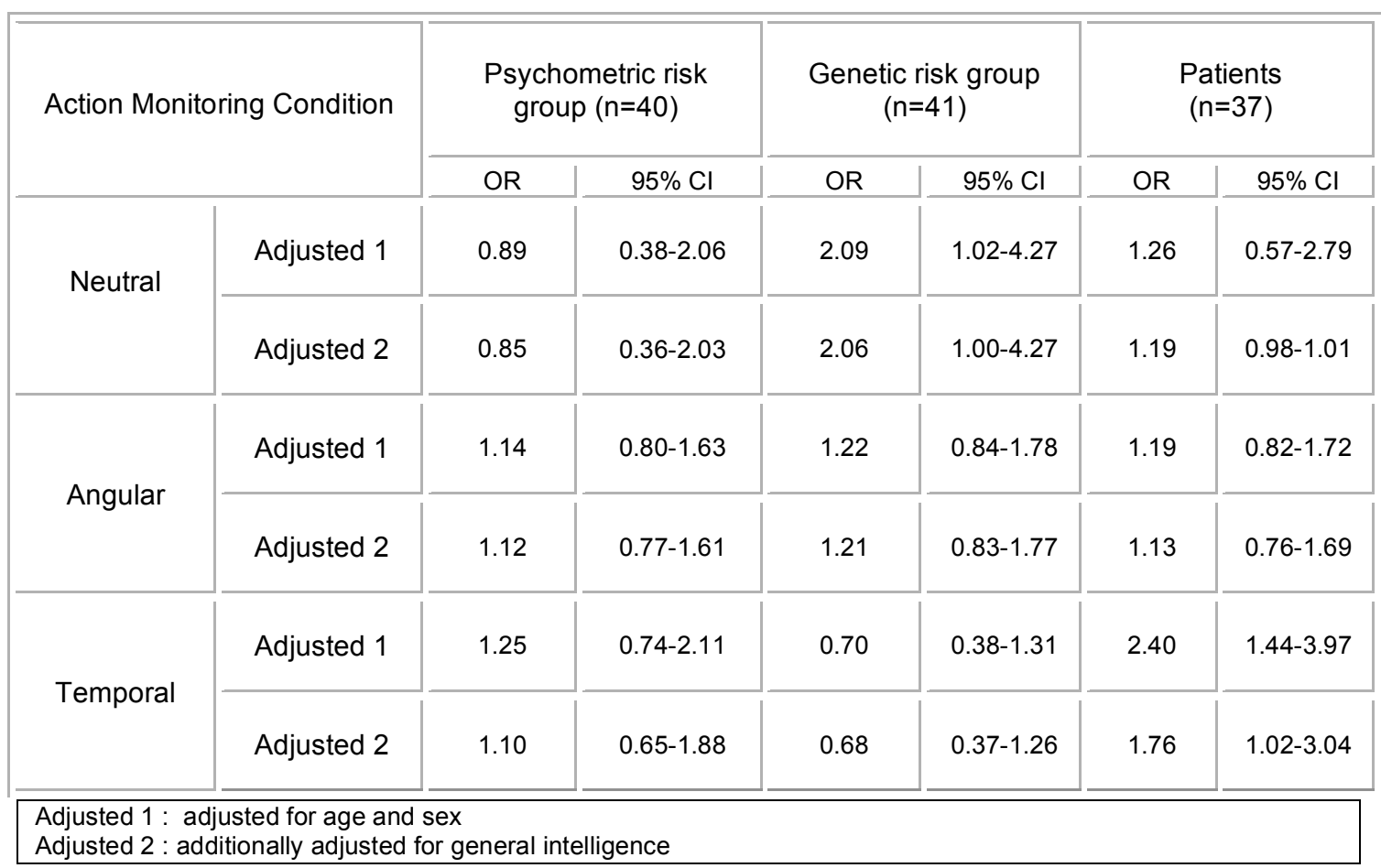

\section{Action-monitoring and psychotic symptoms}

In all trials combined, there was an association between errors and delusional ideation measured by the PSE (OR=1.13, 95\% $\mathrm{Cl} 1.00-1.26)$. The strength of this association between errors and delusional ideation, adjusted for group, was highest for the highest level of delusional ideation (moderate level: $\mathrm{OR}=0.9395 \% \mathrm{Cl}$ 0.72-1.20) and severe level $\mathrm{OR}=1.36$, $95 \% \mathrm{Cl} 1.06-1.73)$ compared with the level of no delusional ideation. No associations were found between errors and the continuous hallucination subscale on the PSE (OR=1.00, 95\% $\mathrm{Cl} 0.97-1.02)$, nor with the continuous total PSE score ( $\mathrm{OR}=1.00,95 \% \mathrm{Cl} 0.99-1.01$ ) overall groups.

\section{Discussion}

The results of our study are in agreement with the findings of Franck and colleagues (2001) and suggest that alterations in self-monitoring may be part of the endophenotypic risk to psychosis. Furthermore, the findings support the hypothesis that a self-monitoring deficit is associated with the phenotype, characterised by delusional ideation, which is in accordance with conclusions from previous studies that all found an association between alterations in self-monitoring and positive psychotic symptomatology (Bentall, Baker et al. 1991; Johns, 
Rossell et al. 2001).

\section{Temporal versus angular bias}

As shown in Fig. 1 there are few or no differences between the participant groups in trials eith an angular bias. These findings are partially in agreement with the conclusions of Franck et al (2001) who similarly found no differences between the general participants with schizophrenia and the control group. Only dissimilarities between the participants with psychosis group with delusions of influence and the control group were observed. However, differences between the groups were more apparent in the temporal trials. This difference may point to the underlying mechanism, given the fact that cerebral processing of the temporal and geometric self-monitoring information is likely to involve, at least in part, different areas. Previous works have demonstrated general alterations in temporal orientation (Crow and Stevens 1978; Franck, Posada et al. 2005) in individuals with schizophrenia. These disturbances could underlie the high number of errors by participants with psychosis in trials with temporal bias.

\section{At-risk groups}

The use of an ordinal risk group variable is common (Miller, Lawrie et al. 2001; Janssen, Versmissen et al. 2006), and has face validity, given the fact that both genetic and psychometric at-risk groups have been shown to share phenotypic and endophenotypic characteristics as well as common risk factors with the clinical phenotype (Claridge 1994; Faraone, Seidman et al. 2000; Spauwen, Krabbendam et al. 2004) and that over time transitions from psychometric risk to clinical phenotype are frequent (Chapman, Chapman et al. 1994; Poulton, Caspi et al. 2000). There was evidence for an overall action-recognition bias in the analyses using the ordinal risk variable, and analyses with the risk groups separately indicated intermediate positions for the latter, suggesting the presence of doseresponse inherent to the ordinal risk hypothesis.

Between the genetic-risk group an the one hand and both the psychometric-risk group and the participants with psychosis group on the other, a dissimilarity with regard to errors made in different conditions could be observed. There is no direct explanation for the significant effect size of misidentifying one's own action in the genetic-risk group, compared to the bias in recognising movements dissimilar to their own in the participants with psychosis group. As the difference between the genetic-risk group on the one hand and the participants with psychosis group on the other is the expression of psychosis, one hypothesis is that misidentifying one's own actions, similar movements, reflects a vulnerability effect, whereas bias in recognising movements dissimilar to their own is more reflective of an illness effects. Comparable observations concerning dissimilarities between vulnerability and illness effects were described in previous work on neuropsychological alterations. Verbal memory, abstraction, language functions and attention were more affected in people with the psychosis phenotype. Spatial memory, spatial abilities and sensory-motor functions, on the other hand, were more strongly affected in the genetic-risk group (Cannon, Zorrilla et al. 1994). 
Conceivably, the bottom-up process that was investigated can be controlled and dominated by a top-down mechanism, such as attribution style. It has been shown that individuals in the psychosis spectrum use an external attribution style for negative events (Fear, Sharp et al. 1996; Bentall, Corcoran et al. 2001). Even though an externalising bias could not be observed in first-degree relatives using the Internal, Personal and Situational Attribution Questionnaire (Janssen, Versmissen et al. 2006), the possibility remains that deviant attribution styles are only observable in at-risk groups when measured in a less explicit way. In all likelihood, firstdegree relatives, being aware of the concept of vulnerability and heightened risk for which they are examined, experience participating in a study about psychotic illness as an unpleasant, negative event and therefore develop the tendency to use external attributions resulting in a higher observed number of misidentifications of their own actions.

\section{Conclusions}

Alterations in self-monitoring are associated with psychosis with evidence of specificity for delusional ideation. In the risk state, this is expressed more as failure to recognize selfgenerated actions, whereas in the illness state failure to recognize alien sources comes to the fore. To the extent that certain delusions are the result of a failure in the identification of the source of an action in combination with an externalising attribution bias, they may be amenable to change by psychological therapies, such as cognitive-behavioral therapy (CBT). The effectiveness of CBT with respect to the treatment of delusions had been proved in previous research (Gould, Mueser et al. 2001). 


\section{REFERENCES}

Allen, P. P., L. C. Johns, et al. (2004). "Misattribution of external speech in patients with hallucinations and delusions." Schizophrenia Research 69(2-3): 277-87.

Bentall, R. P. (1990). "The illusion of reality: a review and integration of psychological research on hallucinations." Psychological Bulletin 107(1): 82-95.

Bentall, R. P., G. A. Baker, et al. (1991). "Reality monitoring and psychotic hallucinations." British Journal of Clinical Psychology 30 ( Pt 3): 213-22.

Bentall, R. P., R. Corcoran, et al. (2001). "Persecutory delusions: a review and theoretical integration." Clinical Psychology Review 21(8): 1143-92.

Cannon, T. D., L. E. Zorrilla, et al. (1994). "Neuropsychological functioning in siblings discordant for schizophrenia and healthy volunteers." Archives of General Psychiatry 51(8): 651-61.

Chapman, L. J., J. P. Chapman, et al. (1994). "Putatively psychosis-prone subjects 10 years later." Journal of Abnormal Psychology 103(2): 171-83.

Claridge, G. (1994). "Single indicator of risk for schizophrenia: probable fact or likely myth?" Schizophrenia Bulletin 20(1): 151-68.

Crow, T. J. and M. Stevens (1978). "Age disorientation in chronic schizophrenia: the nature of the cognitive deficit." British Journal of Psychiatry 133: 137-42.

Faraone, S. V., L. J. Seidman, et al. (2000). "Neuropsychologic functioning among the nonpsychotic relatives of schizophrenic patients: the effect of genetic loading." Biological Psychiatry 48(2): 120-6.

Fear, C., H. Sharp, et al. (1996). "Cognitive processes in delusional disorders." British Journal of Psychiatry 168(1): 61-7.

Franck, N., C. Farrer, et al. (2001). "Defective recognition of one's own actions in patients with schizophrenia." American Journal of Psychiatry 158(3): 454-9. 
Franck, N., A. Posada, et al. (2005). "Altered subjective time of events in schizophrenia." The Journal of Nervous and Mental Disease 193(5): 350-3.

Frith, C. D., S. Blakemore, et al. (2000). "Explaining the symptoms of schizophrenia: abnormalities in the awareness of action." Brain Research. Brain Research Reviews 31(2-3): 357-63.

Gould, R. A., K. T. Mueser, et al. (2001). "Cognitive therapy for psychosis in schizophrenia: an effect size analysis." Schizophrenia Research 48(2-3): 335-42.

Hanssen, M., F. Peeters, et al. (2003). "How psychotic are individuals with non-psychotic disorders?" Social Psychiatry and Psychiatric Epidemiology 38(3): 149-54.

Henquet, C., L. Krabbendam, et al. (2005). "Confusing thoughts and speech: source monitoring and psychosis." Psychiatry Research 133(1): 57-63.

Janssen, I., L. Krabbendam, et al. (2003). "Alterations in theory of mind in patients with schizophrenia and non-psychotic relatives." Acta Psychiatrica Scandinavia 108(2): 110-7.

Janssen, I., D. Versmissen, et al. (2006). "Attribution style and psychosis: evidence for an externalizing bias in patients but not in individuals at high risk." Psychological Medicine: 1-8.

Johns, L. C., S. Rossell, et al. (2001). "Verbal self-monitoring and auditory verbal hallucinations in patients with schizophrenia." Psychological Medicine 31(4): 705-15.

Johnson, M. K., S. Hashtroudi, et al. (1993). "Source monitoring." Psychological Bulletin 114(1): 3-28.

Luteijn, F., Van der Ploeg, F.A.E. (1983). Handleiding Groninger Intelligentietest (GIT) (Manual Groningen Intelligence Test). Lisse, The Netherlands, Swets \& Zeitlinger.

Miller, P., S. M. Lawrie, et al. (2001). "Genetic liability, illicit drug use, life stress and psychotic symptoms: preliminary findings from the Edinburgh study of people at high risk for schizophrenia." Social Psychiatry and Psychiatric Epidemiology 36(7): 338-42.

Poulton, R., A. Caspi, et al. (2000). "Children's self-reported psychotic symptoms and adult schizophreniform disorder: a 15-year longitudinal study." Archives of General Psychiatry 57(11): 1053-8.

Schneider, K. (1959). Clinical Psychopathology. New York, Grune \& Stratton. 
Spauwen, J., L. Krabbendam, et al. (2004). "Does urbanicity shift the population expression of psychosis?" Journal of Psychiatric Research 38(6): 613-8.

Wing, J. K., J. E. Cooper, et al. (1974). Measurement and classification of psychiatric symptoms; An instruction manual for the PSE and Catego program. Oxford, England, Cambridge U Press.

\section{Source monitoring in psychosis: is the deficit specific for self-generated information?}

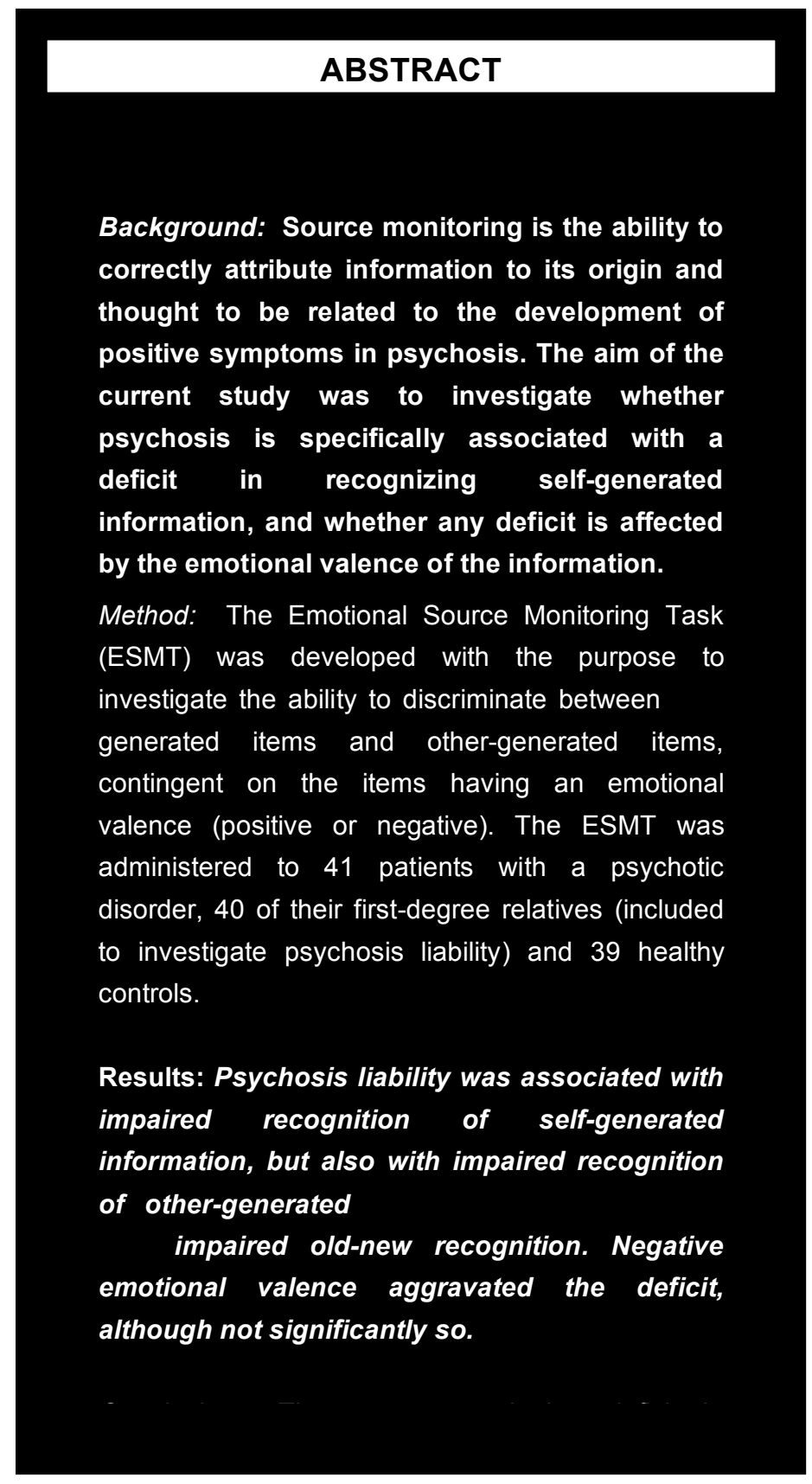


This paper will be published as:

D. Versmissen, C.Henquet, T. Van Kouteren, I.Myin-Germeys, R. Mengelers, J. a Campo, J. van Os, L. Krabbendam. Source-monitoring in psychosis: is the deficit specific for self-

generated information?

\section{INTRODUCTION}

The ability to discriminate between externally versus internally generated information, i.e. source monitoring, has been associated with the presence of auditory hallucinations (Brunelin et al., 2006, Heilbrun, 1980, Keefe et al., 2002, Laroi et al., 2005). The likely interpretation of this association is that failed recognition of self-generated thoughts may result in the identification of these thoughts as alien voices (Frith and Dolan, 1996). The aim of the current study was to investigate whether any bias towards external attribution of self-generated items (i) is disproportionate to the overall memory and source monitoring performance, (ii) is worse for material with a negative emotional valence, given the fact that the content of auditory hallucinations is frequently negative, (iii) is associated with the presence of positive symptoms, particularly auditory hallucinations, and (iv) is not only present in individuals with a clinical psychotic disorder, but also in individuals with an increased risk for psychotic symptoms, such as first-degree relatives of patients.

\section{Materials and method}

\section{Sample}

The study sample consisted of 41 patients with a non-affective psychotic disorder according to DSM-IV criteria (APA, 1994), 40 of their first degree relatives and 39 control subjects. Written informed consent conform the local ethics committee guidelines was obtained from all subjects. Inclusion criteria were: fluent in Dutch; an intelligence quotient higher than 70 on the WAIS III (short form; Blyler et al 2000), aged 16 to 55 years and, for patients, first contact with mental health facilities for psychosis within the last ten years. For the control subjects, the occurrence of a psychotic disorder in either the subject or any first-degree family members constituted an exclusion criterion. The relatives group was composed out of parents (25\%) and siblings $(75 \%)$ of the included patients. 
Patients were recruited through the Community Mental Health Centers and the Psychiatric Hospitals of the catchment area (South Limburg, The Netherlands). Relatives were sampled through participants with psychosis. Control subjects were recruited through random mailings in nearby municipalities and through advertisement in newspapers.

\section{Instruments}

\section{Emotional Source Monitoring Task}

The Emotional Source Monitoring Task (ESMT) was developed in order to investigate the ability to discriminate between self-generated items and those that are externally generated.

The ESMT was conducted using an encoding phase, followed by the actual test phase. During the encoding phase, stimuli were presented via a computer in a fixed order. Mode of presentation was as follows: each first stimulus was presented in the auditory modality, followed by a visual stimulus, followed in turn by a third stimulus which had to be generated by the participant. The test leader recorded all self-generated items. A total of 20 stimuli were presented and 10 were self-generated by the subject. Except for the self-generated items, for which the exposure was determined by the time needed to generate the stimulus (with a maximum of $20 \mathrm{sec}$ ), exposure to stimuli together with the inter-stimuli interval lasted for three seconds. The stimuli were adjectives that were presented in combination with the article 'a' and the substantive 'house' or 'man', e.g. 'an unfriendly man'. All stimuli were obtained through a pilot-study in which 33 subjects were asked to add 20 different adjectives to the substantive 'man' and another 20 to the substantive 'house'. The 40 most frequently used adjectives were identified and, together with those generated by the subjects, presented to 23 other subjects in order to define their emotional value on a seven-point Likert scale ("1" most negative, "7" most positive). Adjectives were defined as 'negative' when the average, downwardly rounded score was lower than or equal to four, and 'positive' for higher scores.

In the test phase (20-25 minutes later), 40 items were presented on a paper copy, consisting of the 20 items presented in the encoding phase, 10 new items and the 10 self-generated items. For each item, the subject had to indicate its source (i.e., whether new, self-generated, 
presented visually or auditory). A non-verbal neuropsychological assessment was used as filler task.

\section{Additional assessments}

Current and lifetime symptoms, as well as psychiatric diagnosis, were assessed with the Comprehensive Assessment of Symptoms and History [CASH; (Andreasen, 1987)] (sections on mania, depression and psychosis). Two verbal subtests, Information and Arithmetic, and two performance subtests, Block Design and Symbol Search, of the Wechsler Adult Intelligence Scale-III (Wechsler, 1997) were used to estimate current IQ (Blyler et al., 2000).

\section{Statistical analyses}

All analyses were carried out using Stata version 10.0 (StataCorporation, 2005). A three-level ordinal group variable for psychosis liability was constructed reflecting the a priori hypothesized risk for psychosis ('0' controls, '1' relatives, '2' patients; hereafter: psychosis liability). This allows for the examination of whether the three subject groups differ in a linear, dose-response fashion.

Errors on the ESMT could be either memory or source monitoring errors. Memory errors were errors distinguishing old from new items, regardless of the source of the old item. This error score was calculated in order to obtain a measure of general memory capacity. Source monitoring errors were errors classifying the source of old items, stratified according to source.

For the descriptive statistics, memory errors were calculated as a proportion of the total number of items (40), whereas total source monitoring errors were calculated as a proportion of the total number of old items (30) and the source-specific errors as a proportion of the total number of items of that particular source (10).

The following analyses were conducted. First, associations between errors (memory and source monitoring) on the ESMT and psychosis liability (the three-level group variable for psychosis risk) were modeled using multilevel logistic regression analysis, with the error variables as the outcome measures in separate models. In order to investigate whether psychosis liability was associated with a differential pattern of source monitoring errors (i.e., greater likelihood of externalizing errors) an interaction was fitted between psychosis liability and source of the items, comparing self-generated items with externally generated (auditory or visual) items. Second, the effect of emotional valence was investigated by fitting a two-way interaction between psychosis liability and emotional valence in the model of the total source monitoring errors. Any effect of emotional valence was further investigated in relation to source of the items, by fitting a three-way interaction between psychosis-liability, emotional valence, and source (self-generated versus externally generated). Third, associations 
between externalizing errors on the ESMT and presence of lifetime and current symptoms were assessed, for positive symptoms in general as well as for auditory hallucinations specifically.

For all analyses, the XTGEE module in STATA -a multilevel approach to logistic regressionwas used. Multilevel random effects modeling techniques are a variant of the more often used unilevel regression analysis and are ideally suited for the analysis of data in which multiple observations are nested within each participant. Odds ratios (OR) were used to express the effect sizes with their $95 \%$ confidence interval $(95 \% \mathrm{Cl})$ and $\mathrm{p}$-value $(\mathrm{p})$, using the control group as the reference category. All analyses were a priori adjusted for age, sex and education.

\section{$\boldsymbol{R}_{E S U L T S}$}

\section{Sample characteristics}

Subjects (patients, $n=2$ ) with an intelligence quotient of 70 or lower on the short form of the WAIS-III (Wechsler, 1997), were excluded from the analyses. The DSM-IV diagnoses from the Comprehensive Assessment of Symptoms and History (CASH) were: 33 (79\%) patients with schizophrenia- of which 26 of the paranoid type, five of the undifferentiated type, one of the disorganized type and one of the residual type- three $(7.9 \%)$ patients with schizoaffective disorder, two $(5.3 \%)$ with a brief psychotic disorder and one $(2.6 \%)$ with a psychotic disorder NOS. The three groups were matched for age, but sex, education and IQ differed between the groups (more males and lower education and IQ in the patient group) (Table 1).

Table 1: Demographic characteristics of all research groups

\begin{tabular}{|c|c|c|c|c|c|c|}
\hline क्रा & $\begin{array}{l}\text { Patien } \\
(n=41)\end{array}$ & roup & $\begin{array}{l}\text { Genet } \\
(n=40)\end{array}$ & group & $\begin{array}{l}\text { Contr } \\
(n=39)\end{array}$ & group \\
\hline 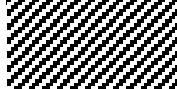 & Mean & $S D$ & Mean & $S D$ & Mean & $S D$ \\
\hline Age & 34.9 & 10.9 & 36.8 & 13.0 & 35.3 & 12.2 \\
\hline $\begin{array}{l}\text { Sex } \\
\text { (\% male) }\end{array}$ & $73.7 \%$ & & $37.4 \%$ & & $36.1 \%$ & \\
\hline
\end{tabular}




\begin{tabular}{|l|l|l|l|l|l|l|}
\hline $\mathrm{IQ}^{\mathrm{a}}$ & 92.8 & 17.5 & 103.6 & 17.0 & 113.7 & 13.6 \\
\hline Education $^{\mathrm{b}}$ & 3.1 & 2.1 & 4.1 & 2.2 & 5.4 & 2.0 \\
\hline
\end{tabular}

${ }^{a}$ Intelligence was measured by a short form of the WAIS-III (Wechsler, 1997).

${ }^{\mathrm{b}}$ Education was measured on an eight-point scale from no education to university degree.

Source monitoring and psychosis

The percentage of memory errors increased progressively with psychosis risk (controls: $28.0 \%$, relatives: $31.4 \%$, patients: $35.4 \%$ ). The multilevel logistic regression analysis showed a significant association between memory errors and the group variable reflecting psychosis risk (Table 2).

Table 2: Associations between errors and group

\begin{tabular}{|c|c|c|c|c|c|c|}
\hline कै & $\begin{array}{l}\text { Pati } \\
(n=4\end{array}$ & group & $\begin{array}{l}\text { Rela } \\
(n=4\end{array}$ & & Line & trend \\
\hline $\mathbb{W}$ & $O R$ & $95 \% C I$ & $O R$ & $95 \% C I$ & $O R$ & $95 \% C I$ \\
\hline Memory & 1.26 & $1.01-1.56$ & 1.12 & $0.92-1.37$ & 1.12 & $1.00-1.25$ \\
\hline Total source errors & 1.38 & $1.03-1.84$ & 1.07 & $0.83-1.40$ & 1.17 & $1.01-1.35$ \\
\hline Auditory items & 1.76 & $1.10-2.83$ & 1.59 & $1.04-2.44$ & 1.33 & $1.05-1.69$ \\
\hline Visual items & 1.00 & $0.60-1.68$ & 0.75 & $0.47-1.20$ & 0.99 & $0.76-1.28$ \\
\hline Self-generated items & 1.57 & $0.98-2.52$ & 1.08 & $0.69-1.67$ & 1.25 & $0.99-1.59$ \\
\hline
\end{tabular}

Similarly, the percentage of total source monitoring errors increased, although less clearly, with psychosis risk: controls: $28.3 \%$, relatives: $28.8 \%$, patients: $30.6 \%$ ). This association was statistically significant, as indicated by the multilevel logistic regression analyses (Table 2).

The percentages of incorrectly classified auditory items were $21.3 \%$ for the controls, $30.3 \%$ for the relatives, and $26.9 \%$ for the patients. For the visually presented items, these figures were $36.9 \%, 27.5 \%$ and $31.3 \%$, respectively. Self-generated items were incorrectly 
recognized in $26.7 \%$ of the occasions in controls, in $28.8 \%$ in the relatives, and in $33.6 \%$ in the patients. The interaction between group and source (the variable indicating the original source of the item, self or extern) was not significant $\left(\chi^{2}=0.11, p=0.74\right)$, indicating that there was no differential pattern in type of source monitoring errors for internally versus externally generated items associated with psychosis liability. The stratified analyses showed group differences in errors for the auditory and the self-generated items, but not for the visually presented items (Table 2).

The proportion of self-generated words with negative valence was similar for all research groups (control group: $58.6 \%$, relative group: $59.7 \%$ and patient group: $58.4 \%$ ). The effect of emotional value on total source monitoring errors did not differ significantly between the groups, as indicated by a non-significant interaction term $\left(\chi^{2}=1.11, p=0.29\right)$. However, the association between total monitoring errors and psychosis liability was stronger for negative stimuli (OR linear trend $=1.27,95 \% \mathrm{Cl} 1.06-1.53, \mathrm{p}=0.009$ ) than it was for positive stimuli (OR linear trend $=1.07,95 \% \mathrm{Cl} 0.89-1.28, p=0.46$ ). The effect of negative valence could largely be accounted for by the results in the patient group (patients $\mathrm{OR}=1.63,95 \% \mathrm{Cl} 1.14-2.35$, relatives $\mathrm{OR}=1.11,95 \% \mathrm{Cl} 0.80-1.55, \mathrm{p}=0.54)$. The three-way interaction between psychosis liability, emotional valence and source of the items was not significant $\left(\chi^{2}=1.03, p=0.31\right)$, indicating that the effect of emotional value on the different types of source monitoring errors was similar across the three groups. This was also evident from the post hoc analyses stratified by source and emotional value that did not suggest large or significant differences (data not shown).

Associations between externalizing errors on the ESMT and lifetime or current positive symptoms were neither large nor significant (ORs between 0.98 and 1.90, all p-values between 0.23 and 0.86 ).

\section{Discussion}

The results show that source monitoring is altered in psychosis. Specifically, and consistent with previous findings (Bentall, 1990, Brebion et al., 2002, Henquet et al., 2005, Keefe et al., 1999, Keefe et al., 2002, Moritz et al., 2003), individuals with psychosis had the tendency to attribute self-generated items to an external source. However, this bias was not disproportionate in comparison to overall source monitoring accuracy or memory performance. In fact, even larger, and statistically more precise, effect sizes were obtained for errors classifying auditory items. Relatives performed intermediate to patients and controls on memory performance and source monitoring, but only significantly below control performance for the classification of auditory items. 
It has been suggested that the misattribution of one's own thoughts or actions in psychosis results from faulty awareness of (the consequences of) self-generated behaviour (Shergill et al., 2005) (Frith et al., 2000) (Kircher and Leube, 2003), possibly in combination with an externalizing response style (Bentall et al., 1991; Morrison and Haddock, 1997). The current results may be compatible with this hypothesis; however, the finding of equally impaired performance in other source monitoring indices may also mean that impaired source monitoring performance is part of the larger generalized memory deficit in psychosis (Aleman et al., 1999, Forbes et al., 2008, Goldberg et al., 1989, Silver et al., 2003). The fact that we did not find any substantial associations with level of positive symptoms adds to the interpretation that impaired source monitoring performance, at least as assessed with the task used in the current study, is part of a general deficit, rather than a mechanism underlying specific symptoms.

Source monitoring performance in individuals with psychosis was worse for material with a negative emotional content, although this effect was not statistically significant, and affected all source monitoring indices equally. A similar effect of emotional salience on source monitoring has been demonstrated previously (Baker and Morrison, 1998, Costafreda et al., 2008, Laroi et al., 2004), and suggests a link with the predominantly negative content of the symptoms of psychosis. However, negative emotional valence did not exclusively affect externalizing attribution, as cognitive models of psychosis would predict (Bentall, 1990, Birchwood and Chadwick, 1997, Garety et al., 2001, Morrison and Haddock, 1997), but also the rate of errors in the opposite direction. This pattern of results suggests that emotional valence interferes with encoding source information during processing of the items, rather than changing the response style towards an externalizing bias (Johnson et al, 1993).

\section{Limitations}

First, similar to many other source monitoring studies to date, the ESMT assesses memory for source of items generated in the context of a task, and thus differs from naturally occurring hallucinations in two ways (Morrison \& Haddock, 1997). First, hallucinations are misattributions of spontaneously generated mental events, and second, hallucinations are the consequences of immediate rather than delayed misattributions. Particularly the memory aspect of the ESMT may have lead to a generalized source monitoring impairment affecting the recognition of self- as well as other-generated items.

Second, although we had an independent sample of healthy volunteers rate the emotional valence of the ESMT, this sample was relatively small and we cannot be sure that the emotional valence of stimuli was similar for the subjects in the study sample.

Third, except for age, demographic details differed between the groups, however, the analyses were controlled for age, sex and education. We did not control for IQ, as this may remove relevant variance from the analyses of group differences on cognitive tasks. 
Finally, with respect to the three-way interaction, there may be a power issue due to the rather small numbers of subjects in each group.

\section{Conclusion}

Impaired recognition of self-generated information forms part of the liability to psychosis, but occurs in the context of other source monitoring deficits and impaired memory performance. 


\section{References}

Aleman, A., Hijman, R., de Haan, E. H. \& Kahn, R. S. (1999). Memory impairment in schizophrenia: a meta-analysis. Am J Psychiatry 156, 1358-66.

APA (1994). Diagnostic and Statistical Manual of Mental Disorders. American Psychiatric Press: Washington DC.

Baker, C. A. \& Morrison, A. P. (1998). Cognitive processes in auditory hallucinations: attributional biases and metacognition. Psychological Medicine 28, 1199-208.

Bentall, R. P. (1990). The illusion of reality: a review and integration of psychological research on hallucinations. Psychological Bulletin 107, 82-95.

Birchwood, M. \& Chadwick, P. (1997). The omnipotence of voices: testing the validity of a cognitive model. Psychol Med 27, 1345-53.

Blyler, C. R., Gold, J. M., lannone, V. N. \& Buchanan, R. W. (2000). Short form of the WAIS-III for use with patients with schizophrenia. Schizophr Res 46, 209-15.

Brebion, G., Gorman, J. M., Amador, X., Malaspina, D. \& Sharif, Z. (2002). Source monitoring impairments in schizophrenia: characterisation and associations with positive and negative symptomatology. Psychiatry Research 112, 27-39.

Brunelin, J., Combris, M., Poulet, E., Kallel, L., D'Amato, T., Dalery, J. \& Saoud, M. (2006). Source monitoring deficits in hallucinating compared to non-hallucinating patients with schizophrenia. European Psychiatry 21, 259-61.

Costafreda, S. G., Brebion, G., Allen, P., McGuire, P. K. \& Fu, C. H. (2008). Affective modulation of external misattribution bias in source monitoring in schizophrenia. Psychological Medicine 38, 821-824.

Forbes, N. F., Carrick, L. A., McIntosh, A. M. \& Lawrie, S. M. (2008). Working memory in schizphrenia: a meta-analysis. Psychological Medicine 23, 1-17.

Frith, C. \& Dolan, R. (1996). The role of the prefrontal cortex in higher cognitive functions. Brain Research. Cognitive Brain Research 5, 175-81.

Frith, C. D., Blakemore, S. \& Wolpert, D. M. (2000). Explaining the symptoms of schizophrenia: abnormalities in the awareness of action. Brain Res Brain Res Rev 31, 35763. 
Garety, P. A., Kuipers, E., Fowler, D., Freeman, D. \& Bebbington, P. E. (2001). A cognitive model of the positive symptoms of psychosis. Psychological Medicine 31, 189-95.

Goldberg, T. E., Weinberger, D. R., Pliskin, N. H., Berman, K. F. \& Podd, M. H. (1989). Recall memory deficit in schizophrenia. A possible manifestation of prefrontal dysfunction. Schizophr Res 2, 251-7.

Heilbrun, A. B., Jr. (1980). Impaired recognition of self-expressed thought in patients with auditory hallucinations. Journal of Abnormal Psychology 89, 728-36.

Henquet, C., Krabbendam, L., Dautzenberg, J., Jolles, J. \& Merckelbach, H. (2005). Confusing thoughts and speech: source monitoring and psychosis. Psychiatry Research 133, 57-63.

Keefe, R. S., Arnold, M. C., Bayen, U. J. \& Harvey, P. D. (1999). Source monitoring deficits in patients with schizophrenia; a multinomial modelling analysis. Psychological Medicine 29, 903-14.

Keefe, R. S., Arnold, M. C., Bayen, U. J., McEvoy, J. P. \& Wilson, W. H. (2002). Sourcemonitoring deficits for self-generated stimuli in schizophrenia: multinomial modeling of data from three sources. Schizophrenia Research 57, 51-67.

Kircher, T. T. \& Leube, D. T. (2003). Self-consciousness, self-agency, and schizophrenia. Conscious Cogn 12, 656-69.

Laroi, F., Collignon, O. \& Van der Linden, M. (2005). Source monitoring for actions in hallucination proneness. Cognitive Neuropsychiatry 10, 105-23.

Laroi, F., Van der Linden, M. \& Marczewski, P. (2004). The effects of emotional salience, cognitive effort and meta-cognitive beliefs on a reality monitoring task in hallucination-prone subjects. Br J Clin Psychol 43, 221-33.

Moritz, S., Woodward, T. S. \& Ruff, C. C. (2003). Source monitoring and memory confidence in schizophrenia. Psychological Medicine 33, 131-9.

Morrison, A. P. \& Haddock, G. (1997). Cognitive factors in source monitoring and auditory hallucinations. Psychological Medicine 27, 669-79.

Silver, H., Feldman, P., Bilker, W. \& Gur, R. C. (2003). Working memory deficit as a core neuropsychological dysfunction in schizophrenia. Am J Psychiatry 160, 1809-16. 
StataCorporation (2005). STATA Statistical Software. Stata Corporation College Station: Texas.

Wechsler, D. (1997). WAIS-III administration and scoring manual. The Psychological

Corporation: San Antonia, TX.

\section{Evidence for a relationship between mentalising deficits and paranoia over the psychosis continuum}

\section{ABSTRACT}

Failing of mentalising has been suggested to underlie certain symptoms of psychosis. An as yet unresolved issue is whether mentalising deficits reflect a characteristic which can also be detected in people at risk for psychosis or people with evidence of subclinical expression of psychosis. This study wanted to assess an aspect of mentalising in four groups with different levels of psychosis vulnerability, and to examine associations between mentalising and symptoms of psychosis. The study included i) 40 patients with psychosis, ii) 49 nonpsychotic first-degree relatives (familial risk), iii) 41 subjects from the general population with a high level of positive psychotic experiences (psychometric risk) and iv) 54 healthy controls. All subjects performed the 'Hinting Task'. There was a significant association between psychosis risk and impairment on the Hinting Task $(\beta$ linear trend $=0.37, p<0.001)$. Using the control group as the reference, the association with impairment on the Hinting Task was highest for the patient group $(\beta=0.46, p<0.001)$, whereas the familial risk group $(\beta=0.16, \quad p=0.06)$ displayed an intermediate probability of failure. The psychometric risk group did not significantly differ from the control group $(\beta=0.04, \quad p=0.653)$. In the patient group, impairment on the Hinting Task was associated with current hallucinations and paranoid symptoms. In the familial risk group, there was an association between the Hinting Task and paranoid symptoms These results suggest that vulnerability to psychosis is expressed as an impairment in mentalising, which may have a mediating role in the formation of certain positive symptoms of psychosis. 
This paper was published as:

D. Versmissen, I. Janssen, I. Myin-Germeys, R. Mengelers, J. a Campo, J. van Os, L. Krabbendam

Evidence for a relationship between mentalising deficits and paranoia over the psychosis continuum Schizophrenia Research, 99 (2008) 103-110

\section{INTRODUCTION}

Ever since Frith (1992) suggested an impairment in decoupling an actual state from a mental representation, i.e. failing of mentalising, underlies certain symptoms of psychosis, there has been debate whether mentalising deficits reflect an enduring trait which is part of the predisposition to psychosis or a state characteristic closely linked to the presence of psychotic symptoms. There is sufficient evidence for mentalising deficits occurring at the time of florid psychosis (Hardy-Bayle et al., 1994, Corcoran et al., 1995, Blackwood et al., 2001) suggestive of the state-related quality of mentalising deficits in psychosis. However, this does not exclude the possibility that deficits of mentalising are also part of the vulnerability to psychosis.

One way to further clarify this issue is to investigate whether psychological mechanisms of psychosis, such as mentalising, can also be shown to operate in individuals at risk but without current clinical need (Bentall, 1990, Van Dael et al., 2006). The aim of the current study was to extend previous mentalising research in high risk groups (Langdon et al., 1999, Janssen et al., 2003, Langdon et al., 2004, Irani et al., 2006, Marjoram et al., 2006a, Marjoram et al., 2006b, Jahshan et al., 2007) by including two high risk groups (Claridge, 1994, Cunningham Owens et al., 2006), namely a familial defined risk group of non-psychotic first-degree relatives of patients with a lifetime history of non-affective psychosis and, secondly, a psychometrically defined risk group of well subjects from the general population with a higher than average level of positive psychotic experiences. This design allows studying the hypothesis that there is an increase in impairment of mentalising parallel to the increased psychosis load, i.e., the greatest impairment in the patient group, followed by the familial risk group, the psychometric risk group, and lastly the control group. A mentalising deficiency in individuals with a higher than average genetic or psychometric risk would imply that alterations in mentalising are not exclusively associated with the expression of the clinical psychosis phenotype, but also with transmission of risk at trait or state level. 
Additionally, a comprehensive assessment of symptoms was used to investigate the association between mentalising deficits and the level of expression of psychotic symptoms, the existence of which would suggest a mediating role of mentalising deficits in symptom formation. Given the original hypothesis (Frith, 1992) that patients with paranoid symptoms, including persecutory delusions and third person auditory hallucinations, would show mentalising deficiencies, the current study focused on positive psychotic symptoms.

\section{Materials and methods}

\section{Subjects}

Four groups differing in the degree of vulnerability to psychosis were sampled in the "Cognitive functioning in Psychosis" (CoP) study: i) patients with lifetime history of nonaffective psychosis, ii) first-degree relatives of patients with non-affective psychosis, iii) well subjects scoring high ( $>75$ th percentile) on the positive dimension of psychosis-proneness measured by the Community Assessment of Psychic Experiences (Stefanis et al., 2002, Hanssen et al., 2003, Hanssen et al., 2005) and iv) well controls, i.e. subjects scoring in the average range (40th-60th percentile) on the CAPE. All participants were between the ages of 18 and 55 years, sufficiently fluent in Dutch and without a history of central neurological disorders. Written informed consent, in accordance with the local ethics committee guidelines, was obtained from all participants.

Patients were recruited from the catchment area Community Mental Health Centre (source population: 350,000 ) and the catchment area Psychiatric Hospital. Initial inclusion criteria for patients were lifetime prevalence of a period of psychosis in clear consciousness, according to the Diagnostic and Statistical Manual of Mental Disorders (DSM-IV) (APA, 1994). Relatives were sampled through participating patients or through associations for relatives of patients with psychotic symptoms. Subjects with average and high levels of psychotic experiences were recruited from a general population sampling frame in the city of Sittard (Hanssen et al., 2003, Hanssen et al., 2006). The participants, 2287 females and 2302 males, had been randomly selected and sent a letter in which they were asked to participate. In addition to the participants themselves, family members were also invited to participate using a snowballsampling procedure. A total of 765 subjects aged 17 to 77 years, pertaining to 374 families filled in the Community Assessment of Psychic Experiences (CAPE; see Instruments section). The subjects with a mean (i.e. between 40th and 60th percentile) and a high (i.e. 
above 75th percentile) score on the CAPE positive psychosis dimension were invited to participate in the CoP-study.

For all participating patients, the Operational Criteria Checklist for Psychotic Disorder [OCCPI; (McGuffin et al., 1991)] was completed, based on case note material and PANSS interview (Kay et al., 1987). Where necessary, additional information was derived from ward staff or case-managers. Using the information in the OCCPI, the computerized program OPCRIT (McGuffin et al., 1991) yielded DSM-IV diagnoses.

\section{Instruments}

\section{Hinting Task}

The study used a Dutch translation of the Hinting Task originally developed by Corcoran and Frith (Corcoran et al., 1995), to assess one aspect of the mentalising capacity, requisite to comprehend real intentions behind indirect speech. The Hinting Task is composed of ten short stories, read aloud by the interviewer, in which an interaction between two individuals is described. Subjects have to answer a question about an implicit message in the dialogue. In case of an incorrect answer, subjects receive an extra hint. A correct answer on the first question results in a score ' 2 ', the need of an extra hint reduces the score to ' 1 '. The score of zero reflects the lack of a correct answer. The Hinting Task score, range 0-20, is the sum of the separate item scores.

\section{$\underline{P S E}$}

The purpose of the Present State Examination (PSE) (Wing et al., 1974) is to assess the presence and severity of symptoms associated with a broad range of major psychiatric disorders over a designated period, i.e. the last week, by means of a structured clinical crossexamination of the patient. In this study, the sections that cover signs and symptoms of psychotic disorders were used (43 items: PSE 55-92, plus their subscale scores) in the patient group only.

\section{$\underline{\text { SAPS and SANS }}$}

The Scale for the Assessment of Positive Symptoms (SAPS) (Andreasen, 1984) and the Scale for the Assessment of Negative Symptoms (SANS) (Andreasen, 1983) were used to assess the severity of symptoms in patients with schizophrenia or other psychotic disorders. The SAPS, designed to assess positive symptoms and disorganization, contains 30 items divided over four domains including hallucinations, delusions, disorganization or bizarre behaviour, and formal thought disorder. The SANS, assessing negative symptoms, contains 20 items divided over five domains including affective flattening and blunting, alogia, avolitionapathy, anhedonia-asociality and attentional impairment. In addition to the individual SAPS 
and SANS items, a global severity rating was made for each domain. Ratings were made by trained interviewers at the level of psychologist on the basis of a standard clinical interview, observed behaviour during the interview and review of all available clinical material. A subscale score for each domain was constructed as the sum of the scores for each item in that domain. The time frame covered by the rating was lifetime (presence ever).

\section{$\underline{C A P E}$}

The Community Assessment of Psychic Experiences (CAPE) (Stefanis et al., 2002), is a selfreport questionnaire to assess dimensions of the subclinical psychosis phenotype (www.cape42.homestead.com). The CAPE includes dimensions of positive (20 items) and negative (14 items) psychotic experiences as well as depressive experiences ( 8 items). For a detailed description of the development of the CAPE, see Stefanis et al. (2002); Hanssen et al. (2003); Hanssen et al. (2006). The CAPE was used to assess psychotic and psychosislike experiences in the two at-risk groups.

\section{$\underline{\text { General intelligence }}$}

General intelligence was measured by a combined score on one performance subtest and one verbal subtest from the Groningen Intelligence Test (GIT), a widely used Dutch intelligence test (Luteijn, 1983). This test yields results that are comparable to those of the Wechsler Adult Intelligence Scale-Revised (Wechsler, 1981).

\section{Analyses}

Statistical analyses were carried out using STATA version 9.1 (StataCorporation, 2005). Since the great majority of the sample had a high score on the Hinting Task, the continuous outcome variable was skewed. Therefore a five-level variable was created with a score one for a Hinting Task score of 20 , score two for a Hinting Task score of 19 , score three for a Hinting Task score of 18, score four for a Hinting Task score of 17 and a score five for all Hinting Task scores smaller than or equal to 16 .

A four-level group variable was constructed reflecting the risk for psychosis in order of a priori hypothesised strength with value 3 for patients, 2 for familial risk, 1 for psychometric risk, and 0 for controls.

In order to assess the association between the Hinting Task score and psychosis risk, linear regression analysis was used with the control group as the reference category. Standardized regression coefficients were used to express the effect sizes. All above analyses were a priori adjusted for age and sex. In addition, all analyses were adjusted for general intelligence, 
since previous studies have shown that mentalising performance may be confounded by general intelligence (Doody et al., 1998, Pickup et al., 2001, Brune, 2003).

\section{Associations between mentalising impairment and psychotic symptoms}

As the psychometric risk group was already defined on the basis of symptoms, it was not possible to carry out additional analyses assessing the relationship between symptoms and mentalising deficit in this group. In the patient group, any impairment on the Hinting Task score was further examined in relation to the lifetime presence of the three main symptom clusters of positive symptoms, negative symptoms and disorganization assessed with the SAPS and the SANS. Any associations with the cluster of positive symptoms were examined in greater detail, by testing dose-effect relationships between current delusions and hallucinations assessed with the PSE and the Hinting Task score. This was done by dividing the patient group into three groups according to their tertile level of symptom score. In the familial risk group, any impairment on the Hinting Task was further examined in relation to lifetime presence of subclinical positive and negative experiences of psychosis assessed with the CAPE. Finally, the hypothesised association between the Hinting Task score and paranoid symptoms, i.e. persecutory delusions and third person auditory hallucinations, was examined in the patient group for present state as well as lifetime occurrence, and in the familial risk group for lifetime subclinical occurrence. To this end, a CAPE paranoid and CAPE hallucinations score was calculated as described in (Verdoux et al., 1998).

\section{$\mathbf{R}_{\text {ESULTS }}$}

\section{Sample characteristics}

The sample consisted of 184 subjects of whom 40 were patients with non-affective psychosis (44\% inpatients), 49 first-degree relatives of patients with non-affective psychosis, 41 well subjects from the general population scoring high ( $>75$ th percentile) on the positive dimension of psychosis-proneness measured by the CAPE and 54 well control subjects with an average score on the positive dimension of the CAPE.

The means of the PSE scores for delusions, hallucinations and the overall PSE score in the patient group were $11.3(S D=10.1), 5.2(S D=6.4)$ and $16.5(S D=14.3)$, respectively (see Table 1). The patient group, which had the lowest mean age, was mainly composed of male subjects (see Table 1). In terms of educational level, all four groups were well matched.

Over half of the patient group had no persecutory delusions at all at the time of the study. Severe current persecutory delusions occurred in $30.8 \%$ of the patient group. The lifetime prevalence of persecutory delusions in the patient group was $51.3 \%$. Current third person auditory hallucinations were observed in $25.6 \%$ of the patient group. The lifetime prevalence 
was $39.5 \%$. In the at-risk groups, the lifetime prevalence of paranoid symptoms was $31.5 \%$ (14.3\% in the familial risk group alone) and the lifetime prevalence of third person auditory hallucinations was $6.9 \%$ (6.4\% in the familial risk group only).

OPCRIT computed a diagnosis of schizophrenia for 13 patients $(32.5 \%$ ), a diagnosis of unspecified functional psychosis for 20 patients $(50 \%)$, a diagnosis of delusional disorder for three patients $(7.5 \%)$ and a diagnosis of schizophreniform disorder for three $(7.5 \%)$. For one patient, $(2.5 \%)$ OPCRIT yielded no diagnosis, however this patient had a clinical diagnosis of non-affective psychotic disorder.

The means of the five-level variable representing the score on the Hinting Task in the four subject groups increased with increasing risk for psychosis. The observed score was 3.2 $(S D=1.6)$ in the patient group, $2.2(S D=1.2)$ in the familial risk group, $1.9(S D=1.2)$ in the psychometric risk group and $1.9(1.1)$ in the control group.

Table 1: Sample summary statistics

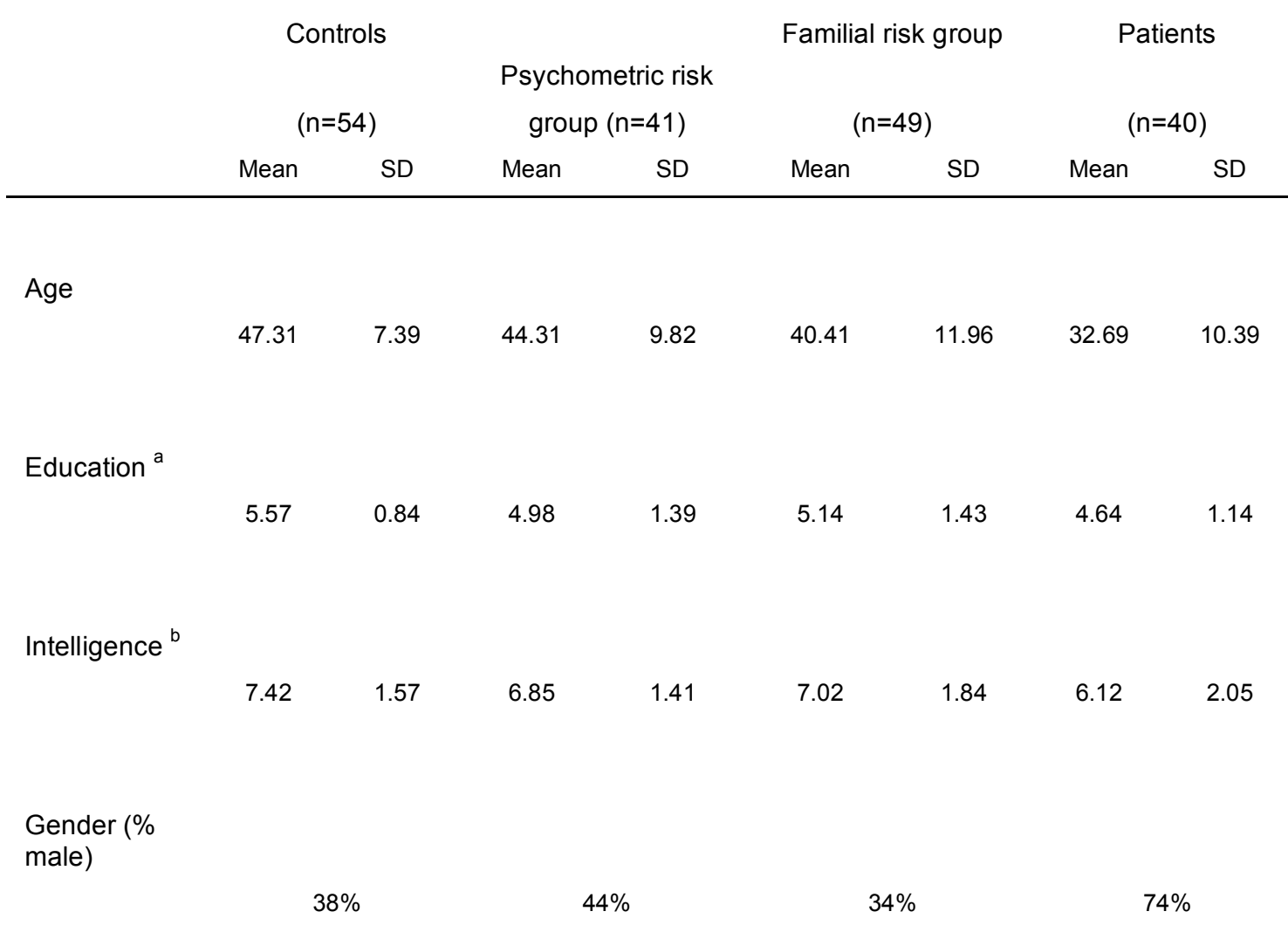




\begin{tabular}{|c|c|c|c|c|c|c|c|c|}
\hline \multicolumn{9}{|l|}{ PSE } \\
\hline Delusions $^{c}$ & 0.00 & 0.00 & 0.56 & 1.82 & 1.35 & 5.25 & 11.26 & 10.07 \\
\hline \multicolumn{9}{|l|}{ PSE } \\
\hline \multirow[t]{3}{*}{$\underset{d}{\text { Hallucinations }}$} & 0.02 & 0.14 & 0.95 & 2.98 & 0.92 & 3.11 & 5.21 & 6.38 \\
\hline & & & & & & & & \\
\hline & 0.02 & 0.14 & 1.51 & 4.20 & 2.27 & 8.06 & 16.46 & 14.28 \\
\hline $\begin{array}{l}\text { SAPS without } \\
\text { Disorganization } \\
\text { f }\end{array}$ & 0.37 & 2.45 & 1.46 & 3.25 & 2.67 & 8.69 & 19.93 & 16.25 \\
\hline \multicolumn{9}{|l|}{ SANS $^{g}$} \\
\hline & 1.69 & 3.06 & 1.88 & 2.77 & 2.22 & 4.09 & 11.78 & 12.29 \\
\hline $\begin{array}{l}\text { SAPS } \\
\text { Disorganization } \\
h\end{array}$ & 0.89 & 1.72 & 1.41 & \\
\hline $\begin{array}{l}\text { a Education was measured } \\
\text { b Intelligence was measure } \\
\text { c PSE delusions summary } \\
\text { d PSE hallucinations sumn } \\
\text { e PSE psychosis summary } \\
\text { f SAPS without disorganiza } \\
\text { g SANS summary score (ra } \\
\text { h SAPS disorganization sur }\end{array}$ & $\begin{array}{l}\text { an eight-pc } \\
\text { na 10-poin } \\
\text { re (range } \\
\text { y score (ran } \\
\text { ore (range } \\
\text { summary } \\
\text { 0-60) } \\
\text { ary score ( }\end{array}$ & ange 0-65) & $\begin{array}{l}1 \text { to univers } \\
\text { sts from the }\end{array}$ & (De Bie, 1 & & & & \\
\hline
\end{tabular}

\section{Mentalising and psychosis risk}

There was a significant association between psychosis risk and impairment on the Hinting Task $(\beta$ linear trend $=0.37, p<0.001)$. The association was highest for the patient group $(\beta=0.46, p<0.001)$, whereas the familial risk group $(\beta=0.16, p=0.055)$ displayed an intermediate risk of failure compared with controls. The psychometric risk group did not significantly differ from the control group $(\beta=0.04, p=0.653)$ (Table 2$)$.

Table 2: Standardized $\beta$ and P-value for the Hinting Task score, relative to well controls 


\begin{tabular}{|c|c|c|c|c|c|c|}
\hline & & & \multicolumn{2}{|c|}{ Familial risk group } & \multicolumn{2}{|c|}{ Patients } \\
\hline & \multicolumn{2}{|c|}{$\begin{array}{l}\text { Psychometric risk } \\
\text { group }(n=41)\end{array}$} & \multicolumn{2}{|c|}{$(n=49)$} & \multicolumn{2}{|c|}{$(n=40)$} \\
\hline & $\beta$ std & $\mathrm{P}$ & $\beta$ std & $\mathrm{P}$ & $\beta$ std & $\mathrm{P}$ \\
\hline Hinting Task score & 0.036 & 0.653 & 0.161 & 0.055 & 0.461 & 0.000 \\
\hline
\end{tabular}

\section{Mentalising and psychotic symptoms in patient and familial risk group}

\section{Lifetime symptoms in patient and familial risk group}

The Hinting Task score was not associated with the lifetime presence of positive symptoms $(\beta=0.09, p=0.57)$ nor with negative symptoms $(\beta=0.06, p=0.69)$ or disorganization $(\beta=-0.18, p=0.29)$ measured with the SAPS and SANS in the patient group. Likewise, in the familial risk group, no associations were found between the Hinting Task score and the lifetime presence of the positive symptom dimension $(\beta=0.09, p=0.55)$ or the negative symptom dimension $(\beta=0.27, p=0.07$ ) of the subclinical psychosis phenotype, measured with the CAPE.

\section{Current hallucinations and delusions in patient group}

There was a significant association between PSE current hallucinations and Hinting Task score in the patient group (linear trend over 3 levels $\beta=0.47, p=0.002$ ) which increased with increasing levels of hallucinations, indicating a dose-effect relationship. For the highest level of hallucinations, the effect size reached significance (moderate level: $\beta=0.23, p=0.15$; severe level: $\beta=0.44, p=0.008$ ) compared to those with the lowest level of hallucinations. With respect to current delusional ideation, associations were neither large nor significant (moderate level: $\beta=-0.18, p=0.40$; severe level: $\beta=0.08, p=0.70$; linear trend $\beta=0.19$, $p=0.25$ ). Entering both symptom scales together in one model enforced the strength of the association with current hallucinations (moderate level: $\beta=0.38, p=0.05$; severe level: $\beta=0.57, p=0.005$ ).

\section{Paranoid delusions/third person hallucinations in patient and familial risk group}

In the patient group, a significant association was found between the Hinting Task score and both current third person auditory hallucinations $(\beta=0.37, p=0.02)$ as well as lifetime third person auditory hallucinations $(\beta=0.36, p=0.025)$, but not with either current $(\beta=0.25$, $p=0.13)$ or lifetime presence of persecutory delusions $(\beta=-0.02, p=0.91)$. In the familial risk group, a significant association between the Hinting Task score and lifetime paranoid like 
experiences, measured with the CAPE, was evident $(\beta=0.38, p=0.008)$, but not with third person auditory hallucinations $(\beta=-0.017, p=0.91)$.

\section{Discussion}

The results of the current study demonstrate that alterations in mentalising are not exclusively associated with the expression of the psychosis phenotype, but also with transmission of risk, suggesting that alterations in mentalising are part of the predisposition to psychosis. Using the four-level ordinal risk variable, there was evidence for greater impairment in mentalising parallel to the increase in psychosis risk. However, while performance in the relatives was intermediate to the patient group and the control group, the psychometric risk group showed no significant impairment relative to the control group.

\section{Mentalisation and psychosis vulnerability}

The observed association between alterations in mentalisation and psychosis vulnerability has been described previously (Langdon et al., 1999, Janssen et al., 2003, Langdon et al., 2004, Irani et al., 2006, Marjoram et al., 2006a, Marjoram et al., 2006b). Concordant with the current study, (Janssen et al., 2003, Irani et al., 2006, Marjoram et al., 2006a) showed the existence of mentalising deficiencies in relatives of people with psychosis. A second study of Marjoram (2006b) showed mentalising deficits in first-degree relatives with two other mentalising tests, but not with the Hinting Task. A relationship between defective mentalising ability and self-reported schizotypal traits, reported by (Langdon et al., 1999, 2004), using a false-belief picture sequencing task and a story comprehension task focusing on irony, was less pronounced in the current study. These tasks possibly tap different mentalising capacities compared to the verbal Hinting Task used in the current study. In agreement with the current study, Jahshan and Sergi found no impairment in mentalising in a psychometric risk group (Jahshan et al., 2007).

\section{Mentalisation and symptomatology}

None of the associations between failure of mentalising and the three major symptom clusters (positive symptoms, negative symptoms and disorganization) of psychosis, assessed lifetime, were significant, whereas there was a significant association with presence of current hallucinations. This, together with the finding of impaired mentalising in the group of relatives, suggests that a subtle deficit of mentalising that is part of the vulnerability to psychosis also may have a mediating role in actual symptom formation. Similar combinations of trait and state-like qualities have been reported for other cognitive mechanisms of psychotic symptoms such as a jumping-to-conclusions reasoning style (Van Dael et al., 2006). 
The pattern of associations between mentalising and paranoid symptoms observed in the present study is in accordance with the original model of (Frith, 1992) which predicted that patients with paranoid symptoms have an impaired mentalising ability and in line with the study of Harrington et al. (Harrington et al., 2005) in which the particular occurrence of mentalising deficits in schizophrenic patients with paranoia was demonstrated. The current study found evidence for this association, not only in the patient group, but also in the familial risk group, indicating that mentalising is not only associated with the clinical expression of paranoid symptomatology, but also with subclinical levels of paranoia. However, associations between symptoms and mentalising ability were not consistent across the groups, as in the patient group they were evident for third person auditory hallucinations only, whereas in the familial risk group there was evidence for an association between mentalising ability and persecutory-like symptoms.

\section{Mentalisation and general cognition}

Any study investigating cognitive mechanisms in psychosis should take the possible influence of general cognitive abilities into account. The fact that the effect size of the association between psychosis vulnerability and mentalising abilities was reduced but remained statistically precise after controlling for intelligence is in line with the findings reported by Doody and colleagues (Doody et al., 1998). This study showed that learning-disabled subjects performed worse than healthy controls on a mentalising test, but compared to the schizophrenia group they performed better. These findings indicate that at least part of the mentalising deficit in individuals with psychosis can not be explained as secondary to alterations in general intelligence.

\section{Methodological issues}

Group (patients, familial risk group, psychometric risk group, controls) was used as a linear variable of continuous psychosis liability. There is no formal way of assessing whether the degree of psychosis liability increases linearly across these groups. However, given that the risk for psychosis is the sum of a number of genetic and environmental factors, it is likely that there is a graded disposition to the disorder. In line with this, both genetic and psychometric risk groups have been shown to share phenotypic and endophenotypic characteristics as well as risk factors with the clinical psychosis phenotype (Claridge, 1994, Faraone et al., 2000, Johns et al., 2001, Spauwen et al., 2004). Therefore, the use of an ordinal risk group variable in this as well as in previous studies (Miller et al., 2001, Janssen et al., 2006, Van Dael et al., 2006), has face validity and, in addition, the effects of each group was separately assessed relative to the control group as well.

The Hinting Task captures one aspect of mentalising and is unlikely to detect the full range of possible mentalising deficits. In addition, performance on the Hinting Task showed a ceiling 
effect. This may have resulted in an underestimation of the mentalising deficiencies possibly explaining why statistically non-precise results were found in the at-risk group. Some previous studies in patients with schizophrenia indeed did not find significant impairment in elementary mentalising tests, while performance on a more complex mentalising test was clearly impaired (Doody et al., 1998, Pickup et al., 2001). However, the disadvantage of the use of a complex mentalising test is possible confounding by intelligence and working memory.

The Hinting Task only taps verbal mentalising skills, but previous studies have suggested that task performance in patients with schizophrenia is independent of a verbal or pictorial mode of presentation (Sarfati et al., 1999a, Sarfati et al., 1999b).

The Hinting Task is an off-line task as subjects are listening passively to a dialogue and performance on this task does not necessarily reflect behaviour in real interactions (Frith, 2004).

Finally, we did not use a matched control task. However, controlling for a verbal IQ task indicated that worse performance on the Hinting Task could not be ascribed to poor verbal skills.

\section{Conclusions}

The current study examined mentalising abilities in patients with a psychotic disorder as well as in individuals at risk without current clinical needs. The results showed that a subtle deficit of mentalising is part of the predisposition to psychosis, and that the severity of this deficit is associated with expression of current hallucinations and paranoid symptoms, suggesting a mediating role in symptom formation. 


\section{References}

Andreasen, N. C. (1983). Scale for the Assessment of Negative Symptoms (SANS). University of lowa: lowa City, IA.

Andreasen, N. C. (1984). Scale of the Assessment of Positive Symptoms (SAPS). University of lowa: lowa City, IA.

APA, 1994. Diagnostic and Statistical Manual of Mental Disorders. American Psychiatric Press, Washington DC.

Bentall, R. P., 1990. The illusion of reality: a review and integration of psychological research on hallucinations. Psychological Bull. 107, 82-95.

Blackwood, N. J., Howard, R. J., Bentall, R. P. Murray, R. M., 2001. Cognitive neuropsychiatric models of persecutory delusions. Am. J. Psychiatry 158, 527-39.

Brune, M., 2003. Theory of mind and the role of IQ in chronic disorganized schizophrenia. Schizophr. Res. 60, 57-64.

Claridge, G., 1994. Single indicator of risk for schizophrenia: probable fact or likely myth? Schizophr. Bull. 20, 151-68.

Corcoran, R., Mercer, G. Frith, C. D., 1995. Schizophrenia, symptomatology and social inference: investigating "theory of mind" in people with schizophrenia. Schizophr. Res. 17, 513.

Cunningham Owens, D. G. Johnstone, E. C., 2006. Precursors and prodromata of schizophrenia: findings from the Edinburgh High Risk Study and their literature context. Psychol. Med. 36, 1501-14.

De Bie, S. E., 1987. Standaardvragen 1987: Voorstellen voor uniformering van vraagstellingen naar achtergrongkenmerken en interviews [Standard questions 1987: Proposal for uniformization of questions regarding background variables and interviews]. Leiden University Press, Leiden.

Doody, G. A., Gotz, M., Johnstone, E. C., Frith, C. D. Owens, D. G., 1998. Theory of mind and psychoses. Psychol. Med. 28, 397-405. 
Faraone, S. V., Seidman, L. J., Kremen, W. S., Toomey, R., Pepple, J. R. Tsuang, M. T., 2000. Neuropsychologic functioning among the nonpsychotic relatives of schizophrenic patients: the effect of genetic loading. Biol. Psychiatry 48, 120-6.

Frith, C., 1992. The Cognitive Neuropsychology of Schizophrenia. UK Lawrence Erlbaum Associates, Hove.

Frith, C. D., 2004. Schizophrenia and theory of mind. Psychol. Med. 34, 385-9.

Hanssen, M., Krabbendam, L., de Graaf, R., Vollebergh, W. van Os, J., 2005. Role of distress in delusion formation. Br. J.Psychiatry Suppl. 48, s55-8.

Hanssen, M., Krabbendam, L., Vollema, M., Delespaul, P. Van Os, J., 2006. Evidence for instrument and family-specific variation of subclinical psychosis dimensions in the general population. J. Abnorm. Psychology 115, 5-14.

Hanssen, M., Peeters, F., Krabbendam, L., Radstake, S., Verdoux, H. van Os, J., 2003. How psychotic are individuals with non-psychotic disorders? Soc. Psychiatry Psychiatr. Epidemiol. $38,149-54$.

Hardy-Bayle, M. C., Passerieux, C., Claudel, B., Olivier, V. Chevalier, J. F., 1994. Communication disorders in schizophrenic patients. Cognitive explanation and clinical reconsideration. Encephale 20, 393-400.

Harrington, L., Langdon, R., Siegert, R. J. McClure, J., 2005. Schizophrenia, theory of mind, and persecutory delusions. Cognit. Neuropsychiatry 10, 87-104.

Irani, F., Platek, S. M., Panyavin, I. S., Calkins, M. E., Kohler, C., Siegel, S. J., Schachter, M., Gur, R. E. Gur, R. C., 2006. Self-face recognition and theory of mind in patients with schizophrenia and first-degree relatives. Schizophr. Res. 88, 151-60.

Jahshan, C. S. Sergi, M. J., 2007. Theory of mind, neurocognition, and functional status in schizotypy. Schizophr. Res. 89, 278-86.

Janssen, I., Krabbendam, L., Jolles, J. van Os, J., 2003. Alterations in theory of mind in patients with schizophrenia and non-psychotic relatives. Acta Psychiatr. Scand. 108, 110-7.

Janssen, I., Versmissen, D., Campo, J. A., Myin-Germeys, I., Os, J. V. Krabbendam, L., 2006. Attribution style and psychosis: evidence for an externalizing bias in patients but not in individuals at high risk. Psychol. Med., 1-8.

Johns, L. C. van Os, J., 2001. The continuity of psychotic experiences in the general population. Clinical Psychology Review 21, 1125-41. 
Kay, S. R., Fiszbein, A. Opler, L. A., 1987. The positive and negative syndrome scale (PANSS) for schizophrenia. Schizophr. Bull. 13, 261-76.

Langdon, R. Coltheart, M., 1999. Mentalising, schizotypy, and schizophrenia. Cognition 71, 43-71.

Langdon, R. Coltheart, M., 2004. Recognition of metaphor and irony in young adults: the impact of schizotypal personality traits. Psychiatry Res. 125, 9-20.

Luteijn, F., Van der Ploeg, F.A.E. (1983). Handleiding Groninger Intelligentietest (GIT) (Manual Groningen Intelligence Test). Swets \& Zeitlinger: Lisse, The Netherlands.

Marjoram, D., Job, D. E., Whalley, H. C., Gountouna, V. E., McIntosh, A. M., Simonotto, E., Cunningham-Owens, D., Johnstone, E. C. Lawrie, S., 2006a. A visual joke fMRI investigation into Theory of Mind and enhanced risk of schizophrenia. Neuroimage 31, 1850-8.

Marjoram, D., Miller, P., Mclntosh, A. M., Cunningham Owens, D. G., Johnstone, E. C. Lawrie, S., 2006b. A neuropsychological investigation into 'Theory of Mind' and enhanced risk of schizophrenia. Psychiatry Res. 144, 29-37.

McGuffin, P., Farmer, A. Harvey, I., 1991. A polydiagnostic application of operational criteria in studies of psychotic illness. Development and reliability of the OPCRIT system. Arch. gen. Psychiatry 48, 764-70.

Miller, P., Lawrie, S. M., Hodges, A., Clafferty, R., Cosway, R. Johnstone, E. C., 2001. Genetic liability, illicit drug use, life stress and psychotic symptoms: preliminary findings from the Edinburgh study of people at high risk for schizophrenia. Soc. Psychiatry Psychiatr. Epidemiol. 36, 338-42.

Pickup, G. J. Frith, C. D., 2001. Theory of mind impairments in schizophrenia: symptomatology, severity and specificity. Psychol. Med. 31, 207-20.

Sarfati, Y. Hardy-Bayle, M. C., 1999a. How do people with schizophrenia explain the behaviour of others? A study of theory of mind and its relationship to thought and speech disorganization in schizophrenia. Psychol. Med. 29, 613-20.

Sarfati, Y., Hardy-Bayle, M. C., Brunet, E. Widlocher, D., 1999b. Investigating theory of mind in schizophrenia: influence of verbalization in disorganized and non-disorganized patients. Schizophr. Res. 37, 183-90.

Spauwen, J., Krabbendam, L., Lieb, R., Wittchen, H. U. van Os, J., 2004. Does urbanicity shift the population expression of psychosis? Journal of Psychiatric Research 38, 613-8. 
StataCorporation (2005). STATA Statistical Software. Stata Corporation College Station: Texas.

Stefanis, N. C., Hanssen, M., Smirnis, N. K., Avramopoulos, D. A., Evdokimidis, I. K., Stefanis, C. N., Verdoux, H. Van Os, J., 2002. Evidence that three dimensions of psychosis have a distribution in the general population. Psychol. Med. 32, 347-58.

Van Dael, F., Versmissen, D., Janssen, I., Myin-Germeys, I., van Os, J. Krabbendam, L., 2006. Data gathering: biased in psychosis? Schizophr Bull 32, 341-51.

Verdoux, H., van Os, J., Maurice-Tison, S., Gay, B., Salamon, R. Bourgeois, M., 1998. Is early adulthood a critical developmental stage for psychosis proneness? A survey of delusional ideation in normal subjects. Schizophr Res 29, 247-54.

Wechsler, D. (1981). Wechsler Adult Intelligence Scale-Revised. Psychological Corporation: New York.

Wing, J. K., Cooper, J. E. Sartorius, N. (1974). Measurement and classification of psychiatric symptoms; An instruction manual for the PSE and Catego program. Cambridge U Press.: Oxford, England.

\section{Epilogue}

Psychosis is associated with major cognitive shortcomings. In this dissertation we focussed on cognitive alterations in the realm of social cognition. Social cognition refers to all cognitive processes involved in interactions between the self and others. We first investigated whether deficits in social cognition can be distinguished from deficits in neurocognition, as suggested by current data on differential associations with symptoms and outcome. Secondly, prior research revealed low explanatory power of neurocognitive deficiencies on the formation of positive psychotic symptoms (Buchanan et al., 2005, Goldberg and Gold, 1995, Mohamed et al., 1999). Since these latter symptoms have a truly hampering effect on everyday functioning, there is a great aspiration to disentangle their cause. Social cognition seems much more promising as a candidate mechanism in understanding the genesis of positive psychotic symptomatology (Bentall et al., 1991, Frith, 1987, Hoffman, 1986). The main part of the thesis is devoted to this topic. In order to study in more depth the association between social cognition and positive symptomatology, in particular with respect to causality of the association, at risk populations also require investigation. Hence, we did not focus exclusively on the clinical level of the psychosis phenotype, but also on the subclinical level and on transmission of the psychosis risk. Since the prevalence of psychotic symptoms approaches 5 to $15 \%$ in the general population (Hanssen et al., 2003, Johns, 2005, van Os et al., 2000, van Os et al., 2001) the inclusion of individuals without a diagnosed psychotic 
disorder and need for care, is of great supplementary value to further clarify the association between psychological mechanisms in the domain of social cognition and psychosis predisposition. The studies described in this thesis examined psychological mechanisms over the psychosis continuum in individuals with clinical disorder, but also at psychometrically or genetically defined risk for the disorder, i.e. first degree relatives of patients with psychosis and individuals from the general population with positive psychotic experiences or symptoms. The presence of social cognitive deficits in individuals at risk would imply that these deficits are markers of the transmission of psychosis risk. The major aim of this thesis was to test several of these mechanisms, i.e. mentalisation and both verbal and motor source monitoring, on their association with psychosis in a fixed genetically sensitive design. Finally, we reflected on the term 'social cognition', which is operationalised through many different paradigms. What is social cognition? Which overtones does the term cover? We examined whether the various social cognitive measures and mechanisms reflect a unitary construct, or rather encompass a variety of cognitive mechanisms. An enumeration of the major findings of the studies described in this thesis, together with a discussion of their clinical implications and recommendation for future research will be provided in this final chapter. The first paragraph will discuss the findings concerning the difference between social cognition and neurocognition. The following paragraphs will explore in detail various social cognitive mechanisms and their unidimensional, or, to the contrary, multidimensional character. A consolidated overview of the main results of this dissertation is provided schematically in fig. 7.1 .

Social cognition can be defined broadly or more narrowly. Depending on the broadness of the definition, the number of mechanisms that are considered as social cognition varies. Examples of mechanisms that can be interpreted as being social cognitive mechanisms, but that are not included in this dissertation, are emotion perception and social perception. The social cognitive mechanisms investigated in this dissertation are: self-monitoring, mentalising, attribution style and reasoning bias.

The studies described in chapters 2, 3, 4 and 6 are based on data collected in the Cognitive functioning in Psychosis (CoP) study. There were four groups, which differed in terms of the degree of psychosis vulnerability, (i) patients with a lifetime history of non-affective psychosis $(n=45)$, (ii) first-degree relatives of those patients $(n=47)$, (iii) healthy individuals scoring high on the positive dimension of psychosis-proneness measured by the Community Assessment of Psychic Experiences (CAPE) $(n=41)$ and (iv) healthy controls scoring in the average range on the positive dimension of psychosis-proneness measured by the CAPE $(n=54)$. The CoP study focused on cognitive functioning, in particular social cognition. 
In chapter 5, the Social Cognition in Psychosis (SCIP) study is described. Patients with a psychotic disorder $(n=41)$, their first-degree relatives $(n=40)$ and control subjects $(n=39)$ were administered a range of instruments, measuring various social cognitive mechanisms. 


\section{Social cognition and neurocognition represent two separate areas of vulnerability}

Psychosis is commonly marked by neurocognitive deficits in several domains such as attention, memory and executive functioning (Fossati et al., 1999, Nuechterlein and Dawson, 1984). It is hypothesised that these cognitive abnormalities may be caused by a dopamine disorder in the frontal lobes of the brain (Braver et al., 1999, Green and Nuechterlein, 1999, Rosa et al., 2004). Besides a decline in neurocognitive functions, the psychotic phenotype features social cognitive anomalies. Deficits in both cognitive domains can co-occur in psychosis. In order to explore the overlap between these domains, we performed correlation analyses and factor analyses on neurocognitive and social cognitive tasks (chapter 2). The results suggest that, to a large degree, neurocognition and social cognition represent two separate areas of vulnerability in psychosis and, therefore, social cognition can be seen as an autonomous area of vulnerability, independent of neurocognition. Since a number of previous studies have shown associations between social cognition and various neurocognitive domains, it has been hypothesised that social cognition is a mediating link between neurocognition and community functioning (Vauth et al., 2004). Yet, the results from the study described in chapter 2, together with former evidence for social cognition and neurocognition being two separate areas of liability with no underlying common factor (Adolphs, 2001, Sergi et al., 2007), undermine this statement. An important implication of this finding is that the two areas of cognitive vulnerability may contribute to explaining the heterogeneity of psychosis. It has been hypothesised that there are two pathways in the development of psychosis (MyinGermeys et al., 2002); on the one hand an affective pathway, characterised by stresssensitivity, a predominance of positive symptoms, and better outcome, and, on the other hand a neurocognitive pathway, characterised by structural brain deficits, negative symptomatology and a more chronic course (Murray et al., 1992). Plausibly, deficiencies in the domain of social cognition are part of the affective pathway, however this should be a topic for further investigation.

What's in a name? That which we call social cognition is not always the same as social cognition.

Despite many studies of today focusing on social cognition in the broad psychosis phenotype, it remains unclear to what extent the different mechanisms clustered under the social cognition heading represent one underlying factor. In chapter 2 , we investigated whether social cognition is best treated as a unidimensional or a multidimensional construct. On the basis of correlation analyses and factor analyses of social cognitive and neurocognitive performance data from the four groups included in the CoP study, it was concluded that social 
cognition seems to be a multidimensional construct that encompasses various cognitive mechanisms that are not freely exchangeable. This implies that the use of the term 'social cognition' should be accompanied by a specification of the particular social cognitive mechanism.

This finding provides a potential explanation for some discrepancies in results represented in this dissertation, as well as results from prior research. Many of the studies investigating social cognition, focussed on the relationship between social cognitive deficits and psychotic symptomatology. Most results show a tendency towards an association between alterations in social cognition and positive psychotic symptoms as described by authorities in the domain of social cognition (Bentall et al., 2001, Frith, 1996), but nevertheless a substantial number of studies demonstrated associations between social cognitive deficiencies and other symptoms, such as negative symptomatology (Corcoran et al., 1997) and disorganisation (Hardy-Bayle et al., 1994). This lack of consistency may be caused by the fact that the various mechanisms clustered together under the denominator 'social cognition' represent more than one vulnerability factor. Likewise, the use of this broad construct of 'social cognition' can be the reason that studies in which at-risk groups are included sometimes demonstrate that social cognitive mechanism only operates in the clinical disorder (Janssen et al., 2006) whereas others show that deficiencies in social cognitive mechanisms do occur in individuals without clinical needs, but with a higher than general risk to develop a psychotic disorder (Janssen et al., 2003, Marjoram et al., 2006, Van Dael et al., 2006, Versmissen et al., 2007).

The following paragraphs will discuss the findings with regard to specific social cognitive mechanisms in detail.

\section{Alterations in self-monitoring mark genetic transmission of psychosis risk}

Source monitoring refers to different processes involved in ascribing memories, knowledge and beliefs to a certain source of information (Henquet et al., 2005a, Johnson et al., 1993). Self-monitoring is a specific type of source monitoring, namely the capacity to distinguish the consequences of self-generated items from those that are generated externally. Whether abnormalities in both motor and verbal on-line self-monitoring may indicate vulnerability for psychosis was investigated in the studies described in chapters 3 and 4 . Therefore, four groups that differed in terms of the level of psychosis expression, i.e. patients with psychosis, a genetic risk group, a psychometric risk group and healthy controls, were included in the CoP study. Firstly, an action recognition task, developed by Franck and his colleagues (Franck et al., 2001), was carried out by all participants (chapter 3 ). The results demonstrate alterations in self-monitoring performance in both the patient group and their first-degree relatives, indicating that these constitute markers of genetic transmission of psychosis risk. 
Moreover, in line with previous research (Franck et al., 2001), as well as with cognitive models of the positive symptomatology of psychosis (Frith, 1987, Garety et al., 2001), the findings of the study described in chapter 3 proved that the self-monitoring deficit is in particular associated with a phenotype characterised by delusional ideation and passivity experiences. It can be surmised that the wrong discrimination between internally versus externally generated material must be an odd and fearsome experience and any attempt to make sense of this may result in an alienation of own actions, a lack of control, the feeling of being steered by someone or something else, thus the so-called passivity phenomena.

Secondly, a speech attribution task, developed by Johns and colleagues (Johns et al., 2001), was performed by the participants of the CoP study (chapter 4). Neither large nor significant differences were found between the four research groups, which is in contrast with prior research using this paradigm (Johns et al., 2005, Johns et al., 2006, Johns et al., 2003, Johns et al., 2001) and with the study described in chapter 3 during which evidence was found for an association between the expression of psychosis or risk for psychosis and impairment in self-monitoring. In addition, no associations between error rates and positive psychotic symptoms were found. In an attempt to explain these discrepancies, it may be speculated that performance on self-monitoring tasks relies on a combination of top-down, e.g. expectations about the sensorial information, and bottom-up, e.g. the sensorial information itself to which one is exposed, processes, which may be differentially compromised in psychosis. Future research should try to disentangle the relative contribution of both processes in the self-monitoring deficits in psychosis.

\section{Mentalising deficits are associated with paranoia over the psychosis continuum}

A failing of mentalising ability is defined by the inability to decouple an actual state from a mental representation. The study described in chapter 6 aimed to resolve the debate on whether mentalising deficiencies reflect either an enduring trait and is, therefore, part of the vulnerability to psychosis, or a state characteristic closely linked to the presence of psychotic symptoms. Following the vulnerability hypothesis, alteration in mentalising needs to be demonstrable in patients with psychosis as well as in individuals with a higher than average risk to develop a psychotic disorder. Mentalising capacity was assessed by the Hinting Task (Corcoran et al., 1995), an instrument which measures comprehension of real intentions behind indirect speech, in the participants in the CoP study. Results demonstrate significant associations between the patient group, as well as the familial risk group, and impairment on the Hinting Task. A low Hinting Task score was associated with paranoia in patients and individuals at risk. This is in accordance with the original model of Frith (Frith, 1992) which states that a dysfunctional cognitive mechanism for recognition and monitoring own intentions and the attribution of intention, thoughts and beliefs to others is responsible for psychotic 
symptoms, in particular paranoia. The results largely confirmed the hypothesis that there is an increase in impairment of mentalising parallel to the increased psychosis load, i.e., the greatest impairment in the patient group, followed by the familial risk group, except for the lack of any significant impairment in the psychometric risk group. The occurrence of mentalising deficiency in individuals with a higher than average genetic risk implies that alterations in mentalising are not exclusively associated with the expression of the clinical psychosis phenotype, but also with transmission of risk.

However, it should be noted that the use of the Hinting Task may not meet with proper approval due to two reasons. First of all the test suffers from a ceiling effect, as a large number of subjects obtained the maximum score. This may explain the lack of any significant effect in the psychometric risk group. Secondly, the findings in the study described in chapter 2 question the validity of the Hinting Task as a purely mentalising task, given the correlation between the Hinting Task and neurocognitive tasks. Most likely, a Hinting Task score represents both mentalising abilities and general intelligence.

\section{Effect of emotion on cognition}

Aiming to further clarify the dysfunctional source-monitoring mechanism in psychosis, the study described in chapter 5 focused on the effects of an interaction between cognition and emotion. More precisely, the study investigated whether the ability to monitor the source of information is influenced by emotional salience of that information. The second aim of the study was to investigate whether any deficit in source-monitoring ability differentially affects the recognition of self-generated versus other-generated information. Patients with psychosis and a control group performed the Emotional Source Monitoring Task, developed with the purpose of investigating the ability to discriminate self-generated items from those that are externally generated. By using adjectives only, which generally have a more explicit emotional value compared to most substantives and which can be used to describe human characteristics, the possible moderation of source monitoring abilities by emotional value could be investigated. The results demonstrated that, first of all, the phenotypic expression of psychosis is characterised by source-monitoring deficits, in particular impaired recognition of self-generated information, but also with impaired recognition of other-generated auditory information, and with impaired old-new recognition. Negative emotional valence aggravated the deficit, although not significantly so. Overall, these findings indicate that cognitive mechanisms, which are assumed to underlie the development of positive symptoms of psychosis, cannot be separated from emotional salience. This is in accordance with the cognitive model of positive symptoms of psychosis by Garety and colleagues (Garety et al., 2001), which emphasises the effect of both cognition and emotion in the ontogenesis of positive psychotic symptoms. The relevance of the main findings and conclusions from this dissertation with respect to this latter model is elaborated in the following paragraph. 
An additional point of discussion focuses on the difference between on-line and off-line paradigms. The Emotional Source Monitoring Task is an off-line instrument, unlike the other two instruments used to measure source-monitoring capacities, which are on-line instruments. Off-line instruments do not necessarily reflect behaviour in real interactions (Frith, 2004). Furthermore, potential memory deficits can influence the results obtained with an off-line instrument. This latter effect of off-line paradigms may explain why the results of the study described in chapter 5 also show deficits for externally generated information.

\section{Cognitive alterations may influence the genesis of psychotic symptoms}

Current cognitive models explaining the formation and maintenance of positive psychotic symptoms (Bentall et al., 1991, Birchwood, 1999, Birchwood and Chadwick, 1997, Garety et al., 2001, Morrison and Haddock, 1997) provide a theoretical framework to interpret the results of the studies described in chapters $3,4,5$ and 6 . According to these models, altered cognitive processes incite the development of positive psychotic symptoms and may also play a role in their persistence. This dissertation contributed to the clarification of some of these processes, particularly mentalising and source monitoring, situated in the realm of social cognition. The common factor in these processes seems to be a disorder in representing the mental states of others and ourselves. For one thing, some positive psychotic symptoms reflect a deficit in the recognition and monitoring of one's own actions or thoughts and the preceding willed intentions (self-monitoring). This may lead to the experience of passivity experiences, such as thought insertion, since a lack of a sense of agency is experienced with respect to one's own thoughts. Equally, certain positive psychotic symptoms may be a reflection of alterations in monitoring another individual's intentions (mentalising or theory of mind), which in turn can cause paranoid delusional ideation (Frith, 1992). Thus, social cognitive disturbances like these, can lead to bizarre experiences, such as experiencing a lack of control over one's own actions and thoughts, or the inability to differentiate between one's own thoughts and the thoughts of other individuals. Emotional changes caused by the bizarre experiences render, in turn, negative content to the bizarre, often threatening, experiences (Garety et al., 2001). Since, in this thesis, the presence of cognitive disruptions was proven both in patients with psychosis and in high-risk populations, it can be concluded that the cognitive alterations are part of the vulnerability to psychosis and it may be hypothesised that they contribute causally to the symptoms, rather than just being epiphenomenal, although further research is necessary to investigate this hypothesis. At the same time, this suggests that other factors are needed to provoke the transition into clinical 
psychosis. Likely examples of such factors are cannabis use, urban upbringing or psychological trauma (Henquet et al., 2005b, Spauwen et al., 2004, 2006).

Thus, considering the findings from this thesis, it can be stated that altered cognitive processes such as impaired monitoring of the intentions of self and others may lead to anomalous experiences. These, in combination with an externalising bias (Janssen et al., 2006, Kinderman and Bentall, 2000) may lead to attribution of one's own actions or thoughts to an external source, and, given that the bias is strongest for negative information, will lead to experiences with derogative content that fuel paranoid thinking. 
Fig 7.1: A consolidated overview of the main findings of this dissertation

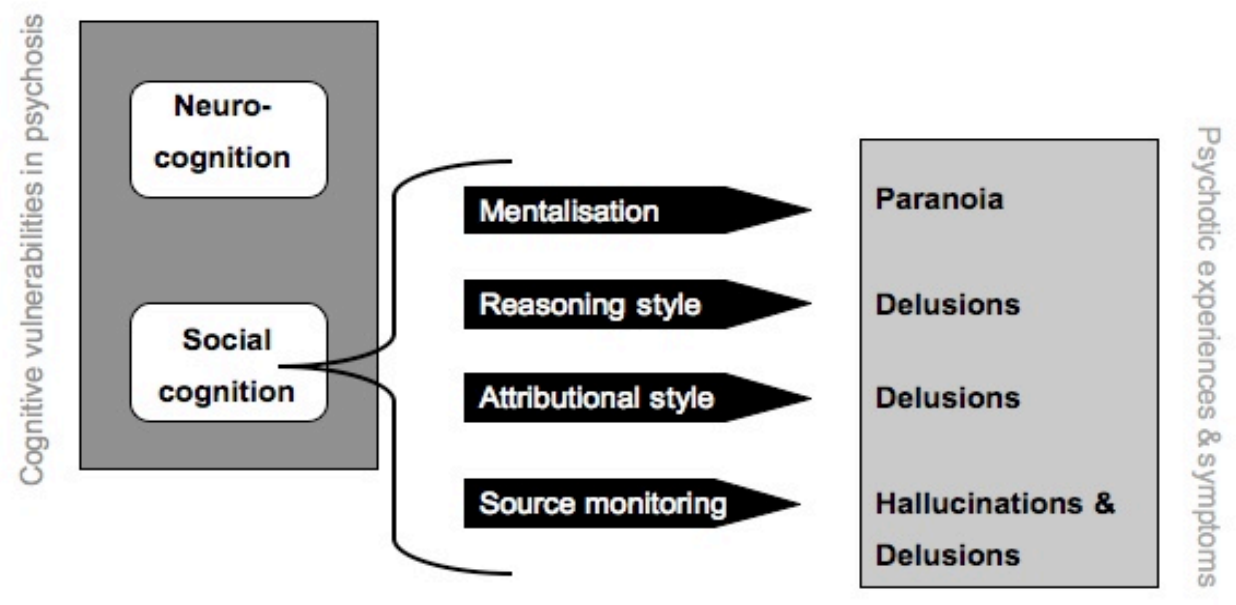

\section{Clinical and social implications}

The studies presented in this dissertation have a symptom-oriented starting point. The results demonstrate the associations between altered mechanisms in the domain of social cognition and individual positive psychotic symptoms, rather than with the overall psychotic syndrome. Hence, a symptom-oriented treatment may be more effective than the classic, syndromeoriented approach (APA, 1994). The effectiveness of psychological treatments, such as Cognitive Behavioural Therapy (CBT) with respect to the cure or lightening of, or coping with, positive symptoms of psychosis, has been demonstrated in several studies (Gould et al., 2001, Turkington et al., 2006, Valmaggia et al., 2005). CBT mainly concentrates on challenging automatic thoughts and the assumption that mechanisms underlying the genesis of psychopathology are an excessive form of normal cognitive processes (Kingdon and Turkington, 1991). This latter assumption is supported by the abundant proof that the psychosis phenotype exists as a continuum in nature, with healthy functioning at one extreme and people with a clinically diagnosed psychotic disorder and need for care at the other (Hanssen et al., 2003, Johns and van Os, 2001). The studies described in this thesis suggest that specific cognitive mechanisms, i.e. mentalisation and self-monitoring measured with the Action Recognition Task and the Emotional Source Monitoring Task, may contribute causally 
to the development of positive symptoms of psychosis. Some of these may be amenable to psychological treatment. A promising new therapy, the rationale of which is also based on a symptom-oriented approach, is the 'Metacognitive Training for Schizophrenia Patients' (MCT). The aim of this programme is to increase the awareness of cognitive and behavioural biases in patients with schizophrenia and by this, ameliorating these biases. For example, by training patients' mentalising skills, levels of paranoia could be reduced.

The results of this thesis do also have social implications. Proving that psychotic symptoms not only occur in people with a psychotic disorder, but also in the general population, albeit to a lesser degree, may cause a decline in the stigmatisation of schizophrenia, other psychotic disorders and psychopathology in general (Gonzalez-Torres et al., 2007, Penn et al., 1999). By clarifying the underlying psychological mechanisms, such as mentalising and sourcemonitoring, psychotic experiences become more understandable and recognisable. This notwithstanding, even though psychotic or psychosis-like experiences in the general population are common, screening for disorder on the basis of these experiences may be of little use, since in all probability, high rates of false-positive indications may occur (van Os et al., 1997).

\section{Recommendations for future research}

Since a major part of the variance in the psychosis phenotype is most likely attributable to genetic factors, a large amount of research has been conducted towards associations between genetic polymorphisms and features of psychosis (Lin and Tsai, 2004, McClay et al., 2006, Prasad et al., 2005, Saadat et al., 2008). Starting again from a symptom-oriented approach, efforts in psychiatric genetics may well focus on aspects of cognition and information processing, which are causal mechanisms in the development of psychotic symptoms, rather than focusing on the clinical phenotype. Until now, only neurocognitive endophenotypes have been studied. Amongst others, an important candidate gene for psychosis and its neurocognitive anomalies is the COMT-gene. Catechol-o-methyltransferase (COMT) is an enzyme that regulates dopamine transmission in the frontal cortex. There is evidence for an association between the COMT val ${ }^{108 / 158}$ met genotype and neurocognitive functioning (Egan et al., 2002). The results from this thesis suggest future research should also investigate social cognitive endophenotypes, besides the neurocognitive endophenotypes.

The studies from which this thesis has been composed, investigated not only clinical psychosis, but also the psychosis phenotype in the general population, thus in subjects without current clinical needs in whom psychotic experiences nevertheless occur. Future research should benefit from the inclusion of subjects from the broader psychosis phenotype, as a decisive factor is, amongst others, the absence of possible confounding effects that are 
present in clinical populations, such as a history of hospitalisation and the effects of psychotropic medication. In addition, the inclusion of subclinical psychosis allows the investigation of vulnerability effects over and above disease effects. However, in this context, one final note should be made. Including subjects at the subclinical levels of psychosis who are, therefore, at risk to develop the clinical disorder will have some repercussions. Besides ethical implications associated with the inclusion of high-risk populations, the awareness of being part of a high-risk population may reinforce or create the idea of having an enlarged personal risk for psychosis, which may cause a response bias influencing the overall results of a study. It could be pleaded that participating subjects, as a group, are not informed about their risk status prior to their participation, but that this is done at the end of the study. This is particularly relevant for psychometric risk groups, since genetically defined risk groups are generally aware of their at-risk status.

The presence of cognitive alterations in patients with psychosis, as well as in high-risk populations, is indicating that these cognitive alterations are part of the vulnerability for psychosis. On the basis of these findings, a causal relationship between cognitive deficits and the formation of positive psychotic symptoms can be hypothesised. Longitudinal studies are in the best position to study causality, as such designs allow for studying fluctuations in symptoms in relation to cognitive processes.

A considerable number of instruments are available that aim to investigate social cognition. The majority of those instruments have been developed recently and information about validity and reliability is not yet available. In this dissertation, it is shown that various instruments developed to measure a single cognitive domain result in contradictory effects in the same research groups. Future research should establish the psychometric qualities of the new paradigms. Furthermore, skills will be needed when developing paradigms which purely investigate the postulated mechanism and avoid contamination by neurocognition, e.g. by intelligence, memory or attention. 


\section{References}

Adolphs, R. (2001). The neurobiology of social cognition. Curr Opin Neurobiol 11, 231-9.

APA (1994). Diagnostic and Statistical Manual of Mental Disorders. American Psychiatric Press: Washington DC.

Bentall, R. P., Baker, G. A. \& Havers, S. (1991). Reality monitoring and psychotic hallucinations. British Journal of Clinical Psychology 30 ( Pt 3), 213-22.

Bentall, R. P., Corcoran, R., Howard, R., Blackwood, N. \& Kinderman, P. (2001). Persecutory delusions: a review and theoretical integration. Clinical Psychology Review 21, 1143-92.

Birchwood, M. (1999). Commentary on Garety \& Freeman. I: 'Cognitive approaches to delusions--a critical review of theories and evidence'. Br J Clin Psychol 38 ( Pt 3), 315-8.

Birchwood, M. \& Chadwick, P. (1997). The omnipotence of voices: testing the validity of a cognitive model. Psychol Med 27, 1345-53.

Braver, T. S., Barch, D. M. \& Cohen, J. D. (1999). Cognition and control in schizophrenia: a computational model of dopamine and prefrontal function. Biol Psychiatry 46, 312-28.

Buchanan, R. W., Davis, M., Goff, D., Green, M. F., Keefe, R. S., Leon, A. C., Nuechterlein, K. H., Laughren, T., Levin, R., Stover, E., Fenton, W. \& Marder, S. R. (2005). A summary of the FDA-NIMH-MATRICS workshop on clinical trial design for neurocognitive drugs for schizophrenia. Schizophrenia Bulletin 31, 5-19.

Corcoran, R., Cahill, C. \& Frith, C. D. (1997). The appreciation of visual jokes in people with schizophrenia: a study of 'mentalizing' ability. Schizophrenia Research 24, 319-27.

Corcoran, R., Mercer, G. \& Frith, C. D. (1995). Schizophrenia, symptomatology and social inference: investigating "theory of mind" in people with schizophrenia. Schizophrenia Research 17, 5-13.

Egan, M., Goldman, D. \& Weinberger, D. (2002). The human genome: mutations. Am J Psychiatry 159, 12.

Fossati, P., Amar, G., Raoux, N., Ergis, A. M. \& Allilaire, J. F. (1999). Executive functioning and verbal memory in young patients with unipolar depression and schizophrenia. Psychiatry Res 89, 171-87. 
Franck, N., Farrer, C., Georgieff, N., Marie-Cardine, M., Dalery, J., d'Amato, T. \& Jeannerod, M. (2001). Defective recognition of one's own actions in patients with schizophrenia. American Journal of Psychiatry 158, 454-9.

Frith, C. (1992). The Cognitive Neuropsychology of Schizophrenia. UK Lawrence Erlbaum Associates: Hove.

Frith, C. (1996). Neuropsychology of schizophrenia, what are the implications of intellectual and experiential abnormalities for the neurobiology of schizophrenia? British Medical Bulletin 52, 618-26.

Frith, C. D. (1987). The positive and negative symptoms of schizophrenia reflect impairments in the perception and initiation of action. Psychological Medicine 17, 631-48.

Frith, C. D. (2004). Schizophrenia and theory of mind. Psychological Medicine 34, 385-9.

Garety, P. A., Kuipers, E., Fowler, D., Freeman, D. \& Bebbington, P. E. (2001). A cognitive model of the positive symptoms of psychosis. Psychological Medicine 31, 189-95.

Goldberg, T. E. \& Gold, J. M. (1995). Neurocognitive functioning in patients in schizophrenia. In Psychopharmacology: The Fourth Generation of Progress (ed. F. E. Bloom and D. J. Kupfer), pp. 1245-1257. Raven Press: New York.

Gonzalez-Torres, M. A., Oraa, R., Aristegui, M., Fernandez-Rivas, A. \& Guimon, J. (2007). Stigma and discrimination towards people with schizophrenia and their family members. A qualitative study with focus groups. Soc Psychiatry Psychiatr Epidemiol 42, 1423.

Gould, R. A., Mueser, K. T., Bolton, E., Mays, V. \& Goff, D. (2001). Cognitive therapy for psychosis in schizophrenia: an effect size analysis. Schizophrenia Research 48, 335-42.

Green, M. F. \& Nuechterlein, K. H. (1999). Should schizophrenia be treated as a neurocognitive disorder? Schizophr Bull 25, 309-19.

Hanssen, M., Peeters, F., Krabbendam, L., Radstake, S., Verdoux, H. \& van Os, J. (2003). How psychotic are individuals with non-psychotic disorders? Social Psychiatry and Psychiatric Epidemiology 38, 149-54.

Hardy-Bayle, M. C., Passerieux, C., Claudel, B., Olivier, V. \& Chevalier, J. F. (1994). Communication disorders in schizophrenic patients. Cognitive explanation and clinical reconsideration. Encephale 20, 393-400. 
Henquet, C., Krabbendam, L., Dautzenberg, J., Jolles, J. \& Merckelbach, H. (2005a). Confusing thoughts and speech: source monitoring and psychosis. Psychiatry Research 133, 57-63.

Henquet, C., Krabbendam, L., Spauwen, J., Kaplan, C., Lieb, R., Wittchen, H. U. \& van Os, J. (2005b). Prospective cohort study of cannabis use, predisposition for psychosis, and psychotic symptoms in young people. Bmj 330, 11.

Hoffman, R. C. (1986). Verbal hallucinations and language production processes in schizophrenia. Behavioural and Brain Sciences 9, 503-548.

Janssen, I., Krabbendam, L., Jolles, J. \& van Os, J. (2003). Alterations in theory of mind in patients with schizophrenia and non-psychotic relatives. Acta Psychiatrica Scandinavia 108, 110-7.

Janssen, I., Versmissen, D., Campo, J. A., Myin-Germeys, I., Os, J. V. \& Krabbendam, L. (2006). Attribution style and psychosis: evidence for an externalizing bias in patients but not in individuals at high risk. Psychological Medicine, 1-8.

Johns, L. C. (2005). Hallucinations in the general population. Current Psychiatry Report 7 , $162-7$.

Johns, L. C., Allen, P., Broome, M., Woolley, J., Wykes, T. \& McGuire, P. K. (2005). Verbal self-monitoring in people at high risk of psychosis. Schizophrenia Bulletin: Abstracts of the XX international congress on schizophrenia research April 2005, 183-605.

Johns, L. C., Gregg, L., Allen, P. \& McGuire, P. K. (2006). Impaired verbal self-monitoring in psychosis: effects of state, trait and diagnosis. Psychological Medicine 36, 465-74.

Johns, L. C., Gregg, L., Vythelingum, N. \& McGuire, P. K. (2003). Establishing the reliability of a verbal self-monitoring paradigm. Psychopathology 36, 299-303.

Johns, L. C., Rossell, S., Frith, C., Ahmad, F., Hemsley, D., Kuipers, E. \& McGuire, P. K. (2001). Verbal self-monitoring and auditory verbal hallucinations in patients with schizophrenia. Psychological Medicine 31, 705-15.

Johns, L. C. \& van Os, J. (2001). The continuity of psychotic experiences in the general population. Clinical Psychology Review 21, 1125-41.

Johnson, M. K., Hashtroudi, S. \& Lindsay, D. S. (1993). Source monitoring. Psychological Bulletin 114, 3-28.

Kinderman, P. \& Bentall, R. P. (2000). Self-discrepancies and causal attributions: studies of hypothesized relationships. The British Journal of Clinical Psychology 39 ( Pt 3), 255-73. 
Kingdon, D. G. \& Turkington, D. (1991). The use of cognitive behavior therapy with a normalizing rationale in schizophrenia. Preliminary report. J Nerv Ment Dis 179, 207-11.

Lin, P. Y. \& Tsai, G. (2004). Meta-analyses of the association between genetic polymorphisms of neurotrophic factors and schizophrenia. Schizophr Res 71, 353-60.

Marjoram, D., Job, D. E., Whalley, H. C., Gountouna, V. E., McIntosh, A. M., Simonotto, E., Cunningham-Owens, D., Johnstone, E. C. \& Lawrie, S. (2006). A visual joke fMRI investigation into Theory of Mind and enhanced risk of schizophrenia. Neuroimage 31, 18508.

McClay, J. L., Fanous, A., van den Oord, E. J., Webb, B. T., Walsh, D., O'Neill, F. A., Kendler, K. S. \& Chen, X. (2006). Catechol-O-methyltransferase and the clinical features of psychosis. Am J Med Genet B Neuropsychiatr Genet 141B, 935-8.

Mohamed, S., Paulsen, J. S., O'Leary, D., Arndt, S. \& Andreasen, N. C. (1999). Generalized cognitive deficits in schizophrenia. Archives of General Psychiatry 56, 749-754.

Morrison, A. P. \& Haddock, G. (1997). Cognitive factors in source monitoring and auditory hallucinations. Psychological Medicine 27, 669-79.

Murray, R. M., O'Callaghan, E., Castle, D. J. \& Lewis, S. W. (1992). A neurodevelopmental approach to the classification of schizophrenia. Schizophr Bull 18, 319-32.

Myin-Germeys, I., Krabbendam, L., Jolles, J., Delespaul, P. A. \& van Os, J. (2002). Are cognitive impairments associated with sensitivity to stress in schizophrenia? An experience sampling study. American Journal of Psychiatry 159, 443-9.

Nuechterlein, K. H. \& Dawson, M. E. (1984). Information processing and attentional functioning in the developmental course of schizophrenic disorders. Schizophr Bull 10, 160203.

Penn, D. L., Kommana, S., Mansfield, M. \& Link, B. G. (1999). Dispelling the stigma of schizophrenia: II. The impact of information on dangerousness. Schizophr Bull 25, 437-46.

Prasad, K. M., Chowdari, K. V., Nimgaonkar, V. L., Talkowski, M. E., Lewis, D. A. \& Keshavan, M. S. (2005). Genetic polymorphisms of the RGS4 and dorsolateral prefrontal cortex morphometry among first episode schizophrenia patients. Mol Psychiatry 10, 213-9.

Rosa, A., Peralta, V., Cuesta, M. J., Zarzuela, A., Serrano, F., Martinez-Larrea, A. \& Fananas, L. (2004). New evidence of association between COMT gene and prefrontal neurocognitive function in healthy individuals from sibling pairs discordant for psychosis. American Journal of Psychiatry 161, 1110-2. 
Saadat, M., Pakyari, N. \& Farrashbandi, H. (2008). Genetic polymorphism in the DNA repair gene XRCC1 and susceptibility to schizophrenia. Psychiatry Res 157, 241-5.

Sergi, M. J., Rassovsky, Y., Widmark, C., Reist, C., Erhart, S., Braff, D. L., Marder, S. R. \& Green, M. F. (2007). Social cognition in schizophrenia: relationships with neurocognition and negative symptoms. Schizophr Res 90, 316-24.

Spauwen, J., Krabbendam, L., Lieb, R., Wittchen, H. U. \& van Os, J. (2004). Does urbanicity shift the population expression of psychosis? Journal of Psychiatric Research $\mathbf{3 8}$, 613-8.

Spauwen, J., Krabbendam, L., Lieb, R., Wittchen, H. U. \& van Os, J. (2006). Impact of psychological trauma on the development of psychotic symptoms: relationship with psychosis proneness. British Journal of Psychiatry 188, 527-33.

Turkington, D., Kingdon, D. \& Weiden, P. J. (2006). Cognitive behavior therapy for schizophrenia. Am J Psychiatry 163, 365-73.

Valmaggia, L. R., van der Gaag, M., Tarrier, N., Pijnenborg, M. \& Slooff, C. J. (2005). Cognitive-behavioural therapy for refractory psychotic symptoms of schizophrenia resistant to atypical antipsychotic medication. Randomised controlled trial. Br J Psychiatry 186, 324-30.

Van Dael, F., Versmissen, D., Janssen, I., Myin-Germeys, I., van Os, J. \& Krabbendam, L. (2006). Data gathering: biased in psychosis? Schizophr Bull 32, 341-51.

van Os, J., Hanssen, M., Bijl, R. V. \& Ravelli, A. (2000). Strauss (1969) revisited: a psychosis continuum in the general population? Schizophrenia Research 45, 11-20.

van Os, J., Hanssen, M., Bijl, R. V. \& Vollebergh, W. (2001). Prevalence of psychotic disorder and community level of psychotic symptoms: an urban-rural comparison. Archives of General Psychiatry 58, 663-8.

van Os, J., Takei, N., Verdoux, H. \& Delespaul, P. (1997). Early detection of schizophrenia. Br J Psychiatry 170, 579.

Vauth, R., Rusch, N., Wirtz, M. \& Corrigan, P. W. (2004). Does social cognition influence the relation between neurocognitive deficits and vocational functioning in schizophrenia? Psychiatry Res 128, 155-65.

Versmissen, D., Myin-Germeys, I., Janssen, I., Franck, N., Georgieff, N., a Campo, J., Mengelers, R., van Os, J. \& Krabbendam, L. (2007). Impairment of self-monitoring: part of the endophenotypic risk for psychosis. British Journal of Psychiatry, suppl. 191 (suppl. 51), 58-62. 


\section{Summary}

Psychotic symptoms, which are particularly characterised by delusions, hallucinations and negative symptoms, are diagnosed in $3 \%$ till $3.5 \%$ of the population. Schizophrenia, the psychotic disorder with the highest prevalence, is considered as one of the most severe psychiatric disorders. Besides extreme psychotic experiences that lead to serious hampering in every day functioning and generally result in need for professional care, there are also moderate, subclinical psychotic experiences. The prevalence of these subclinical symptoms approach $5-15 \%$ in the general population. Despite a considerable extent of inheritance, the genesis of psychotic symptoms cannot be explained by a genetic predisposition exclusively, but it seems that interactions between genetic predisposition and environmental factors may result in a vulnerability for psychosis. This vulnerability may manifest itself in cognitive dysfunction. In this dissertation, first, it is investigated whether cognitive deficits in the realm of neurocognition and social cognition represent one area of vulnerability to psychosis or that they can be distinguished. This is of interest given the low explanatory power of neurocognition in the formation of positive psychotic symptoms. Since these symptoms have a truly hampering effect on every day functioning there is great aspiration to disentangle their cause. Social cognition is considered a candidate mechanism in the explanation of the genesis of these positive psychotic symptoms. The second aim of this thesis examines various social cognitive mechanisms as vulnerability markers and explanatory mechanisms for psychosis

Chapter 1 offers the reader an introduction to the phenomenology and the aetiology of the psychotic disorder. Furthermore, this chapter focuses on the continuum approach of psychosis, which states that psychotic symptoms are not exclusively linked to the clinical disorder, but also occur in individuals who have a vulnerability for psychosis but no clinical needs. Cognitive models suggest that the genesis of psychotic symptoms is the result of alterations in cognitive mechanisms, particularly alteration in social cognition. Thus, these deficits in social cognition may represent a vulnerability to develop psychotic symptoms. As a consequence, social cognition seems a possible intermediate phenotype representing the missing link between a predisposition to psychosis and the actual psychotic behavior. Various social cognitive mechanisms are discussed more in detail in this dissertation.

In chapter 2 a study is reported examining whether the domains neurocognition and social cognition can be embedded under one denominator and, as a consequence whether alterations in the domain of both neurocognition and social cognition are caused by one underlying deficit or that they are distinguishable areas in cognition which represent different areas of vulnerability. This study included four groups with an increasing vulnerability for psychosis, 54 healthy controls, 41 individuals with an enlarged psychometric risk for 
psychosis, 47 first-degree relatives with an enlarged genetic risk for psychosis and 44 patients with psychosis. First, the results, based on factor analyses and correlation analyses, confirm that neurocognition and social cognition represent two areas of vulnerability for psychosis, independent of each other. Furthermore, from these results it can be inferred that social cognition has to be approached as a multidimensional construct since different mechanisms nominated as social cognitive ones do not correlate with each other. From the findings can be concluded that the term 'social cognition' can only to be used on the condition that an extension specifying the exact mechanism is added.

Chapter 3 describes a study on defects in verbal self-monitoring as a measure for psychotic vulnerability. Testing this hypothesis requires, besides the inclusion of patients with a history of psychosis, the inclusion of individuals that are located on lower levels of the continuum. This study included the same sample as described in chapter 2. The results gave no evidence for an association between alterations in verbal self-monitoring and the expression of psychosis, a finding that is sharply in contrast with previous research. In addition, no evidence was found for the hypothesised association between alteration in verbal selfmonitoring and psychotic vulnerability since there were neither large nor significant differences between the research groups.

Chapter 4 presents a second self-monitoring study in which the same method and sample was used as the method used in the study described in chapter 3 , with this difference that the verbal task was replaced by a non-verbal task. The results proofed that psychotic vulnerability is linearly associated with a deficiency in non-verbal self-monitoring, which indicates that a deficit in self-monitoring is a vulnerability marker for psychosis. In the risk state, this is expressed as a failure to recognise self-generated actions, whereas in illness failure to recognise alien sources come to the front. In addition, the data showed a dose-response relationship between alterations in self-monitoring and delusional ideation.

Aiming to further clarify the dysfunctional source-monitoring mechanism in psychosis, chapter 5 addressed first, the effects of the emotional valence of the information on source monitoring ability, and second, psychosis is specifically associated with a deficit in the recognition of self rather than other generated information. The study described in chapter 5 was conducted on a sample of 41 patients with psychosis, 40 of their first-degree relatives (parents, brothers and sisters) and 39 healthy controls. A paradigm aiming to investigate the discrimination between self-generated and externally generated stimuli was introduced. The results showed that negative emotional valence aggravate the source-monitoring deficit, although not significantly so. Moreover, psychosis was not exclusively associated with dysfunctional recognition of self-generated material, but the recognition of externally generated information was also altered. Overall, these findings indicate that cognitive 
mechanisms, which underlie the formation of positive psychotic symptoms, cannot be separated from emotional salience, which is in accordance with cognitive models of psychosis.

In chapter 6, again a potential vulnerability marker for psychosis is examined, which is mentalising. All participants were administered the Hinting Task, an instrument investigating the ability to comprehend real intentions behind indirect speech. The same four groups with an increasing vulnerability for psychosis as in chapter 2,3 and 4 were included, i.e. a control group, a group with a psychometric vulnerability for psychosis, a group with a genetic predisposition and patients with psychosis. Individuals with clinical psychosis, as well as the genetic predisposition for psychosis showed a deficit in mentalising capacities. The results show that (genetic) vulnerability for psychosis is expressed in dysfunctional mentalising ability. In the genetic risk group as well as the patient group associations with third person auditory hallucinations or persecutory delusions, both paranoid symptoms, were demonstrated. In conclusion, abnormal mentalising ability may have a mediating role in the formation of positive psychotic symptoms, particularly in paranoia.

In chapter 7 a resume of each chapter will be provided, to round off this dissertation. On the basis of the results of the studies described in the different chapters, the main findings are discussed. In this last chapter we further examined the importance of the finding that social cognition and neurocognition represent two separate domain of vulnerability (chapter 2). Two important questions were discussed. First, it was shown that the term 'social cognition', like it is used nowadays, is too broad and mechanisms lumped together under this denominator not always correlate with each other (chapter 2). Second, from the findings it emerged that source-monitoring and mentalisation are two mechanisms of which an alteration represent a vulnerability for psychosis (chapter 3,4,5 and 6). Finally, these main results were discussed with regard to their implications for clinical practice and future research.

\section{Samenvatting}

Psychotische stoornissen, die in het bijzonder worden gekenmerkt door wanen, hallucinaties en negatieve symptomen, worden gediagnosticeerd bij $3 \%$ tot $3.5 \%$ van de bevolking. Schizofrenie, de psychotische stoornis met de hoogste prevalentie, wordt beschouwd als een van de meest ernstige psychiatrische aandoeningen. Naast extreme psychotische ervaringen die leiden tot ernstige belemmeringen in het dagelijks functioneren en doorgaans resulteren in een professionele hulpvraag zijn er tevens mildere, subklinische vormen van psychotische 
ervaringen. Cijfers met betrekking tot de prevalentie van deze psychoseachtige ervaringen variëren van 5 tot $15 \%$ in de algemene populatie (Johns, 2005, van Os et al., 2001). Ondanks de hoge mate van erfelijkheid, blijkt het ontstaan van psychotische symptomen niet exclusief te verklaren vanuit een genetische predispositie, maar blijkt een sterke genetische predispositie in interactie met omgevingsfactoren te leiden tot kwetsbaarheid voor psychose. Cognitieve disfuncties zijn een uiting van kwetsbaarheid en mogelijk causaal met symptomen verbonden. In dit proefschrift ligt de focus op deze cognitieve en psychologische mechanismen. Er wordt ondermeer nagegaan of cognitieve problemen in het domein van neurocognitie en sociale cognitie één domein van kwetsbaarheid voor psychose representeren of dat beide te onderscheiden domeinen zijn. Dit is van groot belang gezien het beperkte verklarende vermogen van neurocognitie met betrekking tot de vorming van positieve psychotische symptomen. Aangezien deze laatste een zeer belemmerend effect hebben op het dagelijks functioneren is het belangrijk om de oorzaak van deze symptomen te achterhalen. Sociale cognitie, een term die in hedendaags onderzoek naar de etiologie van psychotische symptomen vaak opduikt, wordt gezien als een belangrijk kandidaat mechanisme ter verklaring van het ontstaan van deze positieve psychotische symptomen.

Hoofdstuk 1 biedt de lezer een introductie tot de fenomenologie en de etiologie van de psychotische stoornis. Verder komt in dit hoofdstuk de continuüm opvatting van psychose aan de orde. Deze stelt dat psychotische symptomen geen fenomeen zijn, exclusief gekoppeld aan de klinische stoornis, maar eveneens voorkomen bij individuen met enkel een kwetsbaarheid voor psychose.

Cognitieve modellen suggereren dat het ontstaan van psychotische symptomen het resultaat is van verstoringen in cognitieve mechanismen, in het bijzonder verstoringen in sociale cognitie. Deze tekortkomingen in sociale cognitie zouden dus een kwetsbaarheid voor het ontwikkelen van psychotische symptomen vormen. Sociale cognitie blijkt bijgevolg een potentieel intermediair fenotype dat de missing link representeert tussen een predispositie voor psychose en het eigenlijke psychotische gedrag. Verschillende sociaal cognitieve mechanismen worden in dit proefschrift verder besproken.

In hoofdstuk 2 wordt een studie beschreven die nagaat of de domeinen neurocognitie en sociale cognitie onder één noemer te vatten zijn, en bijgevolg problemen op het vlak van zowel neurocognitie als sociale cognitie het gevolg van één onderliggend defect zijn, ofwel dat het gaat om te onderscheiden cognitieve domeinen die verschillende gebieden van kwetsbaarheid weerspiegelen. Deze studie includeerde vier groepen met een toenemende kwetsbaarheid voor psychose, namelijk 54 gezonde controles, 41 individuen met een psychometrisch verhoogd risico voor psychose, 47 eerstegraads familieleden met een genetisch verhoogd risico voor psychose en 44 patiënten met psychose. De resultaten, op basis van factoranalyse en correlatie analyses, bevestigen allereerst dat neurocognitie en sociale cognitie twee aparte domeinen van kwetsbaarheid voor psychose weerspiegelen, 
onafhankelijk van elkaar. Daarnaast kon uit de resultaten worden afgeleid dat sociale cognitie als multidimensioneel construct benaderd dient te worden, gezien het feit dat de verschillende mechanismen die benoemd worden als sociaal cognitief niet onderling correleren. Uit deze bevindingen kan dus geconcludeerd worden dat de term 'sociale cognitie' gebruikt dient te worden mits een extensie die specificeert welk exact mechanisme het betreft.

Hoofdstuk 3 beschrijft een studie naar defecten in verbale self-monitoring als een maat voor psychotisch kwetsbaarheid. Het testen van deze hypothese vereist naast de inclusie van patiënten met een geschiedenis van een psychotische stoornis tevens de inclusie van personen die zich op een lager niveau van het psychose continuüm bevinden. Deze studie gebruikte dezelfde steekproef als beschreven in hoofdstuk 2. Uit de resultaten bleken geen aanwijzingen voor een associatie tussen verstoringen in verbale self-monitoring en de expressie van psychose, een bevinding die in contrast staat met eerder onderzoek. Daarenboven werd er geen bewijs gevonden omtrent de hypothetische associatie tussen verstoringen in verbale self-monitoring en psychose kwetsbaarheid daar er noch grote, noch significante verschillen gevonden werden tussen de onderzoeksgroepen onderling.

Hoofdstuk 4 presenteert een tweede self-monitoring studie waarin een vergelijkbare methodiek en dezelfde steekproef als de studie beschreven in hoofdstuk 3 werden gebruikt, met dit verschil dat de verbale taak vervangen werd door een niet-verbale taak. De resultaten toonden aan dat psychose kwetsbaarheid lineair geassocieerd is met een verstoring in selfmonitoring van motorische handelingen, wat erop duidt dat verstoorde self-monitoring een maat is voor psychose kwetsbaarheid. Een verhoogd risico voor psychose bleek met name geassocieerd met verstoring in het herkennen van zelf gegenereerde acties, terwijl het klinische psychose fenotype gekenmerkt werd door een verstoring in het herkennen van stimuli afkomstig uit externe bronnen. Verder lieten de data een dosisrespons relatie zien tussen verstoorde self-monitoring en waanachtige ideatie.

Met als doel het disfunctionele source-monitoring mechanisme in psychose verder te verhelderen, richt hoofdstuk $\mathbf{5}$ zich enerzijds op de effecten van de interactie tussen cognitie en emotie. Anderzijds werd er nagegaan of psychose en psychose kwetsbaarheid al dan niet specifiek geassocieerd is met een defect in de herkenning van zelf gegenereerde informatie. De studie beschreven in hoofdstuk 5 werd uitgevoerd in een steekproef samengesteld uit 41 patiënten met een psychotische stoornis, 40 van hun eerstegraads familieleden (ouders, broers en zussen) en 39 gezonde controles. Er werd een paradigma geintroduceerd met tot doel de mogelijkheid tot discriminatie tussen zelf gegenereerde en extern gegenereerde stimuli te onderzoeken. De resultaten tonen aan dat negatief emotioneel materiaal waarschijnlijk het source-monitoring deficit verergert, hoewel dit effect niet significant bleek te zijn Bovendien was psychose niet exclusief geassocieerd is met een disfunctionele herkenning van zelf gegenereerd materiaal, maar was ook de herkenning van externgegenereerde informatie gestoord. Samenvattend tonen deze bevindingen aan dat 
cognitieve mechanismen, welke aan de vorming van positieve psychotische symptomen ten grondslag liggen, niet los gezien kunnen worden van emotie. Dit is in overeenstemming met cognitieve modellen van psychose.

In hoofdstuk 6 wordt opnieuw een potentiële kwetsbaarheidsmaat voor psychose onderzocht, namelijk mentaliseren. De Hinting Task, een instrument dat de vaardigheid om werkelijke intenties achter indirecte boodschappen te achterhalen in kaart brengt, werd bij alle proefpersonen afgenomen. Dezelfde vier groepen met een oplopende kwetsbaarheid voor psychose als in hoofdstuk 2, 3 en 4 werden geincludeerd, zijnde een controle groep, een groep met psychometrische psychose kwetsbaarheid, een groep met genetische psychose kwetsbaarheid en patiënten met psychose. De expressie van het psychose fenotype, alsook de genetische predispositie voor psychose bleken geassocieerd met een deficit in mentalising capaciteit. Een psychometrisch risico voor psychose was niet significant geassocieerd met een verstoring in mentaliseren. Uit de resultaten blijkt dat (genetische) psychose kwetsbaarheid zich uit in een slecht functionerende mentalisatie. Dit kan een mediërende rol spelen in de vorming van positieve psychotische symptomen, in het bijzonder paranoia. Bij zowel de genetisch risico groep als bij de patiënten werd er namelijk een associatie aangetoond met derde persoonshallucinaties, dan wel achtervolgingswanen, beide paranoïde symptomen.

In hoofdstuk 7 wordt, ter afsluiting van dit proefschrift, een resumé van elk hoofdstuk gegeven. Op basis van de resultaten van de studies die in de verschillende hoofdstukken beschreven werden, worden de belangrijkste bevinden bediscussieerd. Zo wordt er in dit laatste hoofdstuk dieper ingegaan op het belang van de bevinding dat sociale cognitie en neurocognitie twee aparte domeinen van kwetsbaarheid voor psychose weerspiegelen (hoofdstuk 2). Nadien ligt de focus van dit proefschrift op sociale cognitie. Twee belangrijke vraagstellingen werden behandeld. Enerzijds werd aangetoond dat het begrip 'sociale cognitie', zoals het heden ten dage gebruikt wordt te breed is en dat mechanismen die onder deze noemer vallen niet altijd onderling correleren (hoofdstuk 2). Anderzijds blijkt uit de bevindingen van dit proefschrift dat source-monitoring en mentaliseren twee mechanismen zijn waarvan de verstoring een kwetsbaarheid voor psychose weerspiegelt (hoofdstuk 3, 4, 5 en 6). Daarnaast worden de belangrijkste resultaten bediscussieerd met het oog op de klinische praktijk en toekomstig onderzoek. 